\title{
The Amazon Tall Tower Observatory (ATTO): overview of pilot measurements on ecosystem ecology, meteorology, trace gases, and aerosols
}

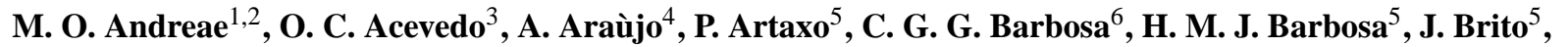
S. Carbone ${ }^{5}$, X. Chi ${ }^{1}$, B. B. L. Cintra ${ }^{7}$, N. F. da Silva ${ }^{7}$, N. L. Dias ${ }^{6}$, C. Q. Dias-Júnior ${ }^{8,11}$, F. Ditas ${ }^{1}$, R. Ditz ${ }^{1}$, A. F. L. Godoi ${ }^{6}$, R. H. M. Godoi ${ }^{6}$, M. Heimann ${ }^{9}$, T. Hoffmann ${ }^{10}$, J. Kesselmeier ${ }^{11}$, T. Könemann ${ }^{1}$, M. L. Krüger ${ }^{1}$, J. V. Lavric ${ }^{9}$, A. O. Manzi $^{11}$, A. P. Lopes ${ }^{15}$, D. L. Martins ${ }^{15}$, E. F. Mikhailov ${ }^{1,20}$, D. Moran-Zuloaga ${ }^{1}$, B. W. Nelson ${ }^{15}$, A. C. Nölscher ${ }^{1}$, D. Santos Nogueira ${ }^{12, b}$, M. T. F. Piedade ${ }^{7}$, C. Pöhlker ${ }^{1}$, U. Pöschl ${ }^{1}$, C. A. Quesada ${ }^{15}$, L. V. Rizzo ${ }^{5}$, C.-U. Ro ${ }^{13}$, N. Ruckteschler ${ }^{1}$, L. D. A. Sá ${ }^{14}$, M. de Oliveira Sá ${ }^{15}$, C. B. Sales ${ }^{11,16}$, R. M. N. dos Santos ${ }^{17}$, J. Saturno ${ }^{1}$, J. Schöngart ${ }^{1,7}$, M. Sörgel ${ }^{1}$, C. M. de Souza ${ }^{11,18}$, R. A. F. de Souza ${ }^{17}$, H. Su ${ }^{1}$, N. Targhetta ${ }^{7}$, J. Tóta ${ }^{17,19}$, I. Trebs ${ }^{1, a}$, S. Trumbore ${ }^{9}$, A. van Eijck ${ }^{10}$, D. Walter ${ }^{1}$, Z. Wang ${ }^{1}$, B. Weber $^{1}$, J. Williams ${ }^{1}$, J. Winderlich ${ }^{1,9}$, F. Wittmann ${ }^{1}$, S. Wolff ${ }^{1,11}$, and A. M. Yáñez-Serrano ${ }^{1,11}$

${ }^{1}$ Biogeochemistry, Multiphase Chemistry, and Air Chemistry Departments, Max Planck Institute for Chemistry, P.O. Box 3060, 55020, Mainz, Germany

${ }^{2}$ Scripps Institution of Oceanography, University of California San Diego, La Jolla, CA 92037, USA

${ }^{3}$ Universidade Federal Santa Maria, Dept. Fisica, 97119900 Santa Maria, RS, Brazil

${ }^{4}$ Empresa Brasileira de Pesquisa Agropecuária (EMBRAPA), Trav. Dr. Enéas Pinheiro, Belém-PA, CEP 66095-100, Brasil

${ }^{5}$ Instituto de Física, Universidade de São Paulo (USP), Rua do Matão, Travessa R, 187, CEP 05508-900, São Paulo, SP, Brasil

${ }^{6}$ Department of Environmental Engineering, Federal University of Paraná UFPR, Curitiba, PR, Brazil

${ }^{7}$ Instituto Nacional de Pesquisas da Amazônia (INPA), MAUA group, Av. André Araújo 2936, Manaus-AM, CEP 69067-375, Brasil

${ }^{8}$ Instituto Nacional de Educação, Ciência e Tecnologia do Pará (IFPA/Bragança), Pará, Brazil

${ }^{9}$ Max Planck Institute for Biogeochemistry, Hans-Knöll-Straße 10, 07745 Jena, Germany

${ }^{10}$ Department of Chemistry, Johannes Gutenberg University, Mainz, Germany

${ }^{11}$ Instituto Nacional de Pesquisas da Amazônia (INPA), Clima e Ambiente (CLIAMB), Av. André Araújo 2936, Manaus-AM, CEP 69083-000, Brazil

${ }^{12}$ Centro Gestor e Operacional do Sistema de Proteção da Amazônia (CENSIPAM), Belém, Pará

${ }^{13}$ Department of Chemistry, Inha University, Incheon 402-751, Korea

${ }^{14}$ Centro Regional da Amazônia, Instituto Nacional de Pesquisas Espaciais (INPE), Belém, Pará, Brazil

${ }^{15}$ Instituto Nacional de Pesquisas da Amazônia (INPA), LBA, Av. André Araújo 2936, Manaus-AM, CEP 69067-375, Brazil

${ }^{16}$ Centro de Estudos Superiores de Parintins (CESP/UEA), Parintins, Amazonas, Brazil

${ }^{17}$ Universidade do Estado do Amazonas (UEA), Manaus, Amazonas, Brazil

${ }^{18}$ Universidade Federal do Amazonas (UFAM/ICSEZ-Parintins), Parintins, Amazonas, Brazil

${ }^{19}$ Universidade Federal do Oeste do Pará - UFOPA, Santarém, Pará, Brazil

${ }^{20}$ Atmospheric Physics Department, Institute of Physics, St. Petersburg State University, St. Petersburg, Russia

${ }^{a}$ now at: Luxembourg Institute of Science and Technology, Environmental Research and Innovation (ERIN) Department, 4422 Belvaux, Luxembourg

b on leave from: Amazon Regional Center, National Institute for Space Research (INPE), Belém, Pará

Correspondence to: M. O. Andreae (m.andreae@mpic.de)

Received: 19 March 2015 - Published in Atmos. Chem. Phys. Discuss.: 21 April 2015

Revised: 24 July 2015 - Accepted: 6 September 2015 - Published: 28 September 2015

Published by Copernicus Publications on behalf of the European Geosciences Union. 
Abstract. The Amazon Basin plays key roles in the carbon and water cycles, climate change, atmospheric chemistry, and biodiversity. It has already been changed significantly by human activities, and more pervasive change is expected to occur in the coming decades. It is therefore essential to establish long-term measurement sites that provide a baseline record of present-day climatic, biogeochemical, and atmospheric conditions and that will be operated over coming decades to monitor change in the Amazon region, as human perturbations increase in the future.

The Amazon Tall Tower Observatory (ATTO) has been set up in a pristine rain forest region in the central Amazon Basin, about $150 \mathrm{~km}$ northeast of the city of Manaus. Two $80 \mathrm{~m}$ towers have been operated at the site since 2012, and a $325 \mathrm{~m}$ tower is nearing completion in mid-2015. An ecological survey including a biodiversity assessment has been conducted in the forest region surrounding the site. Measurements of micrometeorological and atmospheric chemical variables were initiated in 2012, and their range has continued to broaden over the last few years. The meteorological and micrometeorological measurements include temperature and wind profiles, precipitation, water and energy fluxes, turbulence components, soil temperature profiles and soil heat fluxes, radiation fluxes, and visibility. A tree has been instrumented to measure stem profiles of temperature, light intensity, and water content in cryptogamic covers. The trace gas measurements comprise continuous monitoring of carbon dioxide, carbon monoxide, methane, and ozone at five to eight different heights, complemented by a variety of additional species measured during intensive campaigns (e.g., $\mathrm{VOC}, \mathrm{NO}, \mathrm{NO}_{2}$, and $\mathrm{OH}$ reactivity). Aerosol optical, microphysical, and chemical measurements are being made above the canopy as well as in the canopy space. They include aerosol light scattering and absorption, fluorescence, number and volume size distributions, chemical composition, cloud condensation nuclei $(\mathrm{CCN})$ concentrations, and hygroscopicity. In this paper, we discuss the scientific context of the ATTO observatory and present an overview of results from ecological, meteorological, and chemical pilot studies at the ATTO site.

\section{Introduction}

A little over 30 years ago, Eneas Salati and Peter Vose published a landmark paper entitled Amazon Basin: A System in Equilibrium (Salati and Vose, 1984). Since then, a paradigm shift has occurred in the minds of the public at large as well as the scientific community, which is reflected in the title of a recent synthesis paper by a group of prominent Amazon researchers, The Amazon Basin in transition (Davidson et al., 2012). Despite its reassuring title, Salati and Vose's paper had already pointed at growing threats to the integrity of the Amazon ecosystem, mostly resulting from ongoing large- scale deforestation. Since then, deforestation has indeed continued and has only begun to abate in recent years (Lapola et al., 2014; Tollefson, 2015). It goes hand in hand with road construction and urbanization (Fraser, 2014), affecting ecosystems and air quality in many parts of the basin. And, whereas Salati and Vose were concerned with climate change as a regional phenomenon driven by deforestation and its impact on the hydrological cycle, the focus now is on the interactions of global climate change with the functioning of the Amazon forest ecosystem (Keller et al., 2009). In the following sections, we will present the key roles the Amazon is playing in the global ecosystem, which form the rationale for setting up a long-term measuring station, including a tall tower, for monitoring its functioning and health.

\subsection{Carbon cycle}

The Amazon Basin covers about one-third of the South American continent and extends over about $6.9 \times 10^{6} \mathrm{~km}^{2}$, of which about $80 \%$ is covered with rain forest (Goulding et al., 2003). It contains $90-120 \mathrm{Pg} \mathrm{C}$ in living biomass, representing about $84 \%$ of the aboveground biomass in Latin America and ca. $40 \%$ of all tropical forests worldwide (Baccini et al., 2012; Gloor et al., 2012). Another $160 \mathrm{Pg} \mathrm{C}$ are stored in the Amazon Basin's soils; putting this in perspective, the Amazon holds about half as much carbon as was in the Earth's atmosphere before the industrial revolution (Gloor et al., 2012). Given the magnitude of this carbon reservoir, it is clear that tropical forests in general, and the Amazon forest in particular, have the potential to play a crucial role in climate change because of their potential to gain or lose large amounts of carbon as a result of land use and climate change. A recent study shows a strong correlation between climate change on the tropical continents and the rate at which $\mathrm{CO}_{2}$ increases in the atmosphere, and indicates that the strength of this feedback has doubled since the 1970s (Wang et al., 2014). The interaction between physical climate and the biosphere represents one of the largest uncertainties in the assessment of the response of the climate system to human emissions of greenhouse gases.

Depending on the path land use change takes and the interactions between the forest biota and the changing climate, the Amazon can act as a net source or sink of atmospheric $\mathrm{CO}_{2}$. The most recent global carbon budget estimates indicate that in the decade of 2004-2013 land use change worldwide resulted in a net carbon release of $0.9 \pm 0.5 \mathrm{Pg} \mathrm{a}^{-1}$, or about $9 \%$ of all anthropogenic carbon emissions (Le Quéré et al., 2015). This represents a significant decrease since the $1960 \mathrm{~s}$, when land-use carbon emissions of $1.5 \pm 0.5 \mathrm{Pg} \mathrm{a}^{-1}$ accounted for $38 \%$ of anthropogenic $\mathrm{CO}_{2}$. Part of this decrease in the relative contribution from land use change is of course due to the increase in fossil fuel emissions, but there has also been a significant decrease in deforestation in recent 
years, particularly in the Brazilian Amazon (Nepstad et al., 2014).

The "net" land use emissions, as presented above, are the sum of "gross" release and uptake fluxes, where deforestation represents the dominant gross source, whereas afforestation, regrowth, and uptake by intact vegetation are the main gross sinks. Using an approach based on forest inventories and land use budgeting, Pan et al. (2011) estimated that tropical land use change represented a net carbon source of $1.3 \pm 0.7 \mathrm{Pg} \mathrm{a}^{-1}$ in the 1990 s and early $2000 \mathrm{~s}$, consisting of a gross tropical deforestation carbon emission of $2.9 \pm 0.5 \mathrm{Pg} \mathrm{a}^{-1}$ partially compensated for by a carbon sink in tropical forest regrowth of $1.6 \pm 0.5 \mathrm{Pg} \mathrm{a}^{-1}$. A more recent comprehensive analysis of the role of land vegetation in the global carbon cycle concluded that carbon sources and sinks in the tropics are approximately balanced, with regrowth and $\mathrm{CO}_{2}$-driven carbon uptake compensating the large deforestation source (Schimel et al., 2015). For the South American continent, a detailed budgeting study also concluded that, at present, carbon uptake by the biosphere approximately compensates the emissions from deforestation and fossil fuel burning, with a slight trend of the continent becoming a carbon source in the most recent period (Gloor et al., 2012).

Attempts to verify these carbon budgets with measurements have remained inconclusive so far. The largest spatial scale is represented by global inversion models, which derive fluxes from concentration measurements and global transport models. An early attempt deduced a large tropical sink from inverse modeling (Stephens et al., 2007), whereas a more recent analysis suggests a net tropical carbon source of $1.1 \pm 0.9 \mathrm{Pg} \mathrm{a}^{-1}$ (Steinkamp and Gruber, 2013). Gloor et al. (2012) have reviewed the numerous attempts to deduce the South American carbon budgets from inverse modeling and came to the conclusion that they are not adequately constrained to produce meaningful results, a conclusion that they extend to the application of digital global vegetation models for larger time and space scales. Molina et al. (2015) also show that application of inversion models to Amazonia is critically limited by model uncertainties and sparseness of observational data.

Efforts to upscale local measurements to larger scales have also led to inconclusive and often contradictory results. Flux measurements using the eddy covariance technique initially suggested a fairly large carbon sink $\left(1-8 \mathrm{tha}^{-1} \mathrm{a}^{-1}\right)$ in intact Amazon forests (e.g., Grace et al., 1995; Carswell et al., 2002; de Araújo et al., 2002). But as more studies were conducted, this uncertainty range expanded, reaching from a sink of $8 \mathrm{tha}^{-1} \mathrm{a}^{-1}$ to a source of $1.4 \mathrm{tha}^{-1} \mathrm{a}^{-1}$. It thus became clear that issues related to nighttime fluxes and terrain effects make upscaling of $\mathrm{CO}_{2}$ fluxes from eddy covariance measurements difficult to impossible (de Araujo et al., 2010, and references therein). Nevertheless, such flux measurements are essential for understanding micrometeorological and ecological processes and for monitoring changes in the functioning of the forest ecosystem.
An alternative approach to upscaling from local to regional carbon balances is followed in the RAINFOR project, where initially some 140 forest plots have been monitored over decades for standing biomass (Phillips et al., 2009). This study suggested substantial carbon uptake by intact forest, interrupted by biomass loss during drought years. It has been proposed that a large fraction of the uptake extrapolated from the RAINFOR sites is compensated by carbon losses due to rare disturbance events, such as forest blowdowns resulting from severe thunderstorms (Chambers et al., 2013, and references therein). The latest analysis from the RAINFOR project, now based on 321 plots and 25 years of data, indicates that the Amazon carbon sink in intact forest has declined by one-third during the past decade compared to the 1990s. This appears to be driven by increased biomass mortality, possibly caused by greater climate variability and feedbacks of faster growth on mortality (Brienen et al., 2015). Like flux-tower measurements, biomass inventories also miss the contributions of wetlands and water bodies to the carbon flux, which may make a substantial contribution to $\mathrm{CO}_{2}$ outgassing (Richey et al., 2002; Abril et al., 2014).

An intermediate scale between global inverse modeling and plot-size flux and inventory studies is captured by aircraft $\mathrm{CO}_{2}$ soundings through the lowest few $\mathrm{km}$ of the troposphere. This method averages regional fluxes on scales of tens to hundreds of kilometers. Early measurements made during the 1987 ABLE-2 experiment were reanalyzed by Chou et al. (2002) and suggested a near-neutral carbon balance for their study region near Manaus. A series of flights north of Manaus during the 2001 wet-to-dry transition season also revealed that daytime carbon uptake and nighttime release were in approximate balance (Lloyd et al., 2007). A 10 -year aircraft profiling study conducted near Santarem in the eastern Amazon concluded that the fetch region was a small net carbon source $\left(0.15 \mathrm{tha}^{-1} \mathrm{a}^{-1}\right)$, mostly as a result of biomass burning, with no significant net flux to or from the forest biosphere (Gatti et al., 2010). In 2010, this study was extended to include the southern and western parts of the Amazon Basin (Gatti et al., 2014). The results from 2010, an unusually dry year, show the Amazon forest biosphere to be sensitive to drought, resulting in net carbon emission from the vegetation. The following year, 2011, was wetter than average, and the basin returned to an approximately neutral carbon balance, with a modest biospheric sink compensating the biomass burning source. A detailed study on the carbon dynamics over the years 2009 to 2011 showed a complex response of the forest ecosystem to the drought episode, which not only affected net primary production (NPP) and tree mortality, but also the allocation of carbon to the canopy, wood, and root compartments (Doughty et al., 2015).

Seen together, these studies suggest that the Amazon Basin teeters on a precarious balance between being a source or sink of carbon to the world's atmosphere, with its future depending on the extent and form of climate change as well 
as on human actions. The region has already warmed by $0.5-0.6^{\circ} \mathrm{C}$, and warming is expected to continue (Malhi and Wright, 2004). Together with the increased frequency of drought episodes (Saatchi et al., 2013), the occurrence of periods of net biospheric carbon emissions will be enhanced and the likelihood of destructive understory fires will increase (Gloor et al., 2013; Balch, 2014; Zeri et al., 2014; van der Laan-Luijkx et al., 2015). On the other hand, the observed $20 \%$ increase in Amazon River discharge may reflect increasing water availability to the vegetation (Gloor et al., 2013), which together with increasing atmospheric $\mathrm{CO}_{2}$ may lead to more net carbon uptake by the intact forest vegetation (Schimel et al., 2015). While remote sensing can provide important information on the response of the Amazon forest to changing climate and ecological factors, the recent controversy about the effects of seasonal change and drought on the "greenness" of the forest illustrates how important longterm ground based observations are to our understanding of the Amazon system (Morton et al., 2014; Soudani and Francois, 2014; Zeri et al., 2014).

Ultimately, the fate of the carbon stored in the Amazon Basin will depend on the interacting and often opposing effects of human actions, especially deforestation, global and regional climate change, and changing atmospheric composition (Soares-Filho et al., 2006; Poulter et al., 2010; Rammig et al., 2010; Davidson et al., 2012; Cirino et al., 2014; Lapola et al., 2014; Nepstad et al., 2014; Schimel et al., 2015; Zhang et al., 2015). Interactions of the carbon cycle with the cycles of other key biospheric elements, especially nitrogen and phosphorus, are also likely to play important roles (Ciais et al., 2013). This applies equally to two other greenhouse gases, methane $\left(\mathrm{CH}_{4}\right)$ and nitrous oxide $\left(\mathrm{N}_{2} \mathrm{O}\right)$, both of which have important sources in the wetlands or soils of the Amazon (Miller et al., 2007; D'Amelio et al., 2009; Beck et al., 2012).

\subsection{Water and energy cycle}

The Amazon River has by far the greatest discharge of all the world's rivers - about $20 \%$ of the world's freshwater discharge - and 5 times that of the Congo, the next largest river in discharge. This reflects the immense amount of water that is cycling through the water bodies, soils, plants, and atmosphere of the Amazon Basin. As a result, the hydrological cycle of the Amazon Basin is crucial for providing the water that supports life within the Basin and even beyond its borders. Most moisture enters the basin from the Atlantic Ocean with the trade wind circulation, but recirculation of water through evapotranspiration maintains a flux of precipitation that becomes increasingly more important as air masses move into the western part of the basin (Spracklen et al., 2012). When reaching the Andes, moisture becomes deflected southward, with the result that Amazonian evaporation even supports the rain-fed agriculture in Argentina (Gimeno et al., 2012). As a result, perturbations of the Ama- zonian moisture flux and the effects of smoke aerosols from fires in Amazonia on cloud processes can affect rainfall even over the distant La Plata Basin (Camponogara et al., 2014; Zemp et al., 2014).

Evaporation of water from the Earth's surface also supports a huge energy flux in the form of latent heat, which is converted to sensible heat and atmospheric buoyancy when the water vapor condenses to cloud droplets. This heat transfer represents one of the major forces that drive atmospheric circulation at all scales (Nobre et al., 2009). Changes in land cover, e.g., conversion of forest to pasture, alter the amount and type of clouds over the region (e.g., Heiblum et al., 2014) and shift the proportion of rain that flows away as runoff vs. the fraction that is transformed to water vapor by evapotranspiration (Silva Dias et al., 2002; Davidson et al., 2012; Gloor et al., 2013, and references therein). This in turn changes local and regional circulation and rainfall patterns, and consequently deforestation has been predicted to reduce the potential for hydropower generation in Amazonia (Stickler et al., 2013). When the scale of deforestation exceeds some $40 \%$ of the basin, these perturbations of the water cycle may change the functioning of the entire Amazon climate and ecosystem (Coe et al., 2009; Nobre and Borma, 2009; Lawrence and Vandecar, 2015).

Our ability to prognosticate the possible outcomes for the Amazon ecosystem in the coming decades is severely curtailed by limitations in the representation of key processes in climate/vegetation models, including the role of the Andes and the teleconnections between the Amazon and the Atlantic and Pacific oceans (Boisier et al., 2015). In addition, the biophysical response of the vegetation to changing water supply and increasing $\mathrm{CO}_{2}$ and temperature remains very poorly understood (Davidson et al., 2012). Long-term measurements and process studies at key locations are urgently needed to improve our understanding of these interactions.

\subsection{Biodiversity}

The Amazon Basin contains the most species-rich terrestrial and freshwater ecosystems in the world (Hoorn et al., 2010; Wittmann et al., 2013). It houses at least 40000 plant species, over 400 mammal species, about 1300 bird species, and countless numbers of invertebrate and microbe species (Da Silva et al., 2005), accounting for about 10-20\% of all the world's species diversity. Of these, the great majority have not yet been described scientifically, and possibly never will be. The variety of species in the Amazon Basin is directly related to the variety of habitats, and consequently is threatened by any form of exploitation that is accompanied by habitat destruction, particularly land clearing and deforestation. The genetic information stored in these ecosystems and their biodiversity is beyond measure and may be of enormous economic significance. This diversity is now under great threat, mostly as a result of habitat loss due to deforestation and other land use changes (Vieira et al., 2008). 
Much of the Amazon's aboveground biomass is in its trees, and a single hectare of the forest can be home to over 100 different tree species. Scientists still do not know how many tree species occur in the Amazon, and the current estimate of about 16000 tree species is the result of an extrapolation from the existing scattered census data. Surprisingly, a relatively small number (227 species, or $1.4 \%$ ) account for half of all individual trees (ter Steege et al., 2013), which therefore account for a large fraction of the Amazon's ecosystem services. This fact may greatly facilitate research in Amazonian biogeochemistry, for example studies on the trace gas exchange between plants and the atmosphere.

\subsection{Atmospheric composition and self-cleansing}

The tropical atmosphere has been referred to as the "washing machine of the atmosphere" by P. Crutzen (personal communication, 2013). Both, human activities and the biosphere, release huge amounts of substances such as nitrogen oxides $\left(\mathrm{NO}_{x}\right)$, carbon monoxide $(\mathrm{CO})$, and volatile organic compounds (VOCs) into the atmosphere, which must be constantly removed again to prevent accumulation to toxic levels. Most such gases are poorly soluble in water, and are thus not effectively washed out by rain. The self-purification of the atmosphere therefore requires chemical reactions by which the trace substances are brought into water-soluble form. These reaction chains normally begin with an initial oxidation step in which the trace gas is attacked by a highly reactive molecule, such as ozone $\left(\mathrm{O}_{3}\right)$ or the hydroxyl radical $(\mathrm{OH})$. Production of these atmospheric detergents requires UV radiation and water vapor, both of which are present in generous quantities in the tropics. It comes thus as no surprise, that the tropics are the region in which large fractions of many atmospheric trace gases, including $\mathrm{CO}$ and $\mathrm{CH}_{4}$, are eliminated (Crutzen, 1987). Recent discoveries indicate that the atmospheric oxidant cycles in the boundary layer are even much more active than had been previously assumed, yet the mechanisms of these reactions are still a matter of active research (Lelieveld et al., 2008; Martinez et al., 2010; Taraborrelli et al., 2012; Nölscher et al., 2014).

The functioning of this self-cleansing mechanism is challenged by human activities that change the emissions from the biosphere and add pollutants from biomass burning and industrial activities. This may convert the "washing machine" into a reactor producing photochemical smog with high concentrations of ozone and other atmospheric pollutants, and large quantities of fine aerosols - which in turn influence the formation of clouds and precipitation and thus modify the water and chemical cycles (Andreae, 2001; Pöschl et al., 2010). Increased ozone concentrations over Amazonia, resulting from biomass burning emissions, have also been implicated in plant damage, which may substantially decrease the carbon uptake by the Amazon forest (Pacifico et al., 2015).
The concentrations and types of aerosol particles over the Amazon Basin exhibit huge variations in time and space. In the absence of pollution from regional or distant sources, and especially in the rainy season, the Amazon has among the lowest aerosol concentrations of any continental region (Roberts et al., 2001; Andreae, 2009; Martin et al., 2010b; Pöschl et al., 2010; Andreae et al., 2012; Artaxo et al., 2013; Rizzo et al., 2013). Biogenic aerosols, either emitted directly by the biota or produced photochemically from biogenic organic vapors, make up most of this "clean-period" aerosol (Martin et al., 2010a). At the other extreme, during the biomass burning season in the southern Amazon, aerosol concentrations over large regions are as high as in the most polluted urban areas worldwide (Artaxo et al., 2002; Eck et al., 2003; Andreae et al., 2004). These changes in the atmospheric aerosol burdens have strong impacts on the radiation budget, cloud physics, precipitation, and plant photosynthesis (Schafer et al., 2002; Williams et al., 2002; Andreae et al., 2004; Lin et al., 2006; Oliveira et al., 2007; Freud et al., 2008; Bevan et al., 2009; Martins et al., 2009; Vendrasco et al., 2009; Sena et al., 2013; Cirino et al., 2014; Rap et al., 2015). Episodic inputs of Saharan dust, biomass smoke from Africa, and marine aerosols transported over long distances with the trade winds further complicate the picture (Formenti et al., 2001; Ansmann et al., 2009; Ben-Ami et al., 2010; Baars et al., 2011). This complexity of aerosol sources is one important reason why the mechanisms that lead to the production of biogenic aerosols in Amazonia are still enigmatic (Pöhlker et al., 2012; Chen et al., 2015).

\subsection{The Amazon Tall Tower Observatory (ATTO)}

The foregoing sections have cast some spotlights on the key roles of the Amazon Basin in the earth system and on the important ecosystem services it provides. It is evident that to avoid irreversible damage to this complex system we need a better understanding of the interactions between biosphere and atmosphere in this important region. While considerable knowledge has been gained from campaign-style studies, it is clear that the full picture will not emerge from these "snapshots," but rather that continuous, long-term studies are required at key locations (Hari et al., 2009; Zeri et al., 2014). This is true especially in view of the fact that the Amazon and its global environment are rapidly changing, and that continuing observations are essential to keep track of these changes. It is particularly urgent to obtain baseline data now, to document the present atmospheric and ecological conditions before upcoming changes, especially in the eastern part of the basin, will forever change the face of Amazonia.

Observations from tall towers are especially useful for this purpose, because they allow measurements at several heights throughout the planetary boundary layer and thereby can reflect both local processes at the lower levels and regional influences at the upper levels (Bakwin et al., 1998; Andrews et al., 2014). The effects of emission and uptake by local veg- 
etation and soil are much reduced at $300 \mathrm{~m}$ as compared to $50 \mathrm{~m}$ (Winderlich et al., 2010), and the analysis of the diurnal variation of the vertical concentration profile provides an estimate of the flux of trace gases such as $\mathrm{CO}_{2}$ and $\mathrm{CH}_{4}$ (Winderlich et al., 2014). The influence footprint of typical flux tower measurements made at a few tens of meters above the canopy is of the order of a few kilometers (e.g., de Araújo et al., 2002; Chen et al., 2012), whereas the concentration footprint of a tall tower is of the order of $1000 \mathrm{~km}$, and measurements at the top of the tower are therefore representative of regional processes (Gloor et al., 2001; Heimann et al., 2014). For micrometeorological investigations, a tall tower provides the unique ability to obtain continuous measurements at a series of heights throughout the lower part of the planetary boundary layer. This makes possible investigations of phenomena such as the formation and dissolution of nocturnal stable boundary layers, the production and behavior of intermittent turbulent structures, gravity waves, boundary layer rolls, etc. A summary of the characteristics of the Amazon planetary boundary layer can be found in Fisch et al. (2004).

The need for tall tower observatories at mid-continental locations, especially in Eurasia, Africa, and South America, was recognized in the late 1990s (Gloor et al., 2000) and the establishment of sites in Siberia and Amazonia was proposed to the Max Planck Society. This lead to the construction of the Zotino Tall Tower Observatory (ZOTTO) as a joint Russian-German project, with measurements beginning in 2006 (Heimann et al., 2014), and to the concept of the Amazon Tall Tower Observatory (ATTO).

The ATTO project was initiated in 2008 as a BrazilianGerman partnership. A site was selected $150 \mathrm{~km}$ northeast of Manaus which fulfilled the following criteria: (1) large fetch with minimal current human perturbation, but with potential future land use change at a large scale, (2) relatively flat topography with no large wetlands in the fetch region, (3) stable and protected land ownership and controlled access, and (4) the possibility to reach the site in a reasonable time to facilitate research and educational activities.

In order to characterize the site and begin research activities, the site was set up initially with two measurement towers of intermediate height $(80 \mathrm{~m})$. Atmospheric measurements from these towers and ecological studies of the surrounding forest ecosystems were initiated in 2012. The construction of the $325 \mathrm{~m}$ tall tower began in September 2014 and is currently nearing completion. The tall tower will serve as a basis for continuous monitoring of long-lived biogeochemically important trace gases such as $\mathrm{CO}_{2}, \mathrm{CH}_{4}, \mathrm{CO}$, and $\mathrm{N}_{2} \mathrm{O}$, and a multitude of reactive gases, including $\mathrm{NO}_{x}, \mathrm{O}_{3}$, and $\mathrm{VOC}$, as well as a broad range of aerosol characteristics. The chemical measurements are complemented by a full suite of micrometeorological measurements. Furthermore, the observing system will also include a component directed at the underlying vegetation canopy, such as phenological observations from the tower by automated cameras, potentially a canopy lidar, as well as an array of in situ sensors of critical physical and biological variables in the ecosystems near the tower and at the ground.

The continuous long-term data collected at ATTO will also serve to evaluate airborne and satellite observations. Expected to operate for an indeterminate length of time, this unique observatory in South America will provide long-term observations of the tropical Amazonian ecosystem affected by climate change.

Specific research objectives at the ATTO observatory are the following:

1. to obtain regionally representative measurements of carbon gas concentrations $\left(\mathrm{CO}_{2}, \mathrm{CH}_{4}, \mathrm{CO}\right.$, and VOC), in order to improve our understanding of the carbon budget of the Amazonian rain forest under changing climate, land use, and other anthropogenic influences in the fetch region of ATTO;

2. to continuously observe anthropogenic and biogenic greenhouse gases in the lower troposphere, within the planetary boundary layer by day and outside it at night, in order to help constrain inverse methods for deriving continental source and sink strengths and their changes over time.

3. to continuously measure trace gases and aerosols for improvement of our understanding of atmospheric chemistry and physics in the Amazon, with emphasis on the atmospheric oxidant cycle and the life cycle of the Amazonian aerosol, and to identify the effects of anthropogenic perturbations, e.g., land use change and pollution, on these processes. Measurements of isotopic composition will be made to help distinguish anthropogenic and biogenic fluxes;

4. to determine vertical trace gas and aerosol fluxes and gradients from the tower top to the ground to estimate biosphere-atmosphere exchange rates;

5. to study turbulence and transport processes in the lower atmospheric boundary layer, as well as to understand the extent and characteristics of the roughness sublayer over the forest;

6. to develop and validate dynamic vegetation models, atmospheric boundary layer models, and inverse models for the description of heat, moisture, aerosol, and trace gas fluxes;

7. to evaluate satellite estimates of greenhouse gas concentrations and temperature and humidity profiles by providing a ground truth site.

This paper is intended as an overview paper for a special issue on research at the ATTO observatory. Here we discuss the scientific background and context of the observatory and 
describe the site characteristics, infrastructure, and measurement methodologies. We present initial results from studies in the ecosystem surrounding ATTO and from measurements at the two $80 \mathrm{~m}$ towers. Future papers in the special issue will provide a detailed discussion of the tall tower and present the results of the various scientific investigations at ATTO.

\section{Site description and infrastructure}

\subsection{Site characteristics}

The ATTO site is located $150 \mathrm{~km}$ northeast of Manaus in the Uatumã Sustainable Development Reserve (USDR) in the central Amazon (Fig. 1a). This conservation unit is under the control and administration of the Department of Environment and Sustainable Development of Amazonas State (SDS/CEUC). The USDR is bisected by the Uatumã River through its entire NE-SW extension. The climate is tropical humid, characterized by a pronounced rainy season from February to May and a drier season from June to October (IDESAM, 2009).

The tower site is located approximately $12 \mathrm{~km} \mathrm{NE}$ of the Uatumã River (Fig. 1b). As is typical for this region in the central Amazon Basin, there is little large-scale relief, but at smaller scales a dense drainage network has produced a pattern of plateaus and valleys with a maximum relief height of about $100 \mathrm{~m}$ (Planalto Dissecado do Rio Trombetas Rio Negro). The ATTO site is located at $120 \mathrm{~m}$ a.s.l. on a plateau that measures about $1.5 \mathrm{~km}$ in the NW-SE direction and about $5 \mathrm{~km}$ along the NE-SW axis. The topography surrounding ATTO resembles that around the Manaus LBA (Large-Scale Biosphere-Atmosphere Experiment in Amazonia) site (ZF2, also referred to as $k 34$ site) in the Cuieiras Reserve, where the influence of topography on the micrometeorology and the fluxes of $\mathrm{CO}_{2}$ have been studied in detail by Tota et al. (2012). From the perspective of micrometeorological flux measurements, this is not an ideal type of terrain because it induces significant upslope and downslope circulations. The effects of local topography on the local flux measurements from the small towers are the subject of ongoing investigations.

It must be pointed out, however, that the main objective of the tall tower with respect to greenhouse gas and aerosol monitoring is the measurement of concentrations above the level of local circulations. For this purpose, measurements from tall towers, such as ATTO, have the advantage of being less influenced by the surface layer variability due to diurnal changes in photosynthesis and respiration, as well as by ecosystem and terrain heterogeneity. This results in smoothening of the large daily cycles of near-surface signals and efficient integration over daily cycles and small-scale heterogeneities, which facilitates the detection of long-term changes in the background atmospheric composition.
The plateaus in this region are covered by yellow clayey ferralsols (latosols, oxisols) overlying the Miocene sedimentary Barreiras formation (Chauvel et al., 1987). In the valleys, alisols and sandy podzols are the dominant soil types.

The USDR consists of several different forested ecosystems. Dense, non-flooded upland forests (terra firme) prevail on plateaus at a maximum altitude of approximately $130 \mathrm{~m}$ above sea level (a.s.l.). Seasonally flooded black-water (igapó) forest dominates along the main river channel, oxbow lakes, and the several smaller tributaries of the Uatumã River (approximately $25 \mathrm{~m}$ a.s.1.). Interspersed with these formations are non-flooded terra firme forests on ancient river terraces (35-45 m a.s.1.), and campinas (savanna on white-sand soils) and campinaranas (white-sand forest), which are predominantly located between the river terraces and the slope to the plateaus.

Upwind of the site in the main wind direction (northeast to east), large areas covered by mostly undisturbed terra firme forests extend over hundreds of kilometers. To the northeast, the nearest region with dense human activity is in the coastal regions of the Guyanas and of Amapá State, about $1100 \mathrm{~km}$ away. In the easterly direction, the main stem of the Amazon is in the fetch region of ATTO, with scattered smaller towns and the cities of Santarém and Belém at distances of about 500 and $900 \mathrm{~km}$, respectively. To the southeast, the densely populated states of the Brazilian Nordeste lie at distances greater than $1000 \mathrm{~km}$. Figure 2 presents on overview of the population density and the dominant land cover in northern South America.

The origins of the predominant air masses at ATTO change throughout the year, as the Intertropical Convergence Zone (ITCZ) undergoes large seasonal shifts over the Amazon Basin, resulting in pronounced differences in meteorological conditions and atmospheric composition (Andreae et al., 2012). This is illustrated in Fig. 3, which shows monthly trajectory frequency plots for 9-day back trajectories arriving at ATTO at an elevation of $1000 \mathrm{~m}$. During boreal winter, the ITCZ can lie as far south as $20^{\circ} \mathrm{S}$ so that a large part of the basin, including ATTO, is in the meteorologically Northern Hemisphere (NH). Air masses then arrive predominantly from the northeast over a clean fetch region covered with rain forest. During this period, long-range transport from the Atlantic and Africa brings episodes of marine aerosol, Saharan dust, smoke from fires in West Africa, and possibly even pollution from North America and Europe. This flow pattern shifts abruptly at the end of May, when the ITCZ moves to the north of ATTO. This shift marks the beginning of the dry season at ATTO, a period of time during which the site is exposed to air masses from the easterly and southeasterly fetch regions, which receive considerable pollution from biomass burning and other human activities in northeastern Brazil. In July almost the entire basin is south of the ITCZ, and thus lies in the meteorologically Southern Hemisphere (SH). The transition to the northeasterly flow pattern is more grad- 

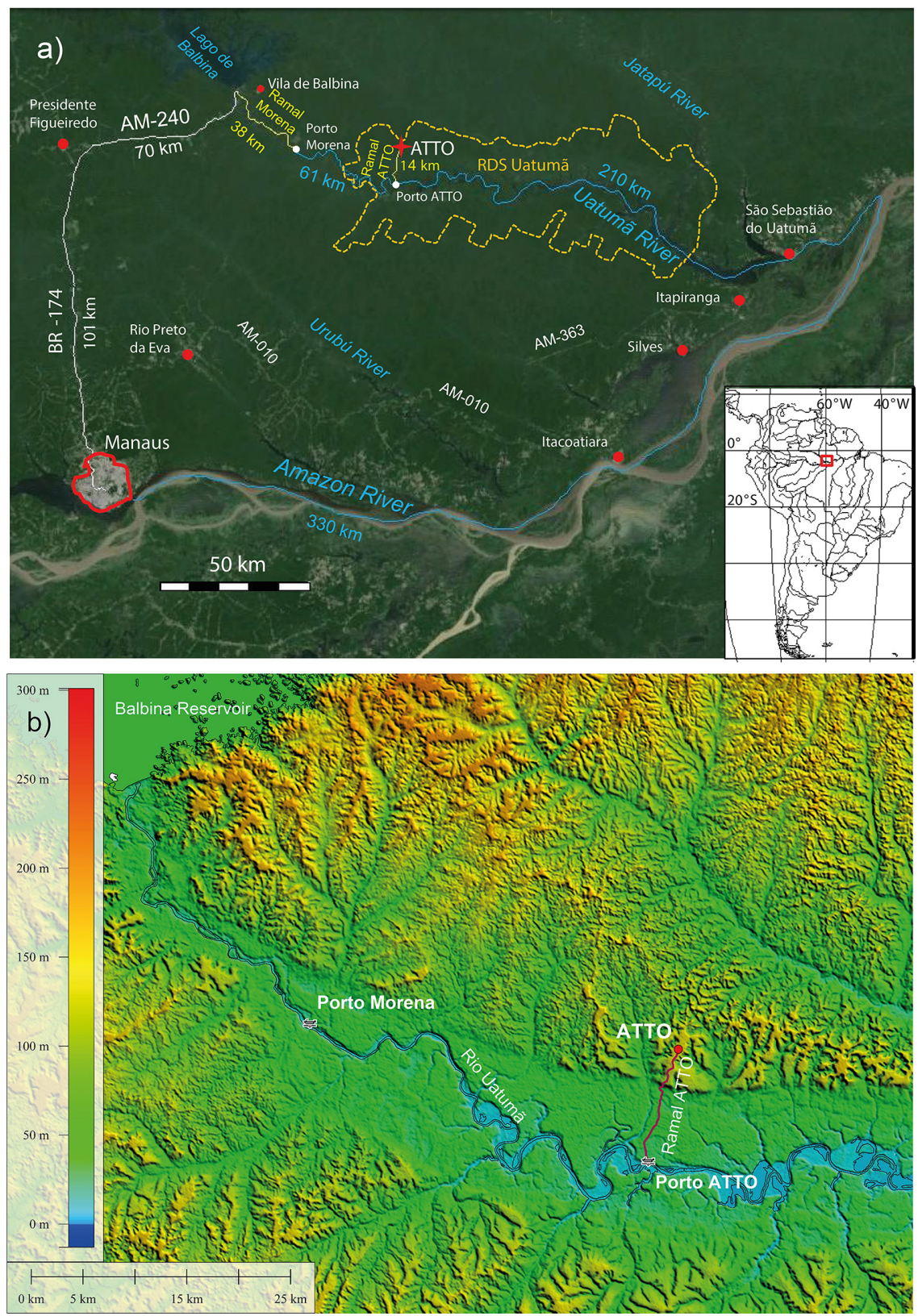

Figure 1. (a) Location of the ATTO site. The main map shows the access to the site via the road and riverboat connections (background map from Google Earth). (b) Topography in the region around the ATTO site. The Balbina Reservoir is in the northwestern corner of the map.

ual, beginning in September and becoming complete only in March.

\subsection{Access}

The ATTO site is reached from Manaus by the paved highway BR-174 for $101 \mathrm{~km}$ northward, then $70 \mathrm{~km}$ to the $\mathrm{E}$ on highway AM-240 towards Balbina. From there, a $38 \mathrm{~km}$ dirt road along the Uatumã River, Ramal de Morena, leads to the small community of Porto Morena, where the road ends. After a $61 \mathrm{~km}$ motor-boat ride on the Rio Uatumã towards the
SE one reaches the landing, Porto ATTO. The access road from the landing to the ATTO site on the plateau follows an old trail used in the 1980s to extract Pau Rosa wood from the forest. This trail was re-opened in 2010 and widened to an ATV and tractor trafficable path that was used during the initial years of the development of the ATTO site. In 2012/13 a $6 \mathrm{~m}$ wide dirt road was constructed between the Uatumã River and the ATTO tower site, which accommodates pickups and trucks. The overall distance along this road, Ramal ATTO, is $13.7 \mathrm{~km}$, rising from 25 to $130 \mathrm{~m}$ a.s.l. Total travel time from Manaus to the site is about $5 \mathrm{~h}$. For the delivery of 


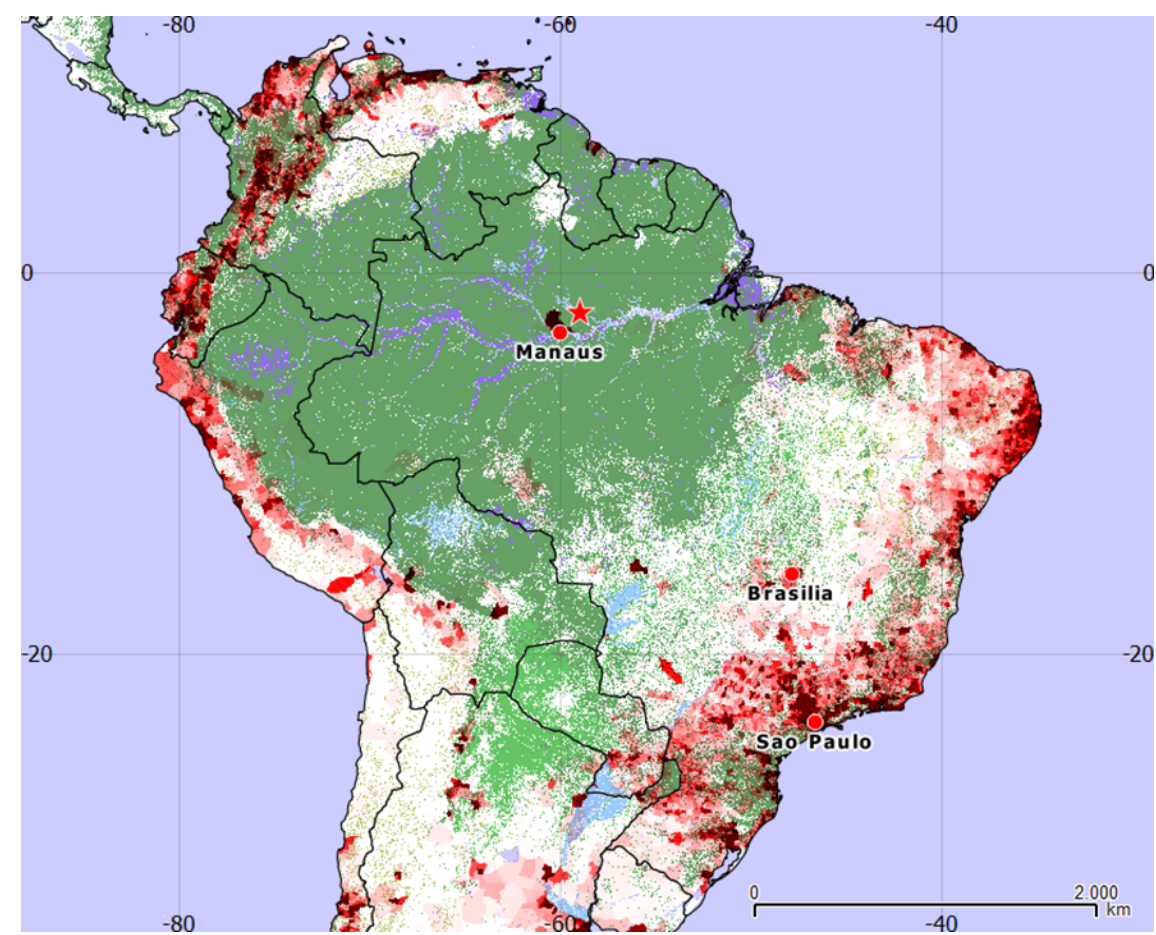

Figure 2. Land cover and population density map of northern South America. The land cover map (GlobCover 2009, downloaded from http://www.esa-landcover-cci.org/, 11 July 2014, ESA and UCLouvain) highlights vegetated areas in green tones (deciduous forest, broadleaf forest, evergreen forest, and mixed broadleaf and needleleaf forest) and water bodies in blue tones (regularly flooded and permanently flooded areas). Populated areas (given as population density map) span a range from 1 (light red) to $1000+$ (dark red) persons per km ${ }^{2}$ (from Gridded Population of the World, Version 3 (GPWv3) provided by the Center for International Earth Science Information Network (CIESIN), Columbia University). The ATTO site is marked by a star.

large and heavy equipment to Porto ATTO, fluvial transportation by ship or pontoon is possible from Manaus by going down the Amazonas River and up its tributary, Rio Uatumã, a distance of ca. $550 \mathrm{~km}$ and travel time of 2 days.

\subsection{Camp}

The base camp on the ATTO plateau was built in 2011/12 and has electrical power and water. Facilities include toilets and a dormitory with hammocks that can accommodate ca. 20 people. Another camp is planned by INPA at the Uatumã River landing, which will serve also as a base station for ecological research in the area. A helicopter landing site is intended adjacent to this camp.

\subsection{Towers}

The measurement facilities on the ATTO plateau consist of two towers of ca. $80 \mathrm{~m}$ height, already implemented, and the $325 \mathrm{~m}$ tall tower, whose construction began in September 2014 and is now nearing completion. In 2010, an $81 \mathrm{~m}$ triangular mast was established for pilot measurements, which is currently used for a wide set of aerosol measurements, followed in 2011 by an $80 \mathrm{~m}$ heavy-duty guy-wired walk-up tower (Instant UpRight, Dublin, Ireland). The walk-up tower can carry a total payload of $900 \mathrm{~kg}$, with outboard platforms on five levels. It is currently used for meteorological and trace gas measurements. The measurements at the top level, at $79.3 \mathrm{~m}$, are the highest ground based measurements within the Amazonian rain forest performed so far. The tower coordinates (WGS 84) are given in Table 1. The measuring instruments are accommodated in three air-conditioned containers, the trace gas lab and the greenhouse gas lab at the base of the walk-up tower, and the aerosol lab at the base of the mast; each lab has inside dimensions of $292 \times 420 \times 200 \mathrm{~cm}$ $(\mathrm{W} \times \mathrm{L} \times \mathrm{H})$ and is supplied by $230 / 135 \mathrm{~V}$ electrical power.

\subsection{Communications}

Since the end of 2013, the ATTO site has been connected to the internet by satellite. The uplink is realized by the mobile satellite terminal Cobham EXPLORER 700 using the INMARSAT/BGAN broadband network, providing a data bandwidth of up to $492 \mathrm{kbps}$. Operating in the L band, its active antenna performance allows up to $20 \mathrm{~dB}$ compensation of signal attenuation due to bad weather. The antenna is mounted at the height of $50 \mathrm{~m}$ on the walk-up tower, aligned by $43.9^{\circ}$ elevation and $273.1^{\circ}$ azimuth towards the geostationary satellite INMARSAT 4-F3 Americas. 

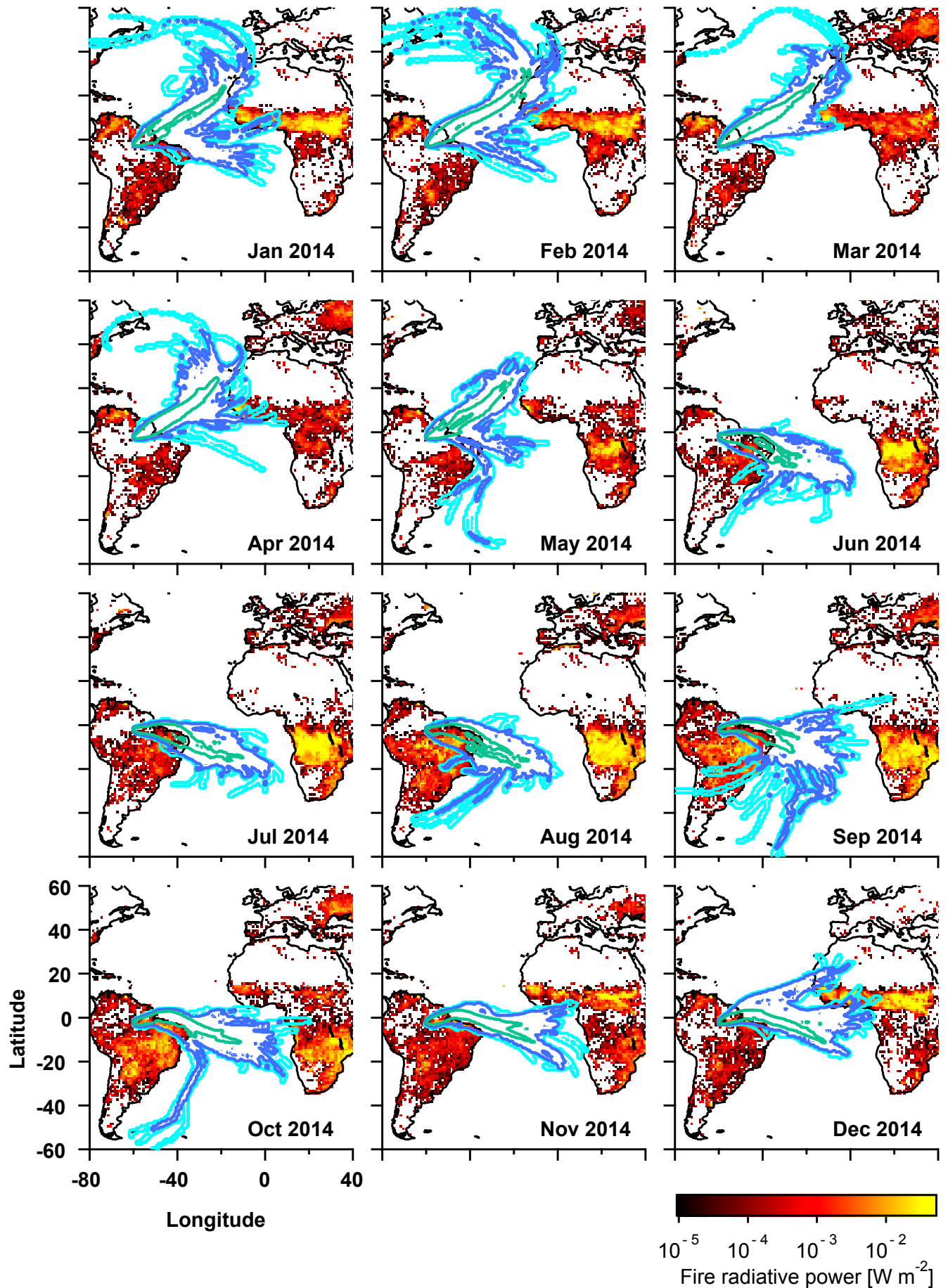

Figure 3. Back trajectory frequency plots and satellite fire maps for the ATTO site in 2014. Back trajectories (9 days) have been calculated with HYSPLIT (NOAA-ARL, GDAS1, start height $1000 \mathrm{~m}$ ) (Draxler and Rolph, 2015). Four back trajectories have been initiated per day $(0: 00,06: 00,12: 00,18: 00$ UTC); frequency plots are based on monthly trajectory ensembles. Color coding of frequency plots: $>10 \%$ (green), $>1 \%$ (blue), $>0.1 \%$ (cyan). Monthly fire map derived from GFAS (Global Fire Assimilation System) and averaged to $1^{\circ}$ grid resolution (Kaiser et al., 2012). 
Table 1. Location and specifications of the towers and masts at the ATTO site.

\begin{tabular}{|c|c|c|c|}
\hline Towers/masts & $\begin{array}{l}\text { Coordinates } \\
\text { (WGS 84) }\end{array}$ & $\begin{array}{l}\text { Base elevation } \\
\text { (m) }\end{array}$ & $\begin{array}{l}\text { Height } \\
(\mathrm{m})\end{array}$ \\
\hline Walk-up tower & $\begin{array}{l}\mathrm{S} 02^{\circ} 08.647^{\prime} \\
\text { W } 58^{\circ} 59.992^{\prime}\end{array}$ & 130 & 80 \\
\hline Triangular mast & $\begin{array}{l}\mathrm{S} 02^{\circ} 08.602^{\prime} \\
\text { W } 59^{\circ} 00.033^{\prime}\end{array}$ & 130 & 81 \\
\hline ATTO Tall Tower & $\begin{array}{l}\mathrm{S} 02^{\circ} 08.752^{\prime} \\
\text { W } 59^{\circ} 00.335^{\prime}\end{array}$ & 130 & 325 \\
\hline
\end{tabular}

A cluster of two redundant routers manages the internet traffic and provides direct access from the internet to the various computers and networkable instruments at the ATTO site. The routers provide additional features like centralized data storage, remote server access, optimized file transfer, monitoring systems, updating clients, VoIP telephony between the local infrastructure sites, etc. Internal data communication between the various sites on the ATTO plateau (towers, labs, camp) is realized via a wireless LAN bridge, operating in the $5 \mathrm{GHz}$ mode, featured by access points with directed-beam antennas.

Data communication within each site occurs via wired LAN with data rates of up to $1000 \mathrm{kbps}$. In addition, at the camp there is WLAN available in the $2.4 \mathrm{GHz}$ mode. The communication system allows monitoring and controlling of networkable instruments in all three lab containers, as well as internet e-mailing, locally and globally. For oral communication with the remote ATTO site and for safety matters, satellite phones (IsatPhonePro) are available operating in the INMARSAT net.

\subsection{Electrical power supply}

Electrical power is provided by a system of diesel generators. Currently, the scientific sites (lab containers and towers) are supplied by two $60 \mathrm{~Hz}$ generators with 45 and $40 \mathrm{kVA}$, operating alternately by weekly switching. They are located ca. $800 \mathrm{~m}$ downwind from the measuring sites to avoid contamination. Due to the long distance between power generation and consumption, power is transmitted via two $600 \mathrm{~V}$ transformers, using two parallel cables, each $3 \times 16 \mathrm{~mm}^{2}$. The voltage provided to the labs is 230 and $135 \mathrm{~V}$, and UPSs are being used to stabilize energy. Power to the camp is provided separately to avoid power fluctuations at the measurement sites. When the tall tower is established, it is planned to upgrade the power generation to a new system of $2 \times 100 \mathrm{kVA}$ generators at a distance of $2-3 \mathrm{~km}$ downwind of the tower.

\section{Measurement methods}

\subsection{Ecological studies}

\subsubsection{Floristic composition and biomass characterization}

Forest plots of three ha each were inventoried in the igapó, the campinarana, the terra firme on ancient river terraces, and the terra firme on the plateau in order to provide a preliminarily description of the floristic composition and turnover as well as the aboveground wood biomass (AGWB). All trees with $\geq 10 \mathrm{~cm} \mathrm{DBH}$ (diameter at breast height) were numbered, tagged with aluminum plates, and, when possible, identified in the field. Fertile and sterile vouchers were collected for later identification in the INPA herbarium. The AGWB was estimated by a pantropical allometric model (Feldpausch et al., 2012) considering DBH, tree height, and wood specific gravity. We measured tree height with a trigonometric measuring device (Blume-Leiss) and determined wood specific gravity by sampling cores from the tree trunk and calculating the ratio between dry mass (after drying the wood samples at $105^{\circ} \mathrm{C}$ for $72 \mathrm{~h}$ ) and fresh volume. Additionally we used data from the Global Wood Density Database DRYAD (Chave et al., 2009) for tree species in the terra firme forests and from Targhetta (2012) for tree species in the campina and igapó forests.

\subsubsection{Leaf phenology}

An RGB camera (StarDot NetCam XL 3MP) was installed in June 2013 at the top of the walk-up tower. The wide-angle view with $2048 \times 1536$ pixel resolution includes over 250 separable tree crowns within an area of $\sim 4$ ha of the forest plateau. The camera aim is steeply oblique and toward the west so that the sun is behind the camera when images are recorded from mid-morning until noon. Illumination artifacts are minimized by selecting images with homogeneous overcast sky and a fixed narrow range of incident radiance, and by post-selection radiometric normalization. Leaf phenology change is most evident in individual crowns, so timelines of the green chromatic coordinate, $g_{\mathrm{c}}$, (Richardson et al., 2007) 
were made for each crown. A steep and sustained increase in the $g_{\mathrm{c}}$ of a crown can only be caused by the flushing of a new leaf cohort. The number of crowns reaching a flush-caused peak of $g_{\mathrm{c}}$ in their individual timelines were counted each month.

\subsubsection{Soil characterization}

Soil sampling was performed on the ancient terraces (old floodplains) and terra firme plateaus at the ATTO site according to a standard protocol (Quesada et al., 2010). Five samples up to $2 \mathrm{~m}$ in depth were taken in each forest plot and one $2 \mathrm{~m}$ depth pit was dug close to each plot. We used the World Reference Base for soil resources to classify soil types (IUSS (International Union of Soil Science) Working Group WRB, 2006). Soil exchangeable cations were determined with the silver thiourea method (Pleysier and Juo, 1980), and soil carbon and nitrogen were analyzed using an automated elemental analyzer (Pella, 1990; Nelson and Sommers, 1996). Particle size was analyzed using the pipette method (Gee and Bauder, 1986). Soil physical properties were calculated for each plot using the "Quesada Index" (Quesada et al., 2010). This index is based on measurements of effective soil depth, soil structure, topography, and anoxia. To investigate the current soil weathering levels, a chemically based weathering index, total reserve bases $\left(\sum \mathrm{RB}\right)$, was calculated. $\sum \mathrm{RB}$ is based on total soil cation concentration and is considered to give a chemical estimation of weatherable minerals (Quesada et al., 2010).

\subsection{Meteorology}

The walk-up tower is equipped with a suite of standard meteorological sensors (Table 2). The following quantities are continuously recorded: (a) soil heat flux, soil moisture, and soil temperature (10 min time resolution), (b) incoming and outgoing short and long wave radiation, photosynthetic active radiation (PAR), net radiation, ultraviolet radiation, rainfall, relative humidity $(\mathrm{RH})$, air temperature, atmospheric pressure, and wind speed and direction ( $1 \mathrm{~min}$ time resolution). Data acquisition is performed by several data loggers (CR3000 and CR1000, Campbell Scientific Inc., USA). Visibility is measured with an optical fog sensor (OFS, Eigenbrodt $\mathrm{GmbH}$, Königsmoor, Germany), which detects the backscattered light intensity from a $650 \mathrm{~nm}$ laser.

\subsection{Turbulence and flux measurements}

Turbulent exchange fluxes of $\mathrm{H}_{2} \mathrm{O}$ and $\mathrm{CO}_{2}$ as well as surface boundary layer stability are measured within and above the canopy using the eddy covariance (EC) technique. The method is well documented in the literature (e.g., Baldocchi, 2003; Foken et al., 2012) and will not be described here. Three-dimensional wind and temperature fluctuations were measured by sonic anemometers at 81,46 and $1.0 \mathrm{~m}$ a.g.l. (see Table 2). $\mathrm{CO}_{2}$ and $\mathrm{H}_{2} \mathrm{O}$ fluctuations are detected by three fast response open-path $\mathrm{CO}_{2} / \mathrm{H}_{2} \mathrm{O}$ infrared gas analyzers installed at a lateral distance of about $10 \mathrm{~cm}$ from the sonic path. The high-frequency signals are recorded at $10 \mathrm{~Hz}$ by CR1000 data loggers. The raw data are processed applying state-of-the-art correction methods using the software Alteddy (version 3.9; www.climatexchange.nl/projects/ alteddy/) based on Aubinet et al. (2000). Fluxes, means and variances are calculated for half-hourly intervals (de Araújo et al., 2002, 2008, 2010). Continuous micrometeorological measurements have been made since September 2012, with some interruptions due to technical problems. The raw data are archived and are made available under the LBA data policy (https://daac.ornl.gov/LBA/lba_data_policy.html).

\subsection{Vertical profiles of reactive trace gases and total $\mathrm{OH}$ reactivity}

Ozone is measured by a UV-absorption technique (Thermo Scientific 49i, Franklin, MA, USA), using Nafion dryers to minimize the effects of changing water vapor concentrations (Wilson and Birks, 2006). Mixing ratios of $\mathrm{CO}_{2}$ and $\mathrm{H}_{2} \mathrm{O}$ are measured by non-dispersive infrared absorption techniques (Licor-7000, LI-COR, Lincoln, USA). The detection limits are $0.5 \mathrm{ppb}$ for ozone, $1 \mathrm{ppm}$ for $\mathrm{CO}_{2}$ and $0.2 \mathrm{mmol} \mathrm{mol}^{-1}$ for $\mathrm{H}_{2} \mathrm{O}$. Instrumental noise for 60 -s averages is $0.25 \mathrm{ppb}$ for ozone, $6 \mathrm{ppb}$ for $\mathrm{CO}_{2}$ (at $370 \mathrm{ppm}$ ), and $0.4 \mathrm{ppm}$ for $\mathrm{H}_{2} \mathrm{O}$ (at $10 \mathrm{mmol} \mathrm{mol}^{-1}$ ).

During intensive campaigns, measurements of mixing ratios of Volatile Organic Compounds (VOC), total OH reactivity, nitric oxide (NO), nitrogen dioxide $\left(\mathrm{NO}_{2}\right)$, ozone $\left(\mathrm{O}_{3}\right)$, and water vapor $\left(\mathrm{H}_{2} \mathrm{O}\right)$ were carried out at 8 heights in and above the rain forest canopy, using a reactive trace gas profile system similar to that described by Rummel et al. (2007). The lower part of the vertical profile $(0.05,0.5$, and $4 \mathrm{~m}$ above the forest floor) was set up at an undisturbed location near the walk-up tower (distance $12 \mathrm{~m}$ ). The upper part of the vertical profile $(12,24,38,53$, and $79 \mathrm{~m}$ above forest floor) was mounted on the northwest corner of the walkup tower. Heated and insulated intake lines (PTFE) were fed to the analyzers, which were housed in the air conditioned lab container $10 \mathrm{~m}$ west of the walk-up tower.

The NO mixing ratio was determined by a gas-phase chemiluminescence technique (CLD TR-780, Ecophysics, Switzerland). $\mathrm{NO}_{2}$ was determined by the same analyzer after specific conversion to $\mathrm{NO}$ by a photolytic converter (Solid-state Photolytic $\mathrm{NO}_{2}$ Converter (BLC); DMT, Boulder/USA). Detection limits are $0.05 \mathrm{ppb}$ for NO and $0.1 \mathrm{ppb}$ for $\mathrm{NO}_{2}$. The signal noise is $<0.5 \%$ of signal, limited by the zero point noise.

Measurements of VOC were performed using a proton transfer reaction mass spectrometer (PTR-MS, Ionicon, Austria) operated under standard conditions $(2.2 \mathrm{hPa}, 600 \mathrm{~V}$, $127 \mathrm{Td} ; 1 \mathrm{Td}=10^{-21} \mathrm{~V} \mathrm{~m}^{2}$.). The instrument is capable of continuously monitoring VOCs with proton affinities higher than water and at low mixing ratios (several ppt with a time 
Table 2. Overview of (micro)-meteorological sensors, trace gas and aerosol instrumentation installed at the walk-up tower.

\begin{tabular}{|c|c|c|c|}
\hline Quantity & Instrument & Height a.g.1./depth (m) & Institution \\
\hline Soil heat flux & Heat flux sensor (HFP01, Hukseflux, Netherlands) & 0.05 & INPA, EMBRAPA, MPIC \\
\hline Soil moisture & $\begin{array}{l}\text { Water content reflectometer (CS615, Campbell Scientific Inc., } \\
\text { USA) }\end{array}$ & $0.1,0.2,0.3,0.4,0.6,1.0$ & INPA, EMBRAPA \\
\hline Soil temperature & Thermistor (108, Campbell Scientific Inc., USA) & $0.1,0.2,0.4$ & INPA, EMBRAPA, MPIC \\
\hline $\begin{array}{l}\text { Shortwave radiation (incoming and re- } \\
\text { flected) }\end{array}$ & Pyranometer (CMP21,Kipp \& Zonen, Netherlands) & 75.0 & INPA, EMBRAPA \\
\hline $\begin{array}{l}\text { Longwave radiation (atmospheric and } \\
\text { terrestrial) }\end{array}$ & Pyrgeometer (CGR4, Kipp \& Zonen, Netherlands) & 75.0 & INPA, EMBRAPA \\
\hline PAR (incoming and reflected) & Quantum sensor (PAR LITE, Kipp \& Zonen, Netherlands) & 75.0 & USP \\
\hline Net radiation & Net radiometer (NR-LITE2, Kipp \& Zonen, Netherlands) & 75.0 & INPA, EMBRAPA \\
\hline Ultra violet radiation & UV radiometer (CUV5, Kipp \& Zonen, Netherlands) & 75.0 & INPA, EMBRAPA \\
\hline Rainfall & Rain gauge (TB4, Hydrological Services Pty. Ltd., Australia) & 81.0 & INPA, EMBRAPA \\
\hline Air temperature and relative humidity & $\begin{array}{l}\text { Termohygrometer (CS215, Rotronic Measurement Solutions, } \\
\text { UK) }\end{array}$ & $\begin{array}{l}81.0,73.0,55.0,40.0,36.0 \\
26.0,12.0,4.0,1.5,0.4\end{array}$ & INPA, EMBRAPA \\
\hline Atmospheric pressure & Barometer (PTB101B, Vaisala, Finnland) & 75.0 & INPA, EMBRAPA \\
\hline Wind speed and direction & 2-D sonic anemometer (WindSonic, Gill Instruments Ltd., UK) & $\begin{array}{l}73.0,65.0,50.0,42.0,26.0 \\
19.0\end{array}$ & INPA, EMBRAPA \\
\hline Wind vector components $(\mathrm{u}, \mathrm{v}, \mathrm{w})$ & 3D sonic anemometer (WindMaster, Gill Instruments Ltd., UK) & $81.0,46.0,36.0,4.0,1.0$ & INPA, EMBRAPA \\
\hline $\mathrm{CO}_{2}$ and $\mathrm{H}_{2} \mathrm{O}$ molar density & $\begin{array}{l}\text { IRGA (LI-7500A, LI-COR Inc., USA) } \\
\text { IRGA (LI-7200, LI-COR Inc., USA) }\end{array}$ & $\begin{array}{l}81.0,46.0 \\
1.0\end{array}$ & INPA, EMBRAPA \\
\hline $\begin{array}{l}\text { Vertical profile of } \mathrm{CO}_{2}, \mathrm{CH}_{4} \text { and } \mathrm{CO} \\
\text { mixing ratios }\end{array}$ & $\begin{array}{l}\text { G1301 (CFADS-109) and G1302 (CKADS-018, both Picarro } \\
\text { Inc., USA) }\end{array}$ & $4.0,24.0,38.0,53.0,79.0$ & MPI-BGC, MPI-C \\
\hline $\begin{array}{l}\text { Vertical profile of } \mathrm{NO}, \mathrm{NO}_{2}, \mathrm{O}_{3}, \mathrm{CO}_{2} \text {, } \\
\text { and } \mathrm{H}_{2} \mathrm{O} \text { mixing ratios }\end{array}$ & $\begin{array}{l}\text { CLD 780TR (Eco Physics, Switzerland), BLC (Droplet Mea- } \\
\text { surement Technologies Inc., USA), TEI 49i (Thermo Electron } \\
\text { Corp, USA), IRGA } 7000 \text { (LI-COR Inc., USA) }\end{array}$ & $\begin{array}{l}0.05,0.5,4.0,12.0,24.0,38.3 \\
53.0,79.3\end{array}$ & INPA, MPI-C, UEA \\
\hline Vertical profile of VOCs & $\begin{array}{l}\text { Proton transfer mass spectrometer (PTR-QMS 500, Ionicon, } \\
\text { Austria) }\end{array}$ & $\begin{array}{l}0.05,0.5,4.0,12.0,24.0,38.3 \\
53.0,79.3\end{array}$ & MPI-C, USP, INPA \\
\hline Vertical profile of total reactivity to $\mathrm{OH}$ & $\begin{array}{l}\text { Comparative reaction method, proton transfer mass spectrome- } \\
\text { ter }\end{array}$ & $\begin{array}{l}0.05,0.5,4.0,12.0,24.0,38.3 \\
53.0,79.3\end{array}$ & MPI-C \\
\hline Black carbon equivalent & $\begin{array}{l}\text { Multiangle Absorption Photometer (model 5012, Thermo- } \\
\text { Scientific, USA) }\end{array}$ & 60.0 & MPI-C \\
\hline Refractory black carbon & $\begin{array}{l}\text { Single Particle Soot Photometer (SP-2, Droplet Measurement } \\
\text { Technologies, USA) }\end{array}$ & 60.0 & MPI-C \\
\hline Black carbon equivalent & $\begin{array}{l}\text { Aethalometer (model AE31 or AE33, Magee Scientific Corpo- } \\
\text { ration, USA) }\end{array}$ & 60.0 & USP \\
\hline Aerosol scattering & $\begin{array}{l}\text { Nephelometer (model } 3563 \text {, TSI, USA) } \\
\text { Ecotech Aurora } 3000 \text {; wavelengths } 450,525 \text {, and } 635 \mathrm{~nm}\end{array}$ & 60.0 & USP \\
\hline Aerosol number concentration & Condensation particle counter (model 3022A,TSI, USA) & 60.0 & MPI-C \\
\hline Aerosol size distribution & $\begin{array}{l}\text { Ultra-High Sensitivity Aerosol Spectrometer (Droplet Measure- } \\
\text { ment Technologies, USA) } \\
\text { Scanning Mobility Particle Sizer (SMPS, TSI model 3080, St. } \\
\text { Paul, MN, USA; size range: } 10-430 \mathrm{~nm} \text { ) } \\
\text { Optical Particle Sizer (OPS, TSI model 3330; size range: 0.3- } \\
10 \mu \mathrm{m} \text { ) } \\
\text { Wide Range Aerosol Spectrometer (WRAS, Grimm Aerosol } \\
\text { Technik, Ainring, Germany; size range: } 6 \mathrm{~nm}-32 \mu \mathrm{m} \text { ) }\end{array}$ & $\begin{array}{l}60.0 \\
60.0 \\
60.0 \\
3.0\end{array}$ & MPI-C \\
\hline $\begin{array}{l}\text { Primary biological aerosol particles } \\
\text { (PBAP) }\end{array}$ & Wideband Integrated Bioaerosol Spectrometer (WIBS-4, DMT) & 60.0 & MPI-C \\
\hline Aerosol chemical composition & $\begin{array}{l}\text { Aerosol Chemical Speciation Monitor (ACSM, Aerodyne, } \\
\text { USA) }\end{array}$ & 60.0 & USP \\
\hline
\end{tabular}

resolution of about 1-20s) (Lindinger et al., 1998). One entire VOC vertical profile (from 0.05 to $80 \mathrm{~m}, 8$ heights in total) can be determined every $16 \mathrm{~min}$ using the same inlet system as the $\mathrm{NO}, \mathrm{NO}_{2}, \mathrm{O}_{3}$, and $\mathrm{CO}_{2}$ instruments.

Calibration was performed using a gravimetrically prepared multicomponent standard (Ionimed, Apel\&Riemer). Occasionally, samples were collected in absorbent packed tubes (130 mg of Carbograph $1\left[90 \mathrm{~m}^{2} \mathrm{~g}^{-1}\right]$ followed by $130 \mathrm{mg}$ of Carbograph $5\left[560 \mathrm{~m}^{2} \mathrm{~g}^{-1}\right]$; Lara s.r.l., Rome, Italy) (Kesselmeier et al., 2002) and analyzed by GC-FID (gas chromatography - flame ionization detection) in order to cross-validate the measurements by PTR-MS and to deter- mine the monoterpene speciation for the total $\mathrm{OH}$ reactivity measurement.

In addition to the measurement of individual reactive inorganic trace gases and the VOCs, the total $\mathrm{OH}$ reactivity was determined. Total $\mathrm{OH}$ reactivity is the summed loss rate of all $\mathrm{OH}$-reactive molecules (mixing ratio $\times$ reaction rate coefficient) present in the atmosphere. Direct measurements of total $\mathrm{OH}$ reactivity were conducted by the Comparative $\mathrm{Re}-$ activity Method (CRM, Sinha et al., 2008) using a PTR-MS as a detector. The PTR-MS monitored the mixing ratio of a reagent (pyrrole) after mixing and reaction in a Teflon-coated glass reactor. Pyrrole alternatingly reacts with $\mathrm{OH}$ alone and with $\mathrm{OH}$ in the presence of ambient air containing many 
more $\mathrm{OH}$ reactive compounds. The competitive reactions of the reagent and the ambient $\mathrm{OH}$ reactive molecules cause a change in the detected levels of pyrrole. This can be equated to the atmospheric total $\mathrm{OH}$ reactivity provided the instrument is well calibrated and appropriate corrections are applied (Nölscher et al., 2012). The total OH reactivity instrument was regularly tested for linearity of response using an isoprene gas standard (Air Liquide). VOC and total $\mathrm{OH}$ reactivity measurements were performed simultaneously with two separate PTR-MS systems measuring from the same inlet so that the results may be directly compared over time, height, and season. The CRM was able to measure $\mathrm{OH}$ reactivity down to $3 \mathrm{~s}^{-1}$, estimated by the minimum observable modulation above two times the standard deviation $(\sigma)$ of the noise (measured in zero air). The overall uncertainty in the measurement was $16 \%$, including errors in detector $(5 \%)$, rate coefficient $(14 \%)$, gas standard $(5 \%)$ and flow dilution $(2 \%)$.

\subsection{Vertical profiles of long-lived trace gases $\left(\mathrm{CO}, \mathrm{CO}_{2}\right.$, and $\mathrm{CH}_{4}$ )}

In March 2012, continuous and high precision $\mathrm{CO}_{2} / \mathrm{CH}_{4} / \mathrm{CO}$ measurements were established in an air-conditioned container at the foot of the $80 \mathrm{~m}$-tall walk-up tower. The sample air inlets are installed at five levels: $79,53,38,24$, and $4 \mathrm{~m}$ above ground. The inlet tubes are constantly flushed at a flow rate of several liters per minute to avoid wall interaction within the tubing. A portion of the sample air is sub-sampled from the high flow lines at a lower flow rate for analysis with instruments based on the cavity ring-down spectroscopy technique (G1301 and G1302 analyzers [Picarro Inc., USA] for measuring $\mathrm{CO}_{2} / \mathrm{CH}_{4}$ and $\mathrm{CO} / \mathrm{CO}_{2}$, respectively).

The G1301 analyzer (Serial CFADS-109) provides data with a standard deviation of the raw data below $0.05 \mathrm{ppm}$ for $\mathrm{CO}_{2}$ and $0.5 \mathrm{ppb}$ for $\mathrm{CH}_{4}$, the long-term drift is below 2 ppm and $1 \mathrm{ppb}$ per year for $\mathrm{CO}_{2}$ and $\mathrm{CH}_{4}$, respectively. For the G1302 (Serial CKADS-018), tests with a stable gas tank show a standard deviation of the raw data of $0.04 \mathrm{ppm}$ for $\mathrm{CO}_{2}$ and $7 \mathrm{ppb}$ for $\mathrm{CO}$. The long-term drift of the analyzer is below $2 \mathrm{ppm}$ and $4 \mathrm{ppb}$ per year for $\mathrm{CO}_{2}$ and $\mathrm{CO}$, respectively. Both analyzers agree well with a $\mathrm{CO}_{2}$ difference below $0.02 \mathrm{ppm}$. When the G1301 analyzer broke down in 2012, it was replaced from December 2012 until October 2013 with a Fast Greenhouse Gas Analyzer (FGGA) based on off-axis integrated cavity output spectroscopy (OAICOS; Los Gatos Research Inc., USA) as an emergency solution. This $\mathrm{CO}_{2} / \mathrm{CH}_{4} / \mathrm{H}_{2} \mathrm{O}$ analyzer is designed for measuring at rates of $\geq 10 \mathrm{~Hz}$ and is primarily used for eddy covariance and chamber flux measurements, where a low drift rate is less vital than for highly precise and stable long-term measurements. The FGGA operates with a raw standard deviation of $0.6 \mathrm{ppm}$ for $\mathrm{CO}_{2}$ and $2 \mathrm{ppb}$ for $\mathrm{CH}_{4}$; the drift is quite large with $1 \mathrm{ppm}$ and $3 \mathrm{ppb}$ per day for $\mathrm{CO}_{2}$ and $\mathrm{CH}_{4}$, respec- tively. For the time when the FGGA was used, the calibration and drift correction routines were adopted accordingly. The detailed description of the whole measurement system, including measurement, calibration, and correction routines will be presented elsewhere.

\subsection{Aerosol measurements}

\subsubsection{Size distributions and optical measurements}

Aerosols are sampled above the canopy at $60 \mathrm{~m}$ height, without size cut-off, and transported in a laminar flow through a $2.5 \mathrm{~cm}$ diameter stainless steel tube into an air-conditioned container (aerosol lab at mast, see Sect. 2.4). The sample humidity is kept below $40 \%$ using silica diffusion driers. Since January 2015, the aerosol sample air is being dried using a fully automatic silica diffusion dryer, developed by the Institute for Tropospheric Research, Leipzig, Germany (Tuch et al., 2009). Aerosol size distributions at $60 \mathrm{~m}$ are currently measured from $10 \mathrm{~nm}$ up to $10 \mu \mathrm{m}$ using three instruments: a Scanning Mobility Particle Sizer (SMPS, TSI model 3080, St. Paul, MN, USA; size range: $10-430 \mathrm{~nm}$ ), an Ultra-High Sensitivity Aerosol Spectrometer (UHSAS, DMT, Boulder, CO, USA; size range: $60-1000 \mathrm{~nm}$ ), and an Optical Particle Sizer (OPS, TSI model 3330; size range: $0.3-10 \mu \mathrm{m})$. The SMPS provides an electromobility size distribution, whereas the UHSAS and OPS measure aerosol light scattering and derive the size distributions from the particle scattering intensity (Cai et al., 2008). In addition to these continuous above-canopy measurements, aerosol size distributions are measured with a Wide Range Aerosol Spectrometer (WRAS, Grimm Aerosol Technik, Ainring, Germany; size range: $6 \mathrm{~nm}-32 \mu \mathrm{m}$ ) from a separate inlet line below the canopy at $3 \mathrm{~m}$ height. The WRAS provides electromobility size distributions in the size range of 6-350 nm and uses particle light scattering for the size range above $300 \mathrm{~nm}$. Details of the instrumentation setup are given in Table 2.

For measuring aerosol light scattering, we use a threewavelength integrating nephelometer (until February 2014: TSI model 3563, wavelengths 450,550 , and $700 \mathrm{~nm}$; after February 2014: Ecotech Aurora 3000, wavelengths 450, 525, and $635 \mathrm{~nm}$ ) (Anderson et al., 1996; Anderson and Ogren, 1998). Calibration is carried out using $\mathrm{CO}_{2}$ as the high span gas and filtered air as the low span gas. The zero signals are measured once every $12 \mathrm{~h}$ using filtered ambient air. For the $300 \mathrm{~s}$ averages applied here, the detection limits, defined as a signal to noise ratio of 2 , for scattering coefficients are 0.45 , 0.17 , and $0.26 \mathrm{Mm}^{-1}$ for $450,550 / 525$, and $700 / 635 \mathrm{~nm}$, respectively. Since sub-micrometer particles predominate in the particle number size distribution at our remote continental site, the sub-micron corrections given in Table 4 of Anderson and Ogren (1998) were used for the truncation corrections. Bond et al. (2009) suggested that this correction is accurate to within $2 \%$ for a wide range of atmospheric par- 
ticles, but that the error could be as high as $5 \%$ for highly absorbing particles.

A Multi-Angle Absorption Photometer (MAAP, Model 5012, Thermo Electron Group, USA, $\lambda=670 \mathrm{~nm}$ ) and a 7 wavelength Aethalometer (until January 2015 model AE31, since then model AE-33) (Magee Scientific Company, Berkeley, CA, USA, $\lambda=370,470,520,590,660,880$, and $950 \mathrm{~nm}$ ) are used for measuring the light absorption by particles. The MAAP and aethalometer have been deployed at ATTO since March 2012. In the MAAP instrument, the optical absorption coefficient of aerosol collected on a filter is determined by radiative transfer calculations, which include multiple scattering effects and absorption enhancement due to reflections from the filter. A mass absorption efficiency $\left(\alpha_{\mathrm{abs}}\right)$ of $6.6 \mathrm{~m}^{2} \mathrm{~g}^{-1}$ was used to convert the MAAP absorption data to equivalent $\mathrm{BC}\left(\mathrm{BC}_{\mathrm{e}}\right)$. For the Aethalometer, an empirical correction method described by Rizzo et al. (2011) was used to correct the data for the scattering artifact.

Refractory black carbon (rBC) is measured by a fourchannel Single Particle Soot Photometer (SP2). The instrument is calibrated every 6 months using monodisperse fullerene aerosol particles for $\mathrm{rBC}$ calibration, and polystyrene latex (PSL) spheres for scattering calibration. The instrument is sensitive to $\mathrm{rBC}$ in the size range between 70 and $280 \mathrm{~nm}$. A recent instrumental upgrade provides a broader rBC dynamic range (70-480 $\mathrm{nm}$ ).

Regular quality checks are performed with all aerosol sizing instruments and CPCs, including flow checks, zero tests, and intercomparisons with ambient aerosol and monodisperse PSL cells. Exemplary plots are already included in the manuscript (Fig. 26). The MAAP and aethalometer are subject to frequent intercomparisons with the other optical instruments. For example, two aethalometers and the MAAP were operated side-by-side during an intensive campaign in November/December 2014. The $\mathrm{BC}_{\mathrm{e}}$ concentrations from the individual instruments agreed well. The SP2 instrument was carefully intercalibrated with another SP2 during the GoAmazon-2014 campaign.

Fluorescent biological aerosol particles (FBAPs) are measured with the Wideband Integrated Bioaerosol Spectrometer (WIBS-4A, DMT). The WIBS utilizes light-induced fluorescence technology to detect biological materials in real-time based on the presence of fluorophores in the ambient particles (Kaye et al., 2005). A $2 \times 2$ excitation ( 280 and $370 \mathrm{~nm}$ ) - emission (310-400 and 420-650 nm) matrix is recorded along with the particle optical size and shape factor. The FBAP concentrations reported in this study correspond to the FL3 channel (excitation at $370 \mathrm{~nm}$ and emission in the waveband of $420-650 \mathrm{~nm}$ ) of the WIBS instrument (Healy et al., 2014).

\subsubsection{Chemical measurements and hygroscopicity}

The submicron non-refractory aerosol composition at a height of $60 \mathrm{~m}$ is measured using an Aerosol Chemical Speci- ation Monitor (ACSM, Aerodyne, USA) as described by Ng et al. (2011). The ACSM samples aerosol particles in the 75$650 \mathrm{~nm}$ size range. The non-refractory fraction flash vaporizes on a hot surface $\left(600^{\circ} \mathrm{C}\right)$, the evaporated gas phase compounds are ionized by $70 \mathrm{eV}$ electron impact, and their spectra determined using a quadrupole mass spectrometer. The chemical speciation is determined via deconvolution of the mass spectra according to Allan et al. (2004). Mass concentrations of particulate organics, sulfate, nitrate, ammonium, and chloride are obtained with detection limits $<0.2 \mu \mathrm{g} \mathrm{m}^{-3}$ for $30 \mathrm{~min}$ of signal averaging. Mass calibration of the system is performed using size-selected ammonium nitrate and ammonium sulfate aerosol following the procedure described by $\mathrm{Ng}$ et al. (2011). A collection efficiency (CE) of 1.0 is applied (similar to Chen et al., 2015), yielding good agreement with other instruments.

$\mathrm{PM}_{2.5}$ sampling was carried out from 7 March to 21 April 2012 on Nuclepore ${ }^{\circledR}$ polycarbonate filters at $80 \mathrm{~m}$ on the walk-up tower using a Harvard Impactor; samples were collected over 48 hour periods. They were analyzed by energy-dispersive X-ray fluorescence (EDXRF) (MiniPal 4, PANalytical) at $1 \mathrm{~mA}$ and $9 \mathrm{kV}$ for low- $\mathrm{Z}$ (Na to $\mathrm{Cl}$ ) elements, and $0.3 \mathrm{~mA}, 30 \mathrm{kV}$, and internal $\mathrm{Al}$ filter for the other elements. Soluble species were determined by ion chromatography (Dionex, ICS-5000) using conductivity detection for cations and anions and UV-VIS for soluble transition metals. For cation separation, a capillary column CS12A was used, for anions, an AS19 column, and for transition metals, a CS5A column (calibrated to quantify traces of $\mathrm{Fe}^{2+}$ and $\left.\mathrm{Fe}^{3+}\right)$.

Size-resolved cloud condensation nuclei $(\mathrm{CCN})$ measurements are performed using a continuous-flow streamwise thermal gradient $\mathrm{CCN}$ counter (CCNC; model CCN-100, DMT, Boulder, CO, USA), a differential mobility analyzer (DMA, Grimm Aerosol Technik, Ainring, Germany) and a condensation particle counter (CPC model 5412, Grimm Aerosol Technik). By changing the temperature gradient, the supersaturation of the CCNC is set to values between 0.1 and $1.1 \%$. The completion of a full measurement cycle comprising $\mathrm{CCN}$ efficiency spectra at 10 different supersaturation levels takes $\sim 4 \mathrm{~h}$. The CCNC is calibrated frequently as part of the maintenance routines with size selected monodisperse ammonium sulfate particles (Rose et al., 2008; Gunthe et al., 2009).

\subsubsection{Microspectroscopic analysis of single aerosol particles}

Aerosol samples for scanning electron microscopy with electron probe micro-analysis (EPMA) were collected on top of the $80 \mathrm{~m}$ tower in April 2012. For the collection of sizesegregated samples for single particle analysis, we used a Battelle impactor with aerodynamic diameter cut-offs at 4 , 2,1 and $0.5 \mu \mathrm{m}$. The particles were collected on TEM (transmission electron microscope) grids covered with a thin car- 
bon film $(15-25 \mathrm{~nm})$. Aerosol samples for x-ray microspectroscopy were collected using a single stage impactor, operated at a flow rate of $1-1.5 \mathrm{~L} \mathrm{~min}^{-1}$ and a corresponding $50 \%$ size cut-off of about $500 \mathrm{~nm}$. Particles below this nominal cut-off are not deposited quantitatively; however, a certain fraction is still collected via diffusive deposition. Aerosol particles were collected onto silicon nitride substrates (membrane width $500 \mu \mathrm{m}$, membrane thickness $100 \mathrm{~nm}$, Silson Ltd., Northampton, UK) for short sampling periods $(\sim 20 \mathrm{~min})$, which ensures a thin particle coverage on the substrate appropriate for single particle analysis.

Scanning transmission X-ray microscopy with nearedge X-ray absorption fine structure analysis (STXMNEXAFS) measurements were made at the Advanced Light Source (ALS, Berkeley, CA, USA) and the Berliner Elektronenspeicherring-Gesellschaft für Synchrotronstrahlung (BESSY II, Helmholtz-Zentrum Berlin für Materialien und Energie (HZB), Germany). A detailed description of the instrumentation and techniques can be found elsewhere (Kilcoyne et al., 2003; Follath et al., 2010; Pöhlker et al., 2012, 2014). Scanning Electron Microscopy with Energy Dispersive X-ray spectroscopy (SEM/EDX) analysis was carried out using a Jeol JSM-6390 SEM equipped with an Oxford Link SATW ultrathin window EDX detector. For EPMA, quantitative and qualitative calculations of the particle composition were performed using iterative Monte Carlo simulations and hierarchical cluster analysis (Ro et al., 2003) to obtain average relative concentrations for each different cluster of similar particle types.

\subsubsection{Chemical composition of secondary organic aerosol}

Filter sampling for secondary organic aerosol (SOA) analysis was performed on the walk-up tower at a height of $42 \mathrm{~m}$ above ground level. Fine aerosol $\left(\mathrm{PM}_{2.5}\right)$ was sampled at a flow rate of $2.3 \mathrm{~m}^{3} \mathrm{~h}^{-1}$ on TFE-coated borosilicate glass fiber filters (Pallflex, T60A20, Pall Life Science, USA). The sampling times were 6,12 , or $24 \mathrm{~h}$. After sampling the filters were stored at $255 \mathrm{~K}$ until extraction.

The extraction of the filters was performed with acetonitrile ( $\geq 99.9 \%$; Sigma Aldrich) in a sonication bath at room temperature. The filter extracts were evaporated with a gentle nitrogen flow at room temperature in an evaporation unit (Reacti Vap 1; Fisher Scientific), and the residue was re-dissolved in $100 \mu \mathrm{L}$ HPLC grade water (Milli-Q water system, Millipore, Bedford, USA) / acetonitrile ( $\geq 99.9 \%$; Sigma Aldrich) mixture $(8: 2)$.

The separation and analysis was performed with an UHPLC (ultrahigh performance liquid chromatography) system (Dionex UltiMate 3000) coupled to a Q Exactive electrospray ionization Orbitrap mass spectrometer (Thermo Scientific). A Hypersil Gold column $(50 \mathrm{~mm} \times 2.1 \mathrm{~mm}, 1.9 \mu \mathrm{m}$ particle size, $175 \AA$ pore size; Thermo Scientific) was used. The elu- ents were HPLC grade water (Milli-Q water system, Millipore, Bedford, USA) with $0.01 \%$ formic acid and $2 \%$ acetonitrile (eluent A) and acetonitrile with $2 \%$ HPLC grade water (eluent B). The flow rate of the mobile phase was $0.5 \mathrm{~mL} \mathrm{~min}^{-1}$. The column was held at a constant temperature of $298 \mathrm{~K}$ in the column oven. The MS was operated with an auxiliary gas flow rate of 15 (instrument specific arbitrary units, AU), a sheath gas flow rate of $30 \mathrm{AU}$, a capillary temperature of $623 \mathrm{~K}$, and a spray voltage of $3000 \mathrm{~V}$. The MS was operated in the negative ion mode, the resolution was 70000 , and the measured mass range was $m / z$ 80-350.

\section{Ongoing research and initial results}

\subsection{Ecological studies}

\subsubsection{Tree species richness, composition, turnover, and aboveground wood biomass}

In total, 7293 trees $\geq 10 \mathrm{~cm}$ DBH were recorded in the 12 1-ha inventoried plots, which included 60 families, 206 genera, and 417 species. Tree species richness was highest in the terra firme forest on the plateau, followed by the terra firme forest on the fluvial terrace, the campinarana, and the seasonally flooded igapó (Table 3). Floristic similarity (BrayCurtis index) within plots of the same forest types ranged from $45-65 \%$, but was highly variable between different forest types (2-54\%). Accordingly, the species turnover across the investigated forest types was high, especially when seasonally inundated forest plots were compared to their nonflooded counterparts (Fig. 4). AGWB varied considerably between the studied forest ecosystems as a result of varying tree heights, DBH, and basal area (Table 3). Carbon stocks in the AGWB increased from $74 \pm 12 \mathrm{Mg} \mathrm{ha}^{-1}$ in the igapó forest to $79 \pm 26 \mathrm{Mg} \mathrm{ha}^{-1}$ in the campina/campinarana, and $101 \pm 13 \mathrm{Mg} \mathrm{ha}^{1}$ on the ancient fluvial terrace, reaching maximum values of $170 \pm 13 \mathrm{Mg} \mathrm{ha}^{-1}$ in the terra firme forests. Tree species richness correlated significantly with carbon stocks in AGWB $\left(n=12 ; r^{2}=0.61 ; p<0.01\right)$.

The floristic data indicate that the rain forests at the ATTO site combine high alpha diversity with high beta diversity at a small geographic scale, where tree species segregate mainly due to contrasting local edaphic conditions (e.g., Tuomisto et al., 2003; ter Steege et al., 2013; Wittmann et al., 2013). Biomass and carbon stocks vary considerably between habitats, and show low values on flooded and nutrient-poor soils and high values on well-drained upland soils, as previously reported elsewhere for other Amazonian regions (e.g., Chave et al., 2005; Malhi et al., 2006; Schöngart et al., 2010).

\subsubsection{Cryptogamic covers}

We are investigating the potential of cryptogamic covers to serve as a source of bioaerosol particles and chemical compounds. Cryptogamic covers comprise photoau- 
Table 3. Tree species richness, forest structure, above-ground wood biomass (AGWB) and carbon stocks of the inventoried forest plots.

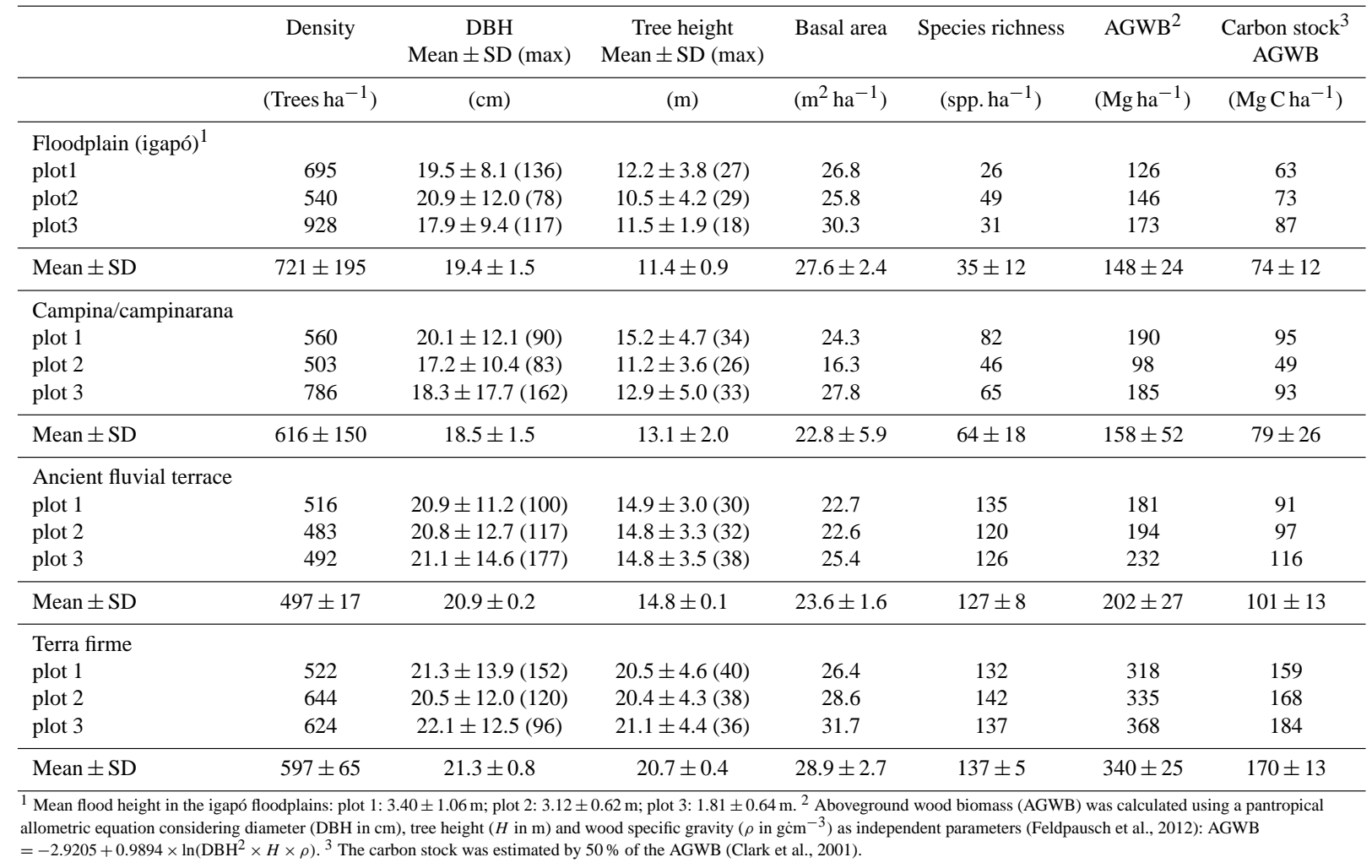

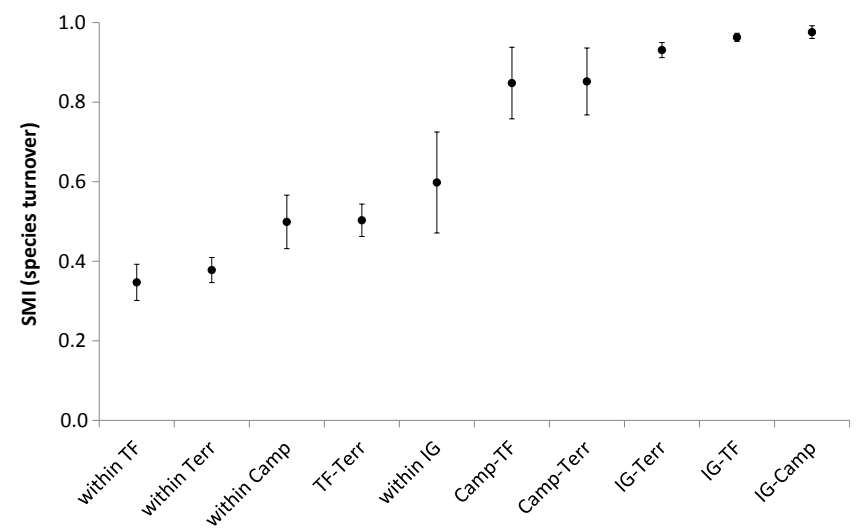

Figure 4. Species turnover of the four inventoried forest types at the ATTO site. Turnover is expressed as Shmida and Wilson's (1985) index: $\mathrm{SMI}=(g+l) /(a+b)$; where $g$ and $l$ are gained and lost species from site 1 to site $2 ; a$ and $b$ are the numbers of species in site 1 and site $2 . \mathrm{TF}=$ terra firme forest upon plateau, Terr $=$ terra firme forest upon fluvial terrace, Camp = campinarana, and IG = seasonally flooded black-water forest (igapó).

totrophic communities of cyanobacteria, algae, lichens, and bryophytes in varying proportions, which may also host fungi, other bacteria, and archaea (Elbert et al., 2012). A common feature of all these organism groups is their poikilohydric nature, meaning that their moisture status follows the external water conditions. Thus the organisms dry out under dry conditions, being reactivated again upon rain, fog, or condensation.

Since September 2014, we have been conducting longterm measurements to monitor the activity patterns of cryptogamic covers at four different canopy heights at $10 \mathrm{~min}$ intervals, during which we measure temperature and water content within and light intensities directly on top of biocrusts growing on the trunk of a tree. First analyses of the microclimate data indicate that microorganisms in the upper stem region of the trees are activated by fog or dewfall in the early morning hours, often coinciding with an aerosol particle burst in the accumulation mode. Particle measurements conducted on isolated organisms also show a significant release of accumulation mode particles by wet and thus active organisms, e.g., fungi belonging to the phylum of Basidiomycota. Thus, we have the first clear indications that cryptogamic covers may play a key role in the enigmatic bioaerosol occurrence frequently observed at the ATTO site.

\subsubsection{Upper canopy leaf phenology}

A single annual leaf flush was seen in most upper canopy crowns, concentrated in the five driest months (July to November) (Fig. 5). Consequently, mature leaves with high light-use efficiency will be most abundant in the late dry season and early wet season. Massive leaf renewal in the dry sea- 

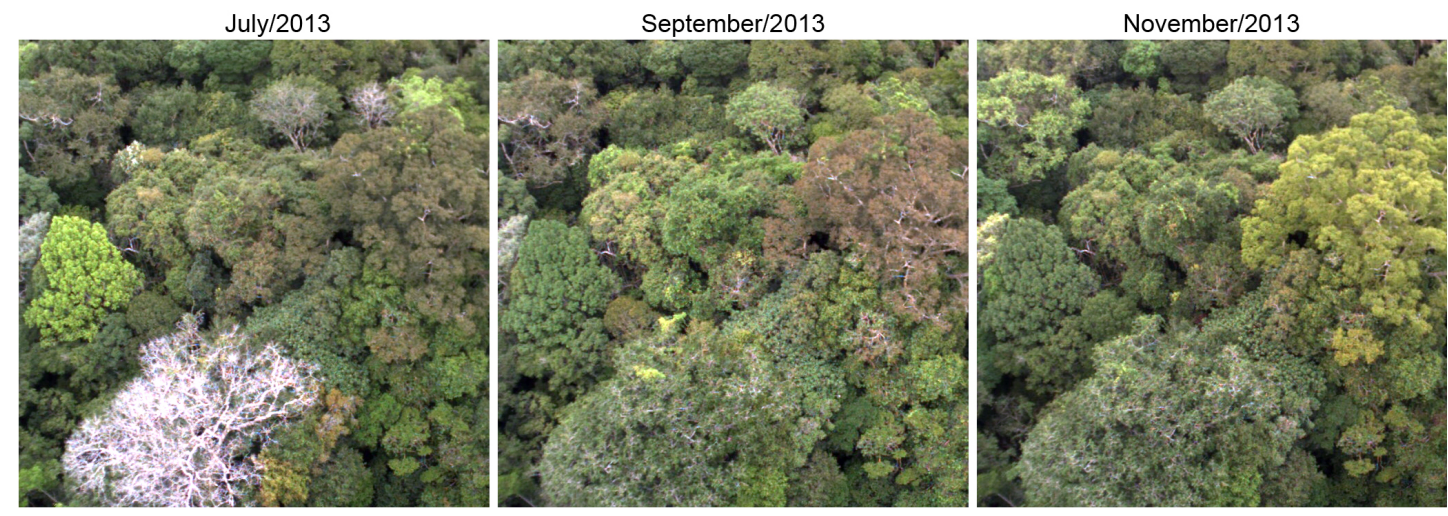

Figure 5. Portion of camera view, contrast enhanced. Spatial and temporal crown color differences are most evident in the five driest months (July to November) when crowns present rapidly changing phenostages associated with leaf flush, briefly deciduous pre-flush abscission, young red unexpanded leaves, or bright green recently expanded leaves.

son on the ATTO plateau may drive seasonality of photosynthesis and of photosynthetic capacity at the landscape scale, as has been indicated at the Santarém and the LBA km34 eddy flux tower sites in the central Amazon (Doughty and Goulden, 2008; Restrepo-Coupe et al., 2013).

The lack of a near-infrared (NIR) band in our camera precludes the direct measurement of leaf amount, but the RGB band space discriminates crown phenostages whose relative NIR reflectances are known. Gradual leaf attrition over the wet season, when leaf replacement is low, followed by early dry season pre-flush abscission and the emergence of young unexpanded leaves, should all lead to a lower landscape-scale amount of fully expanded leaves around June or July. Completion of leaf flushing in most crowns by the late dry season should lead to a maximum amount of fully expanded leaves in the late dry and early wet seasons. This is consistent with the seasonal pattern of central Amazon leaf amount detected with the Enhanced Vegetation Index from the MODIS orbital sensor (e.g., Huete et al., 2006) and counters recent critiques of detectability of seasonal change in Amazon forest greenness (Galvão et al., 2011; Morton et al., 2014).

\subsubsection{Soil characterization}

Soils in the terra firme plateaus were classified as ferralsols, which are ancient, highly weathered, and well-drained soils frequently occurring in geologically ancient surfaces (Chauvel et al., 1987). Soils at the fluvial terraces were classified as alisol, which show a more recent pedogenetic status when compared to the highly weathered Ferralsols at the plateaus. Due to their lower weathering degree, soils from the terrace have a greater capacity to supply nutrients, with higher total $\mathrm{P}$ and higher total reserve bases. The soil carbon stocks varied from $129 \pm 7 \mathrm{Mg} \mathrm{ha}^{-1}$ on the terrace to $164 \pm 7 \mathrm{Mg} \mathrm{ha}^{-1}$ on the plateau, indicating that belowground $\mathrm{C}$ stocks are of similar magnitude to the aboveground carbon stocks in the forest (Table 4). Differences of belowground carbon stocks be-

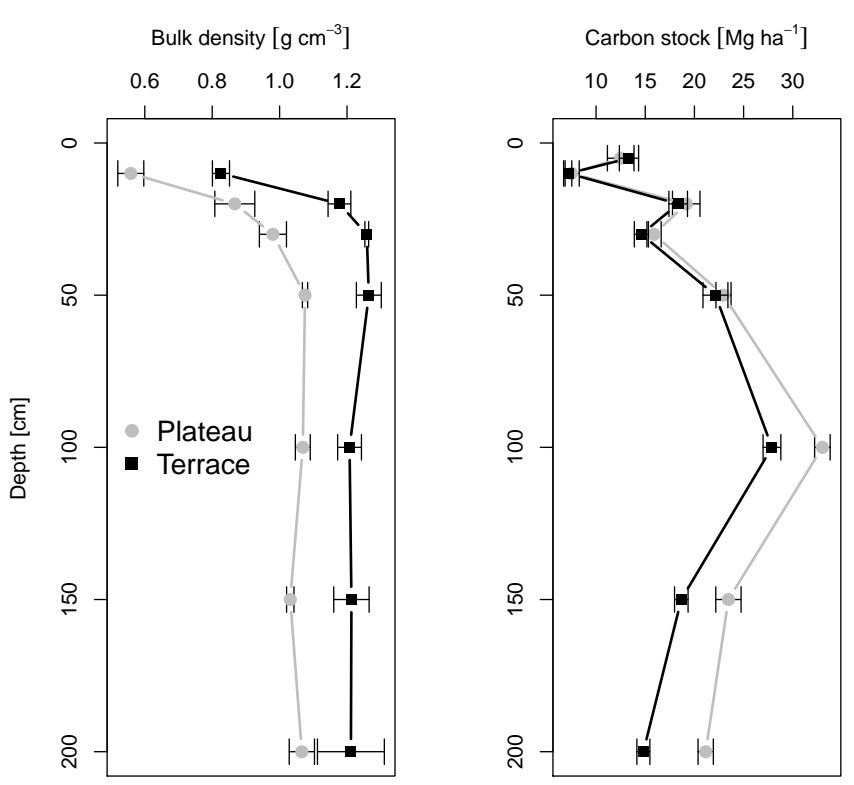

Figure 6. Plot of bulk density $\left(\mathrm{g} \mathrm{cm}^{-3}\right)$ and carbon stocks $\left(\mathrm{Mg} \mathrm{ha}^{-1}\right)$ against soil depth. Pronounced differences of belowground carbon stocks between terrace and plateau occur in deeper layers $($ Depth $>100 \mathrm{~cm})$.

tween terrace and plateau are mainly associated with a higher clay content of the plateau soils.

Soil physical constraints are more frequent on the terraces, which show higher bulk density values (Fig. 6) and therefore increased soil compaction. Some of these terrace soils also show signs of anoxia (mottling) in deeper layers. Such impeditive conditions may have an influence on forest structure (Quesada et al., 2012; Emilio et al., 2014) and dynamics (Cintra et al., 2013), thereby possibly restricting tree height or even tree individual biomass storage (Martins et al., 2015). 


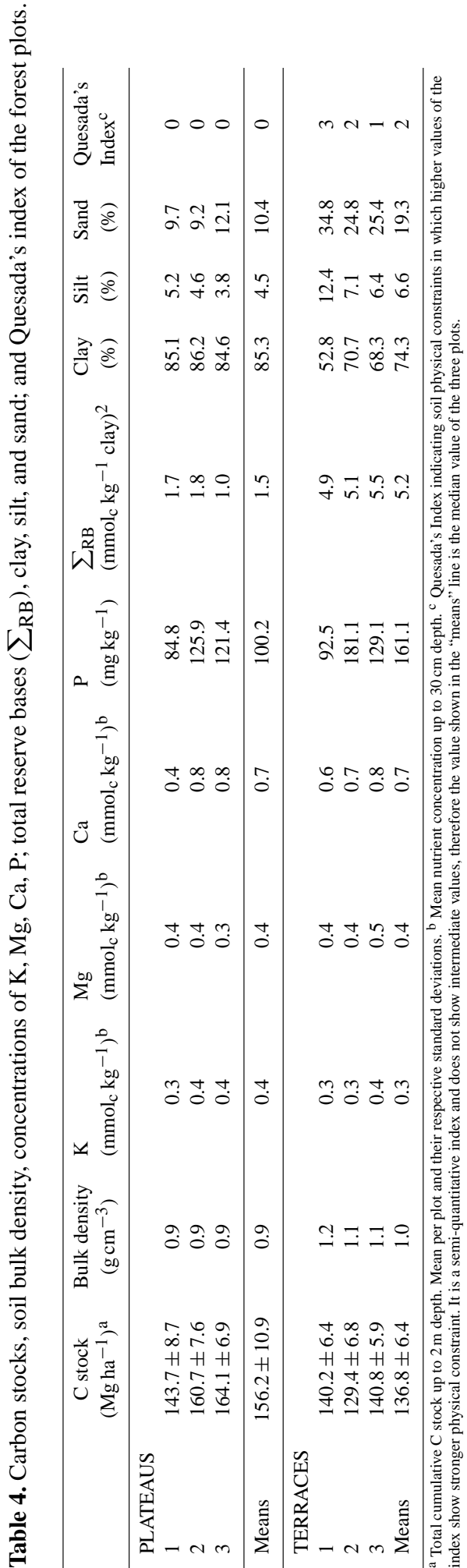

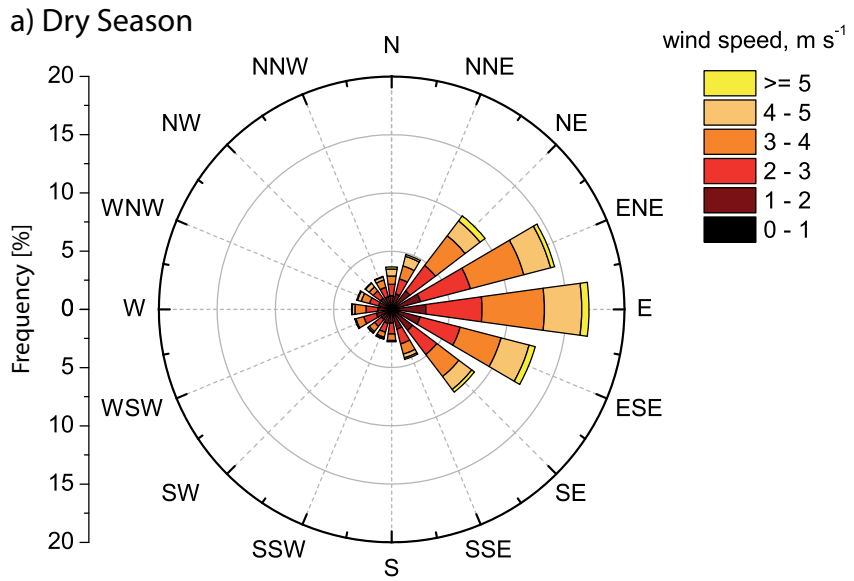

b) Wet Season

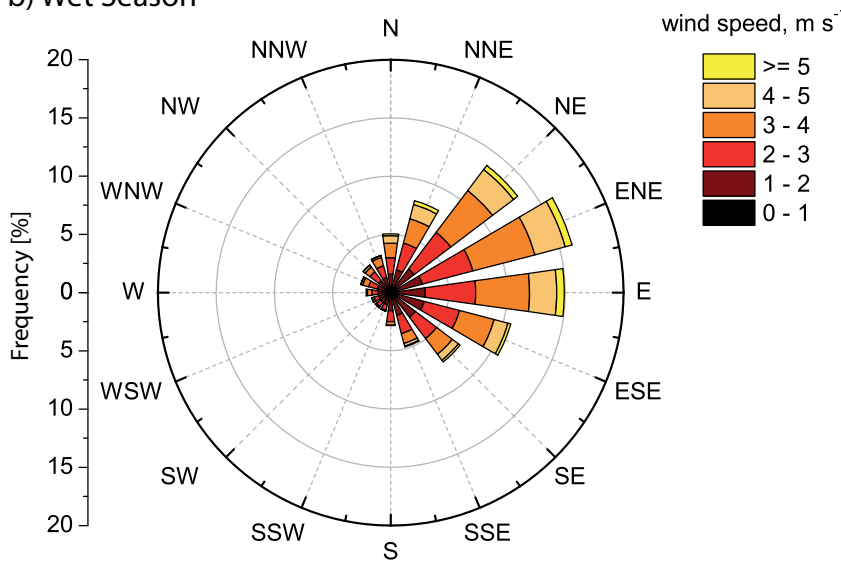

Figure 7. Wind roses for (a) dry season (15 June-30 November) and (b) wet season (1 December-14 June) based on half-hourly averages of wind speed and direction measured at $81 \mathrm{~m}$ a.g.l. for the period from 18 October 2012 to 23 July 2014.

\subsection{Meteorological conditions and fluxes}

An overview of the climatic characteristics of the Amazon Basin has been presented by Nobre et al. (2009). The meteorological setting of the ATTO site has been described in Sect. 2.1, and the basic meteorological measurements (wind, temperature, humidity, radiation, etc.) at the site reflect the regional climate and micrometeorological conditions influenced by local topography and vegetation. In the following sections we present overviews of meteorological observations that characterize the site and initial results of micrometeorological investigations at ATTO. Since the quantification of the exchange of trace gases and aerosols between the rain forest and the atmosphere is a key objective of the ATTO program, the study of the structure and behavior of the atmospheric boundary layer is a central focus here. 


\subsubsection{Wind speed and direction above the forest canopy}

The wind roses for the dry season (15 June-30 November) and the wet season (1 December-14 June) (based on half-hourly averages of wind speed and direction measured at $81 \mathrm{~m}$ a.g.l. for the period from 18 October 2012 to 23 July 2014; Fig. 7) indicate the dominance of easterly trade wind flows at the measurement site. A slight shift of the major wind direction towards ENE is observed during the wet season, whereas flows are mainly from the east during the dry season. This seasonality can be explained by the interannual north-south migration of the Intertropical Convergence Zone (ITCZ), which also governs the amount of rainfall (see Poveda et al., 2006). The wind roses show a slight diurnal variation with small contributions from the north, west and south during nighttime, when the nocturnal boundary layer is decoupled, in both seasons. In contrast, during daytime the wind blows nearly all the time from the east (dry season) and northeast (wet season), with much higher wind speeds. Maximal wind speeds observed at the site are about $9 \mathrm{~m} \mathrm{~s}^{-1}$. The influence of river and/or lake breeze systems caused by the Rio Uatumã ( $\sim 12 \mathrm{~km}$ distance) is of minor importance and an effect from Lake Balbina $(\sim 50 \mathrm{~km}$ distance $)$ or other thermally driven mesoscale circulations could not be detected. This shows that the sampled air masses mainly have their origin within the fetch of the green ocean extending several hundred kilometers to the east of the site.

\subsubsection{Temperature, precipitation, and radiation}

As is typical for the central Amazon Basin, the mean air temperature does not show strong variations at seasonal timescales due to the high incident solar radiation throughout the year (Nobre et al., 2009). Climatologically in the Manaus region, the highest temperatures are observed during the dry season, with a September monthly mean of $27.5^{\circ} \mathrm{C}$, whereas the lowest temperatures prevail in the rainy season, with a monthly mean of $25.9^{\circ} \mathrm{C}$ in March.

Vertical profiles of temperature show clear diurnal cycles driven by radiative heating of the canopy during the day and cooling of the canopy and the forest floor during the night (Fig. 8). Therefore, both temperature minima and maxima are observed at the canopy top during both seasons. A second temperature minimum during night can be observed at the forest floor during the dry and wet season. During the day warm air from above the canopy is transported into the forest. Minimum temperatures at the canopy top are around $22.5^{\circ} \mathrm{C}$ during both seasons, whereas daytime maxima are around $28^{\circ} \mathrm{C}$ during the wet season and may reach slightly above $30^{\circ} \mathrm{C}$ in the dry season.

Rainfall in the Manaus region shows a pronounced seasonal variation, reaching the highest amounts in March (335.4 mm) and the lowest amounts in August (47.3 mm), for an average annual total of $2307.4 \mathrm{~mm}$ at the INMET station in Manaus for the standard reference period 1961 to 1990
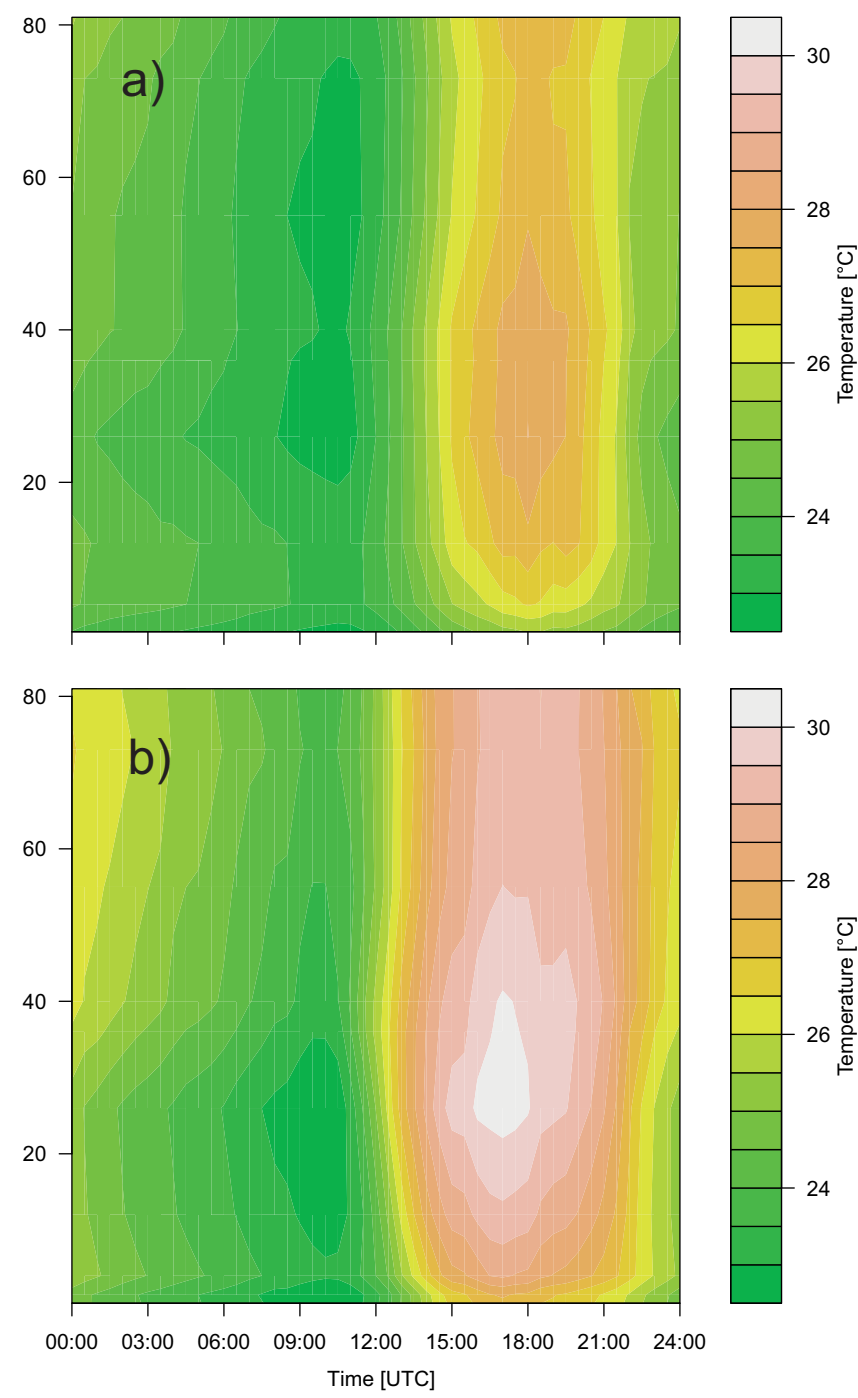

Figure 8. Diurnal profiles of temperature for (a) wet season (March 2014) and (b) dry season (September 2013). Contour plots interpolated from measurements at $0.4,1.5,4,12,26,36,40,55,73$, and $81 \mathrm{~m}$.

(www.inmet.gov.br). Precipitation at the ATTO site follows this seasonal cycle with maximum values around March and minimum values in August and September (Fig. 9). The interannual variability appears to be high at all times of the year, but especially in the transition to the rainy season, a fact that has also been evident in the data from the years 1981 to 2010 at the Manaus station (Fernandes, 2014). Therefore, the large deviations from the regional mean during October to January and also in April, when the ATTO values from the years 2012-2014 differ substantially from the long term mean of Manaus, are likely the result of interannual variability.

Overall, however, the precipitation patterns at the ATTO site are in good agreement with its position in the central Amazon, where the months between February and May are 


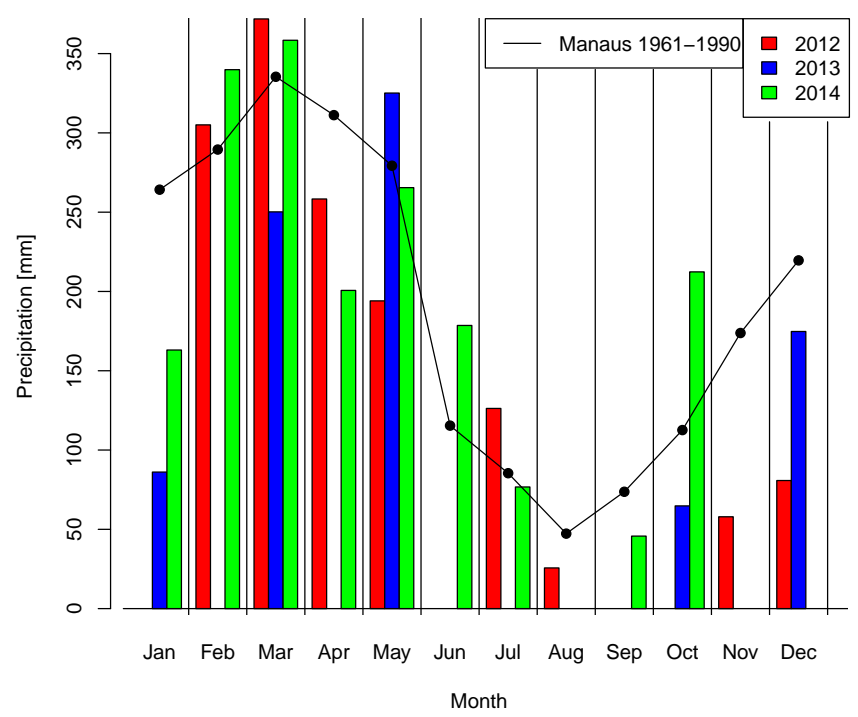

Figure 9. Monthly sums of precipitation at the ATTO site for the years 2012 to 2014. For comparison the data from the Manaus INMET-station (www.inmet.gov.br) for the standard reference period (1961-1990) are shown.

the wettest ones. In this period, the ITCZ reaches its southernmost position and acts as a strong driver of convective cloud formation at the equatorial trough. Due to the interaction of trade winds and sea breeze at the northeast Brazilian coastline, the ITCZ also takes part in the formation of instability lines that enter the continent and regenerate during their westerly propagation (Greco et al., 1990). In this way, they account for substantial amounts of precipitation. After this period, the ITCZ shifts to the Northern Hemisphere, accompanying the movement of the zenith position of the sun. This leads to less precipitation at the ATTO site, with the driest months being between July and September, when precipitation is formed mostly by local convection. In the following months, the amount of precipitation increases again, which coincides with the formation of a cloud band in a NW/SE direction that is linked to convection in the Amazon due to the South Atlantic Convergence Zone (SACZ) (Figueroa and Nobre, 1990; Rocha et al., 2009; Santos and Buchmann, 2010).

The radiation balance at ATTO as well as the albedo presents a clear difference between the wet and the dry seasons. Some episodes when the incident solar radiation exceeds the top-of-atmosphere radiation have been observed for the ATTO data. They were more frequent during the wet season, probably due to the effect of cloud gap modulation that intensifies the radiation received at the surface by reflection and scattering.

\subsubsection{Roughness sublayer measurements}

The measurement of turbulent fluxes over tall forest canopies very often implies that these measurements are made in the so-called roughness sublayer (RSL). It is usually assumed that the RSL extends to 2 or 3 times the height of the roughness obstacles, $h_{0}$ (Williams et al., 2007). The roughness sublayer is considered to be a part of the surface sublayer of the atmospheric boundary layer, but it is too close to the roughness elements for Monin-Obukhov similarity theory (MOST) to hold. Some progress in the parameterization of the RSL has been made in terms of applying correction factors to the traditional similarity functions of the surface layer (see for example, Mölder et al., 1999, and references therein). However, the universality of such procedures remains unknown.

In this section, we briefly show strong evidence that a simple adjustment factor that depends on the factor $z / z_{*}$ (where $z$ is the height of measurement and $z_{*}$ is the height of the RSL), as employed by Mölder et al. (1999), is not able to collapse the "variance method" dimensionless variables

$\phi_{w}(\zeta) \equiv \frac{\sigma_{w}}{u_{*}}$

and

$\phi_{a}(\zeta) \equiv \frac{\sigma_{\mathrm{a}}}{a_{*}}$,

where $\sigma_{w}$ is the standard deviation of the vertical velocity, $u_{*}$ is the friction velocity, $\sigma_{\mathrm{a}}$ is the standard deviation of a scalar, and $a_{*}$ is its turbulent scale (see Eqs. 3 and 4 below). In Eqs. (1) and (2), $\zeta$ is the Obukhov length with a zero-plane displacement height calculated as $d_{0}=2 h_{0} / 3, h_{0}=40 \mathrm{~m}$.

We analyzed measurements collected during April 2012 at the $39.5 \mathrm{~m}$ level, which is right at the height of the tree tops, in terms of the turbulent scales

$\overline{u^{\prime} w^{\prime}} \equiv-u_{*}^{2}$

and

$\left|\overline{w^{\prime} a^{\prime}}\right| \equiv u_{*} a_{*}$.

We only analyzed measurements under unstable conditions, and considered only cases where the sensible and latent heat fluxes are both positive (directed upwards) and the $\mathrm{CO}_{2}$ flux is negative (directed downwards). In Eq. (4), the absolute value is used so that $a_{*}$ is always positive. The scalar $a$ represents virtual temperature $\theta_{v}$ (measured by the sonic anemometer), specific humidity $q$, and $\mathrm{CO}_{2}$ mixing ratio $c$.

The analysis is made in terms of the dimensionless standard deviation functions, $\phi_{w}(\zeta)$ and $\phi_{a}(\zeta)$, defined above. The overall results for vertical velocity, virtual temperature, and $\mathrm{CO}_{2}$ concentration are shown in Fig. 10. The solid lines in the figure give representative functions found in the literature for the surface layer well above the roughness sublayer (see, for example, Dias et al., 2009).

Similar figures were drawn for specific times of day, namely 07:00-09:00, 09:00-11:00, 11:00-13:00, 13:0015:00 and 15:00-17:00 LT, in an attempt to identify periods 

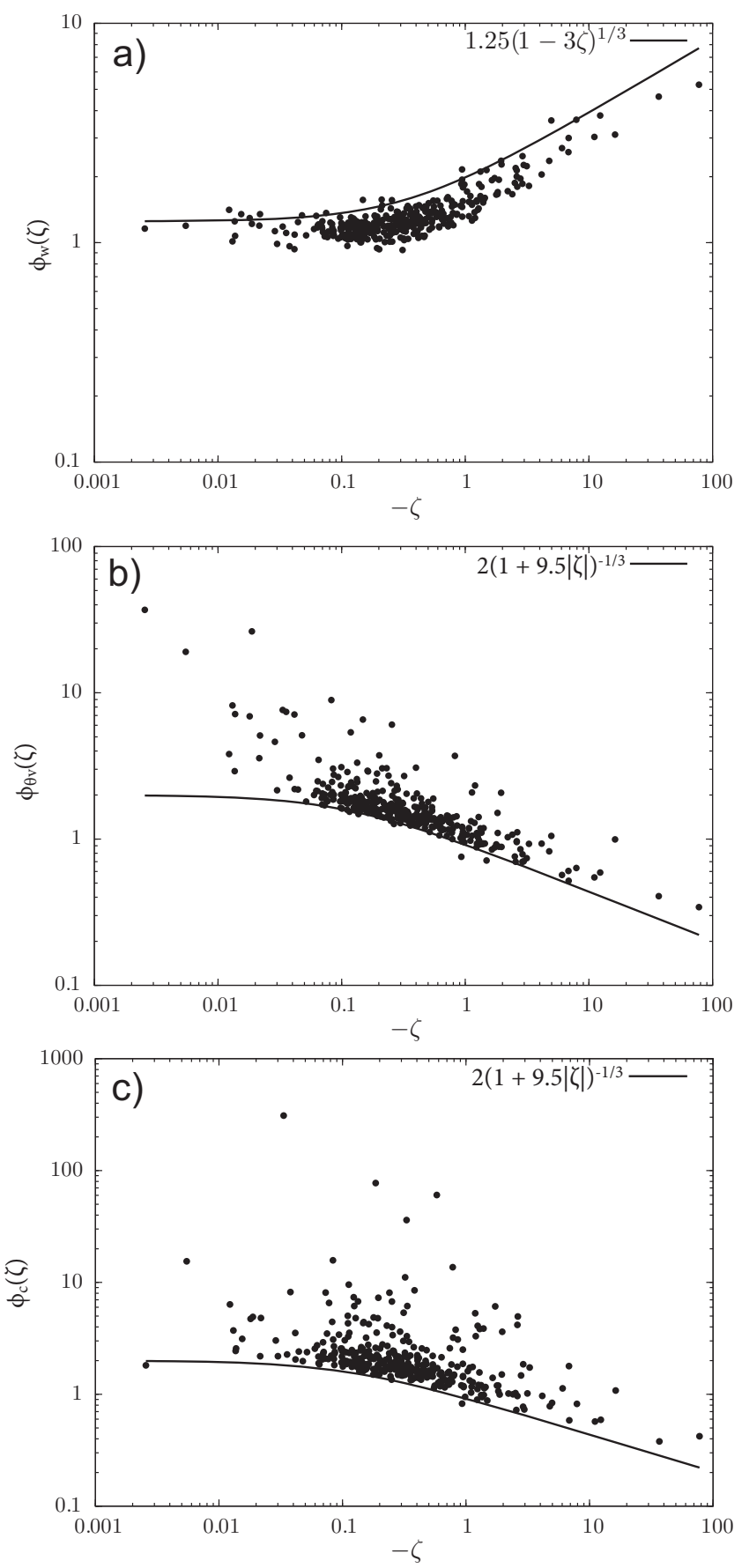

Figure 10. The dimensionless standard deviation function for (a) vertical velocity $\Phi_{w}(\zeta)$, (b) virtual temperature $\phi_{\theta_{\mathrm{v}}}(\zeta)$, and (c) $\mathrm{CO}_{2}$ concentration $\phi_{\mathrm{c}}(\zeta)$ for the ATTO site from measurements at $39.5 \mathrm{~m}$.

of the day when better agreement (or even a systematic departure, for example by a constant vertical shift) with the surface-layer curves could be identified. Temperature and humidity are somewhat better behaved in this case, but not $\mathrm{CO}_{2}$, for reasons that are not clear. Because no conclusive explanation can be found, we do not show these analyses here.
Finally, we tried to apply some concepts recently developed by Cancelli et al. (2012) to relate the applicability of MOST to the strength of the surface forcing. Cancelli et al. (2012) found that the applicability of MOST can be well predicted by their "surface flux number",

$\mathrm{Sf}_{a}=\frac{\left|\overline{w^{\prime} a^{\prime}}\right|\left(z-d_{0}\right)}{v_{a} \Delta \bar{a}}$

where $v_{a}$ is the molecular diffusivity of scalar $a$ in the air, and $\Delta \bar{a}$ is the gradient of its mean concentration between the surface and the measurement height.

In our case, there is no easy way to obtain $\Delta \bar{a}$, so instead we use

$\mathrm{Sf}_{a}=\frac{\left|\overline{w^{\prime} a^{\prime}}\right|\left(z-d_{0}\right)}{v_{a} \sigma_{a}}$

As a measure of the applicability of MOST, we use the absolute value of the difference between the observed value of $\phi_{a}(\zeta)$ and its reference value for the surface layer, as used by Dias et al. (2009), and shown by the solid lines in Fig. 10. The results are shown in Fig. 11. A relatively stronger forcing is clearly related to a behavior that is closer to that expected by MOST for both temperature and humidity, but not for $\mathrm{CO}_{2}$. This suggests that $\mathrm{CO}_{2}$ presents even greater challenges for our proper understanding of its turbulent transport in the roughness sublayer over the Amazon Forest.

Ultimately, the lack of conformity to MOST found in these investigations (a fact that has been generally observed in the roughness sublayer over other forests) implies that scalar fluxes over the Amazon forest derived from standard models, which use MOST, are bound to have larger errors here than over lower vegetation, such as grass or crops. We can expect this to affect any chemical species, and therefore the implications for ATTO are quite wide-ranging. On the other hand, once the $325 \mathrm{~m}$ tall tower is instrumented and operational, a much better picture will emerge on the extent of the roughness sublayer and the best strategies to model scalar fluxes over the forest.

\subsubsection{Nighttime vertical coupling mechanisms between the canopy and the atmosphere}

During daytime, intense turbulent activity provides an effective and vigorous coupling between the canopy layer and the atmosphere above it. As a consequence, vertical profiles of chemical species do not commonly show abrupt variations induced by episodes of intense vertical flux divergence. Accordingly, scalar fluxes between the canopy and the atmosphere are relatively well-behaved during daytime so that their inference from the vertical profiles of mean quantities can be achieved using established similarity relationships. At night, on the other hand, the reduced turbulence intensity often causes the canopy to decouple from the air above it (Fitzjarrald and Moore, 1990; Betts et al., 2009; van Gorsel et al., 

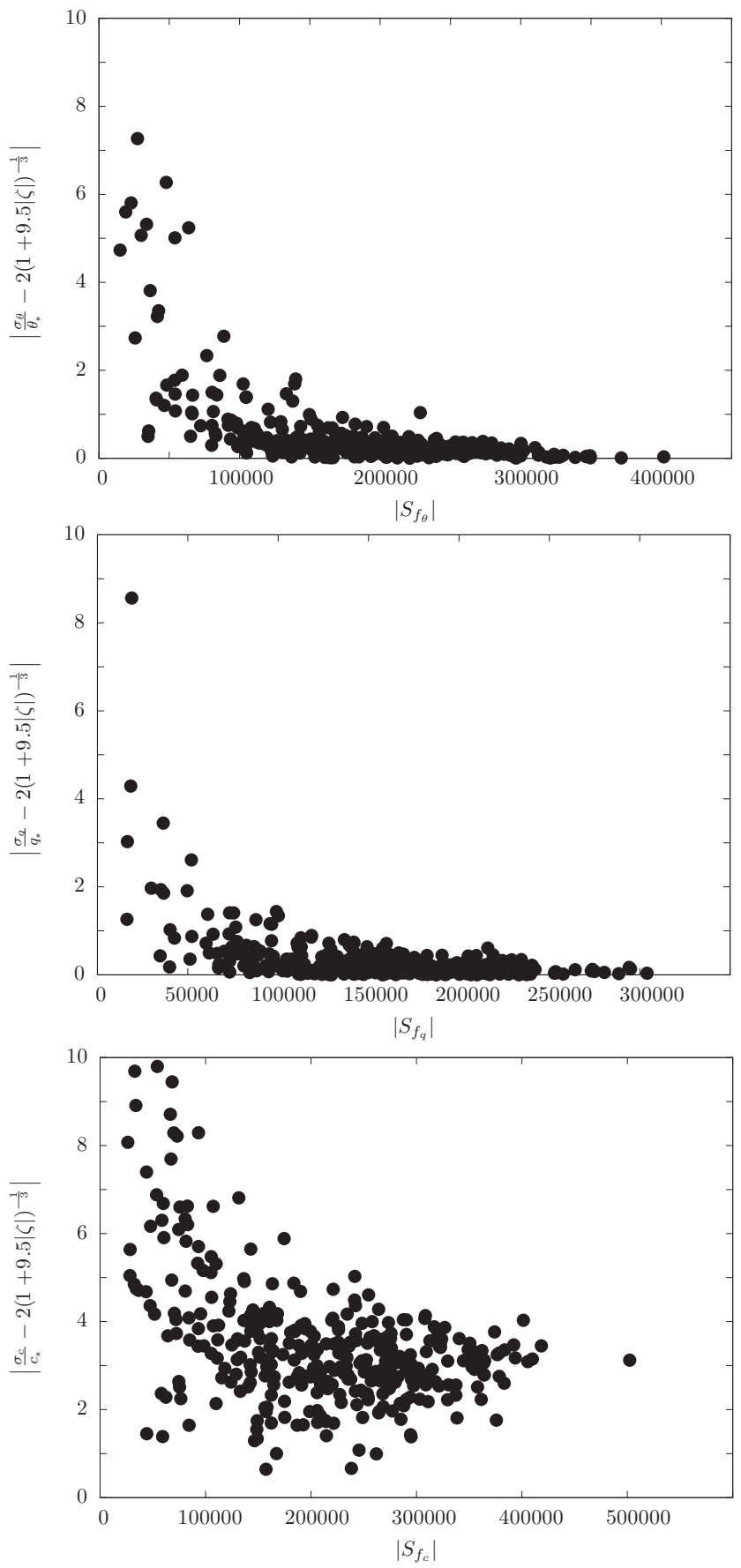

Figure 11. From top to bottom, the departure of the dimensionless standard deviation function, $\phi_{a}(\zeta)$, from its surface-layer behavior for $\theta_{\mathrm{v}}, q$, and $c$, respectively.

2011; Oliveira et al., 2013). In these circumstances, vertical fluxes converge to shallow layers in which the scalars may accumulate intensely over short time periods. In the absence of convective turbulence, which is the main factor for daytime transport, other physical processes become relevant in the stable boundary layer (SBL), such as drainage flow (Sun et al., 2004; Xu et al., 2015), vertical divergence of radiation (Drüe and Heinemann, 2007; Hoch et al., 2007), global intermittency (Mahrt, 1999), atmosphere-surface interactions (Steeneveld et al., 2008), and gravity waves (Nappo, 1991; Brown and Wood, 2003; Zeri and Sa, 2011).

In this section, we discuss the role of intermittent turbulent events of variable intensity and periodicity, which provide episodic connection between the canopy and the atmosphere and can induce oscillatory behavior in the nocturnal boundary layer (Van de Wiel et al., 2002). They are characterized by brief episodes of turbulence with intervening periods of relatively weak or unmeasurably small fluctuations (Mahrt, 1999). In some cases, such events may comprise almost the entirety of the scalar fluxes during a given night. The effects of gravity waves are discussed in the next section.

Nocturnal decoupling occurs rather frequently at the ATTO site, usually punctuated by intermittent mixing episodes, in agreement with previous studies made over the Amazon forest (Fitzjarrald and Moore, 1990; Ramos et al., 2004). During a typical decoupled, intermittent night, the horizontal wind components are weak in magnitude and highly variable temporally, often switching signs in an unpredictable manner (Fig. 12). As a consequence, it is common that winds from all possible directions occur in such a night. The example from the ATTO site indicates that despite such a large variability, both horizontal wind components are generally in phase above the canopy, from the $42 \mathrm{~m}$ to the $80 \mathrm{~m}$ level. Vertical velocity at the $42 \mathrm{~m}$ level is highly intermittent, with various turbulent events of variable intensity scattered throughout the night. While being less turbulent, the $80 \mathrm{~m}$ level is also less intermittent, presenting a more continuous behavior. The relevance of the intermittent events to characterize canopy-atmosphere exchange becomes clear when one looks at the fluxes of the scalars, such as $\mathrm{CO}_{2}$ (Fig. 12, bottom panel). During this night, the majority of the exchange just above the canopy $(42 \mathrm{~m}$ ) happened during two specific events, at around 02:00 and 03:30 LT.

A proper understanding of nocturnal vertical profiles and fluxes of scalars above any forest canopy depends, therefore, on explaining the atmospheric controls on intermittent turbulence at canopy level. In the Amazon forest, this necessity is enhanced, as there are indications that turbulence is more intermittent here, possibly as a consequence of flow instabilities generated by the wind profile at canopy level (Ramos et al., 2004). This is corroborated by early observations at the ATTO site, which indicated decoupling and intermittency occurring during more than half of the nights.

It is not yet clear what triggers these intermittent events. In general, previous studies indicate that the more intense events are generated above the nocturnal boundary layer, propagating from above (Sun et al., 2002, 2004). On the other hand, less intense events that occur in the decoupled state have been characterized as natural modes of turbulence variability generated near the surface (Costa et al., 2011). At ATTO, the occurrence of the highest intensity at $42 \mathrm{~m}$ indi- 


\section{April 2012}
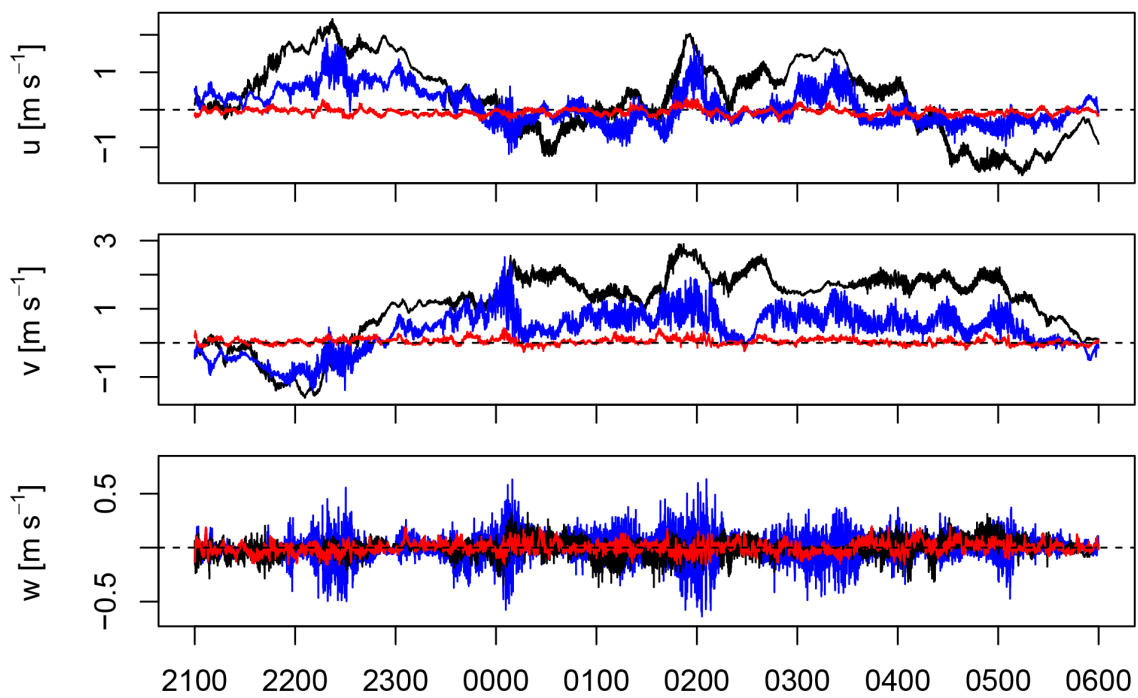

Local time (LST)

$\mathrm{CO}_{2}$ fluxes

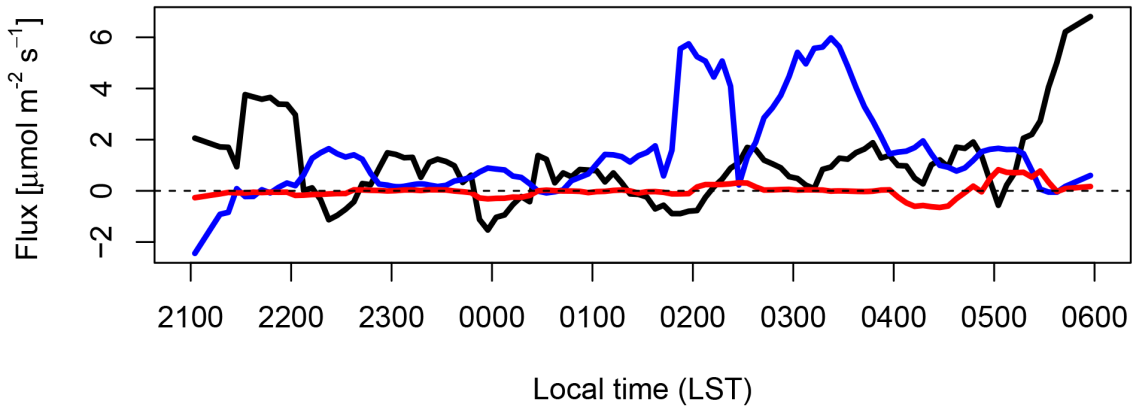

Figure 12. Upper panels: temporal evolution of the three wind components for the night of 27 April 2012 at each of the ATTO observation levels. The lower panel shows the corresponding eddy covariance $\mathrm{CO}_{2}$ fluxes.

cates that intermittency is generated at the canopy level. Is it possible, then, to identify the mechanisms that trigger their occurrence?

Some evidence can be gathered from a spectral decomposition of the turbulent flow at the different observation levels. Although the horizontal velocities in Fig. 12 are highly in phase between 42 and $80 \mathrm{~m}$, it is clear from this plot that the wind speed is generally higher at $80 \mathrm{~m}$, while there are more turbulent fluctuations at $42 \mathrm{~m}$. When these signals are decomposed in terms of their time scale to provide a turbulent kinetic energy (TKE) spectrum (Acevedo et al., 2014), the more intense turbulence at $42 \mathrm{~m}$ appears as a peak at time scales just greater than $10 \mathrm{~s}$ (Fig. 13). At longer time scales, on the other hand, there is a sharp energy increase at $80 \mathrm{~m}$, making this the most energetic level for scales larger than
$100 \mathrm{~s}$. This low-frequency flow at $80 \mathrm{~m}$ is characterized by the large wind direction variability apparent in Fig. 12. These are non-turbulent flow patterns that have been recently classified as "submeso" (Mahrt, 2009). Submeso flow has low intensity, with large and apparently unpredictable temporal variability. It is usually present in the atmospheric boundary layer, becoming dominant in conditions when the turbulent scales are highly reduced, such as in the decoupled nocturnal boundary layer.

Evidence from ATTO indicates that it is possible to associate the intermittent events at canopy level with the mean wind shear above the canopy. In Fig. 14, it is evident that the two intense events at $42 \mathrm{~m}$, around 21:30 and 02:00 LT, are triggered by episodes of intense wind shear between 42 and $80 \mathrm{~m}$. In conditions where the $80 \mathrm{~m}$ wind field is dominated 


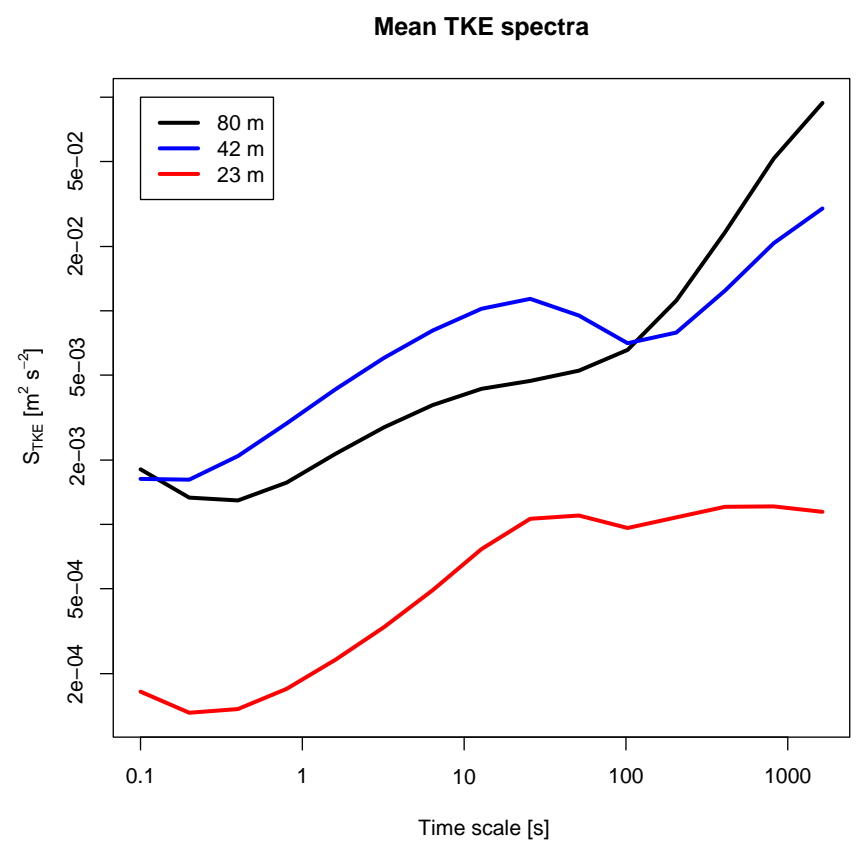

Figure 13. Mean multi-resolution turbulent kinetic energy (TKE) spectra at the three observation levels.

by submeso processes, such as in the examples in Figs. 12 and 14 , it is this portion of the flow that determines the occurrence of intense wind shear episodes. Furthermore, it is clear from these examples that flow patterns at levels as high as $80 \mathrm{~m}$ exert important controls on the exchange of scalars at canopy level. Questions such as the height variation of submeso flow have yet to be answered. Tall tower observations, such as those planned to be carried on at ATTO, are very important to provide the data for this kind of analysis and to deepen the understanding of exchange processes between the canopy and the atmosphere during the calm nights that are common in the Amazon forest.

\subsubsection{Orographically induced gravity waves in the stable boundary layer above the Amazon forest}

Gravity waves (GWs) may occur in the forest boundary layer during relatively calm nights. Depending on the magnitude of the turbulent drag, they influence the exchange processes that take place in the stable boundary layer of the atmosphere (Steeneveld et al., 2009). Internal gravity waves can be generated by several forcing mechanisms, including sudden changes of surface roughness, topography, convection, terrain undulations, etc. (Nappo, 2002). These features can reallocate energy and momentum and are significant in determining atmospheric vertical structure and the coupling of mesoscale to microscale phenomena (Steeneveld et al., 2008, 2009). Chimonas and Nappo (1989) showed that under typical conditions of the planetary boundary layer, GWs can in-
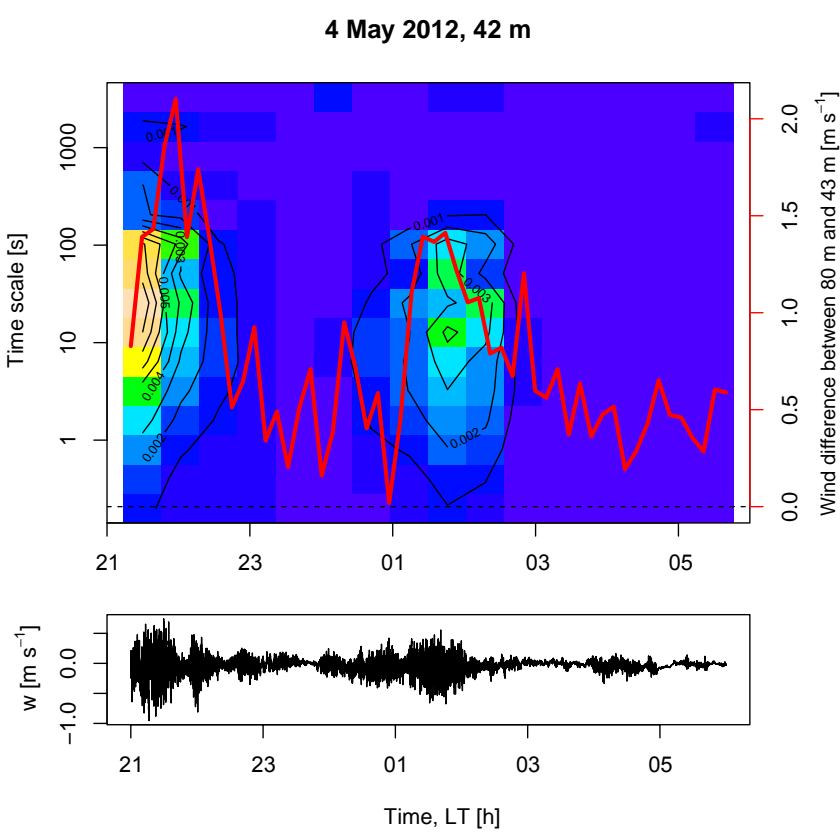

Figure 14. Upper panel: multi-resolution $42 \mathrm{~m}$ vertical velocity spectra for the night of 4 May 2012 (colors and contours), and mean wind difference between the 80 and $42 \mathrm{~m}$ levels (red line, scale at the right side). Lower panel: temporal evolution of vertical velocity at the $42 \mathrm{~m}$ level for the same night.

teract with the mean flow resulting in turbulence at unexpected altitudes.

Fast response data of vertical wind velocity, $w$, and temperature, $T$, measured in the nocturnal boundary layer (NBL) at the ATTO site were analyzed to detect the occurrence of GWs, and to identify under which situations they would be generated by terrain undulations, using the methodology proposed by Steeneveld et al. (2009). One of the goals of this study is to investigate the structure of turbulence associated with the conditions under which GWs would be forced by ground undulations (class I) in contrast to those under which GWs would be expected to be forced by other mechanisms (class II). To reach this goal, the methodology of Steeneveld et al. (2009), based on Chimonas and Nappo (1989), has been used to define whether a specific measurement belongs to class I or class II, based on the condition:

$L_{S}^{2}=N^{2} / U^{2}-U^{\prime \prime} / U>k^{2}$,

where $k$ is the wave number associated with the ground undulations, $L$ is the Scorer parameter, $U$ is the mean wind speed, and $U^{\prime \prime}$ is second derivative of the wind speed in relation to the height, $z$, computed as

$U^{\prime \prime}=\partial^{2} U / \partial z^{2}$.

$N$ is the Brunt-Väisälä frequency, defined as follows:

$N=\sqrt{g \Delta_{z} \theta / \theta}$, 
where $g$ is the gravity acceleration and $\Delta_{z} \theta / \theta$ is the dimensionless gradient of the virtual potential temperature.

Two kinds of data were used: topographic and meteorological. A digital topographic image of the region surrounding the experimental site (Fig. 15a) was used to analyze the features of surface undulations and their scales of occurrence, as well as the space-scale analysis by complex Morlet wavelet transforms (Farge, 1992; Thomas and Foken, 2005). Local geomorphometric variables were derived from the Shuttle Radar Topographic Mission (SRTM) data (Valeriano, 2008). These data were refined to 1 arcsecond $(\sim 30 \mathrm{~m})$ from the original spatial resolution of 3 arcsecond $(\sim 90 \mathrm{~m})$ and are available on the site www.dsr.inpe.br/topodata/dados.php.

Time series of the vertical wind velocity and of the fast response temperature data provided by a sonic anemometer and thermometer were used to detect GW events at a height of $81 \mathrm{~m}$ above the ground. The sampling rate of the measured turbulence data was $10 \mathrm{~Hz}$. Wind speed and temperature vertical profiles were provided by cup anemometer and thermometer measurements, respectively, with a sampling rate of $60 \mathrm{~Hz}$ for both, making it possible to compute the BruntVäisälä frequency, the vertical gradients of wind velocity, and the Scorer parameter for GW classification (Steeneveld et al., 2009). Data from five nights were analyzed, consisting of 120 files of $30 \mathrm{~min}$ each between Julian days 42 and 46 of the year 2012, representing the first observational data available from the ATTO site. The analyses were carried out for the time between 18:00 and 06:00 LT for each night with available data (Fig. 15).

The black points on the arrows in Fig. 15b represent the GW events that were induced by the topography of the terrain, whereas the gray points represent GW events that were not generated by terrain orography. The results show that a considerable fraction of the analyzed situations represent GWs induced by terrain undulations. This finding is very important for the environmental studies that are being carried out at the ATTO site, as it indicates that some mixing characteristics of the nocturnal boundary layer depend on the characteristics of terrain undulations and therefore change with the wind direction.

\subsubsection{Coherent structure time scale above the ATTO site}

Coherent structures (CSs) are a ubiquitous phenomenon in the turbulent atmospheric flow, particularly over forests (Hussain, 1986). They occur in the roughness sub-layer immediately above the plant canopy, where the CSs of the scalar signals show a "ramp-like" shape associated with the twophase movement of sweep and ejection of the flow interacting with the canopy. Coherent structures play an important role in biosphere-atmosphere exchange processes (Gao and Li, 1993; Serafimovich et al., 2011). There is some consensus that CSs are associated with turbulent flows, although there is no full agreement on the percentage of the turbulent fluxes
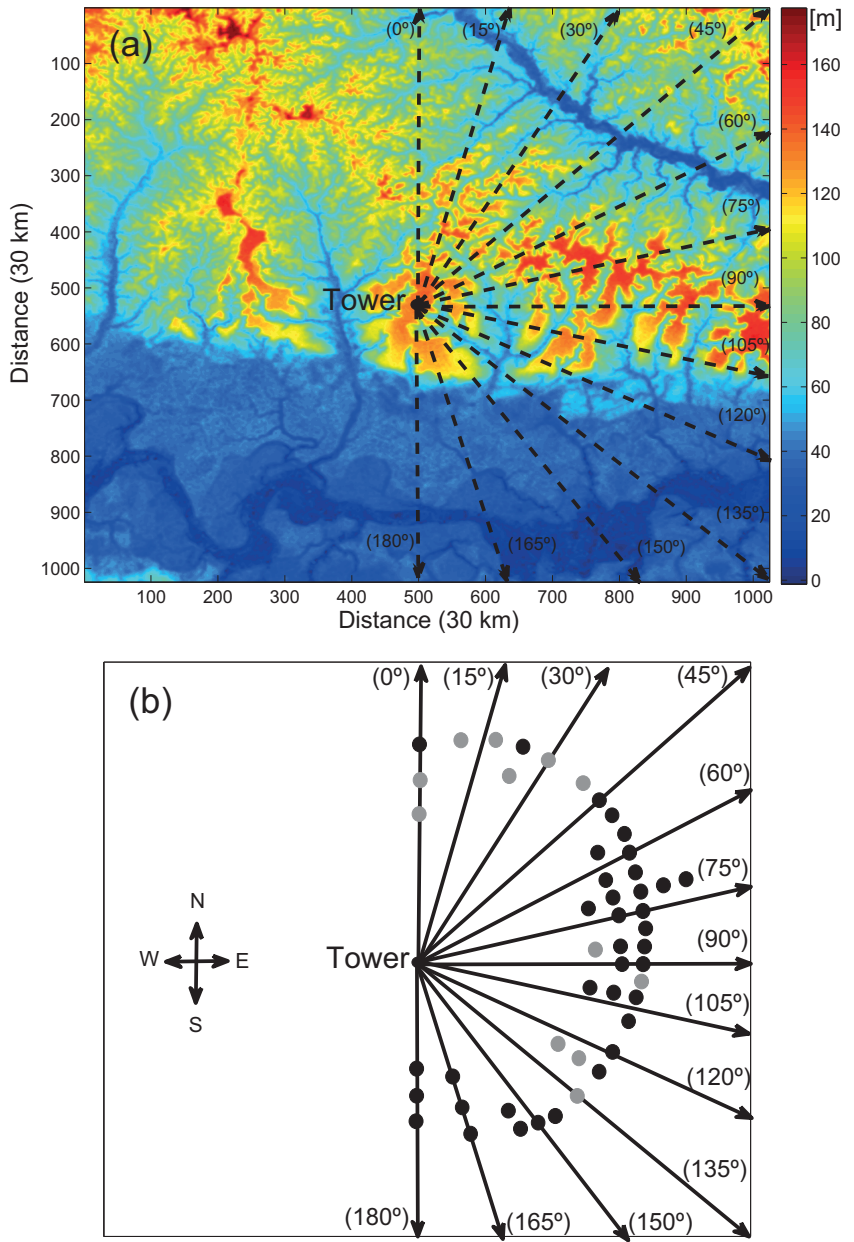

Figure 15. (a) Area of approximately $900 \mathrm{~km}^{2}$ surrounding the ATTO site. The axes represent the directions $(0,5,10,15,175$, $180^{\circ}$ ) from the ATTO tower. The color scale represents terrain elevation in meters above sea level. (b) Schematic with axes corresponding to (a); the black dots indicate gravity wave events induced by terrain undulations and the gray points represent gravity wave events not induced by terrain effects.

associated with them (Lu and Fitzjarrald, 1994; Thomas and Foken, 2007; Foken et al., 2012). There has been much research on the dominant scale of occurrence of CSs (Collineau and Brunet, 1993; Thomas and Foken, 2005) and the physical mechanisms responsible for their generation (Paw U et al., 1992; Raupach et al., 1996; McNaughton and Brunet, 2002; Campanharo et al., 2008; Dias Júnior et al., 2013). Considerable research has also been devoted to the detection of CSs (Collineau and Brunet, 1993; Krusche and Oliveira, 2004) and the dissimilarity between CSs associated with the transport of momentum and scalars (Li and Bou-Zeid, 2011). However, many aspects of their occurrence are still poorly known, particularly: (i) their vertical variability (Lohou et al., 2000); (ii) the manifestations of their interaction with gravity waves (Sorbjan and Czerwinska, 2013); (iii) the influence of 
surface heterogeneity on their features; (iv) aspects of their numerical simulation (Patton, 1997; Bou-Zeid et al., 2004; Dupont and Brunet, 2009; Wan and Porte-Agel, 2011), particularly in the nocturnal boundary layer (Durden et al., 2013; Zilitinkevich et al., 2013), and (v) implications of the existence of CSs for the chemistry of the atmosphere (Steiner et al., 2011; Foken et al., 2012).

A study on the structure of atmospheric turbulence was performed at the ATTO site under daytime conditions, with the aim of contributing to the detection of CSs and developing a better understanding of their vertical and temporal variability over a very uneven terrain covered by primary forest in central Amazonia. Wind, temperature, and humidity data were obtained using sonic anemometers and gas analyzers, installed at 42 and $81 \mathrm{~m}$ above ground, as specified in the methods section. The scales of coherent structures were determined following the methodology proposed by Thomas and Foken (2005). Figure 16 shows the average duration of CSs for horizontal and vertical wind velocities $(u, w)$, temperature $(T)$, and humidity $(q)$. For the data at $81 \mathrm{~m}$ height, the CS of $u$ and $w$ exhibit temporal scales around $46 \mathrm{~s}$ and $29 \mathrm{~s}$, respectively. For the two scalars, $T$ and $q$, the time scales of the CS are about 44 and $55 \mathrm{~s}$, respectively. For the height of $42 \mathrm{~m}$ the coherent structure time scales of $u, w, T$, and $q$ were approximately equal to $33,26,30$, and $31 \mathrm{~s}$, respectively.

The results revealed that the CS time scale of the vertical wind velocity is often smaller than the scales of the horizontal velocity and the scalar properties, for both levels. This can be explained by the fact that the scalar spectra exhibit greater similarity to the spectra of the horizontal velocity than to the vertical velocity for low frequencies. Another interesting feature is that the temporal scale of the CSs for both the wind velocity and scalars are considerably shorter for the data measured at $81 \mathrm{~m}$ compared with those at $42 \mathrm{~m}$, i.e., the region immediately above the forest canopy appears to be under the influence of a high-pass filter that removes the lower frequency oscillations of the turbulent signals (Krusche and Oliveira, 2004; Thomas and Foken, 2005).

\subsubsection{Characteristics of the nocturnal boundary layer}

The characteristics of the nocturnal boundary layer (NBL) at the ATTO site near the Uatumã River were analyzed for the wet and the dry seasons, based on two methodologies: (i) the thermodynamic classes of the NBL proposed by Cava et al. (2004) and (ii) the turbulence regimes proposed by Sun et al. (2012).

Cava et al.'s (2004) classification of nocturnal time series is based on the existence of a dominant pattern in scalar data, such as $\mathrm{CO}_{2}$ concentration, temperature, or specific humidity. It also takes into account the variability of nocturnal net radiation $\left(R_{\mathrm{n}}\right)$, measured at a sufficiently high sampling rate, which allows cloud detection (with passage of clouds being identified by rapid $R_{\mathrm{n}}$ changes greater than $10 \mathrm{~W} \mathrm{~m}^{-2}$ ).
Classes (I), (II), (III), are defined by atmospheric conditions free of the influence of clouds, which can disturb the stable boundary layer above the forest. The classes are defined as followed by Cava et al. (2004): (I) the occurrence of coherent structures in the form of "ramps" in scalar time series; (II) the presence of sinusoidal signals ("ripples") that simultaneously occur in the time series of scalars above the canopy and that are typical for gravity waves; (III) the existence of turbulence fine structure (i.e., according to Cava et al. (2004), "periods that lack any geometric structure or periodicity in the time series data"). The last two categories, (IV) and (V), of Cava et al.'s classification refer to the simultaneous occurrence of clouds and organized movements with variations in $R_{\mathrm{n}}>10 \mathrm{~W} \mathrm{~m}^{-2}$. They are (IV) cases where the net radiation induces organized movements, and (V) those where the change in net radiation is not correlated with changes in organized movements.

The search of parameters to characterize the turbulence regimes of the nocturnal boundary layer is based on Sun et al. (2012). The three turbulence regimes in the NBL are defined as follows: Regime 1 shows weak turbulence generated by local shear instability and modulated by the vertical gradient of potential temperature. Regime 2 shows strong turbulence and wind speed exceeding a threshold value $\left(V_{\lambda}\right)$, above which turbulence increases systematically with increasing wind speed. This describes the turbulence generated by bulk shear instability, defined as the mean wind speed divided by the measuring height. In Regime 3, the turbulence occurs at wind speeds lower than $V_{\lambda}$, but is associated with occasional bursts of top-down turbulence. In Regimes 1 and 2, the scale of turbulent velocity ( $\left.V_{\mathrm{TKE}}\right)$ is related to the mean wind velocity, $V$. The turbulent velocity, $V_{\mathrm{TKE}}$, is defined as follows:

$V_{\mathrm{TKE}}=\left[(1 / 2)\left(\sigma_{u}^{2}+\sigma_{v}^{2}+\sigma_{w}^{2}\right)\right]^{1 / 2}$,

where $u, v$, and $w$ are the components of the zonal, meridional and vertical winds, respectively, and $\sigma$ represents the standard deviation of each variable.

We analyzed 53 data files from the wet season and 79 data files collected during the dry season at the ATTO site. Our results show that the prevailing conditions in the NBL are represented by Cava's classes I, II, and V for both wet and dry seasons (Table 5). Furthermore, during the wet season the classes I and V show their highest percentage of occurrence associated with turbulence Regime 3. Class IV is more frequent when turbulence Regime 1 prevails. For the dry season we observe that turbulence classes I, IV and V occur most frequently in situations associated with Regime 1 (Table 6).

\subsection{Measurements of atmospheric composition}

In March 2012, a basic set of measurements $\left(\mathrm{CO}, \mathrm{CO}_{2}\right.$, $\mathrm{CH}_{4}$, and equivalent black carbon, $\mathrm{BC}_{\mathrm{e}}$ ) was initiated at the site, which has been running almost continuously up to the present. As $\mathrm{CO}_{2}$ and $\mathrm{BC}_{\mathrm{e}}$ were measured with multiple instruments in parallel (see Table 2) an almost complete time 


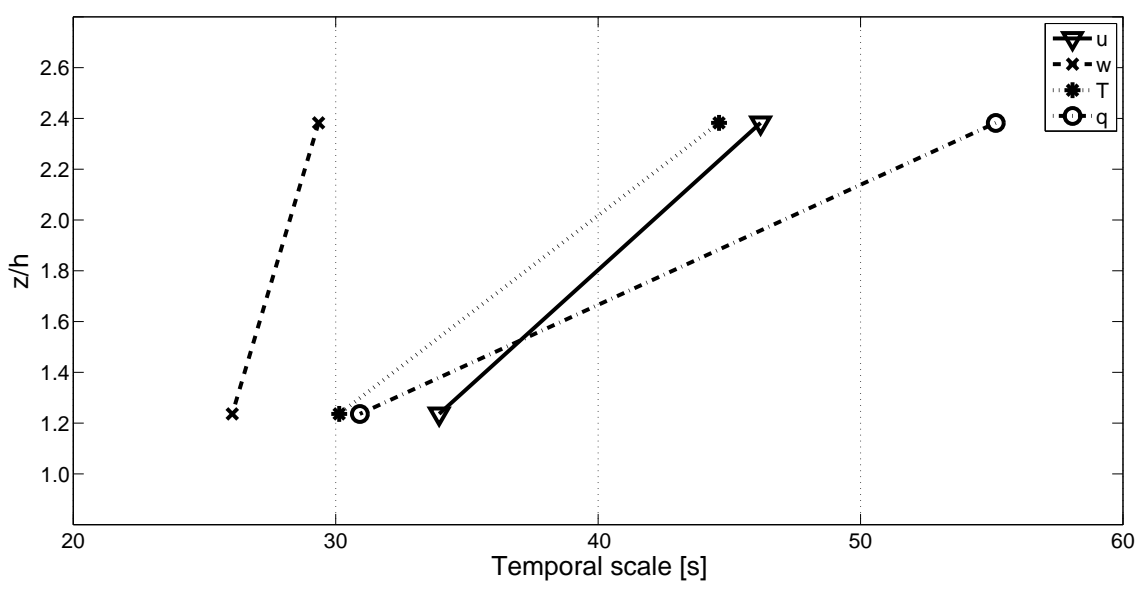

Figure 16. Coherent structures time scale of $w, u, T$, and $q$, recorded at heights of 42 and $81 \mathrm{~m}$ at the ATTO site.

Table 5. Percentage of occurrence of Cava's classes for dry and wet season obtained at the ATTO site and a comparison with the results found by Cava for the Duke Forest, North Carolina, USA.

\begin{tabular}{lrrrr}
\hline Class & \multicolumn{3}{c}{ ATTO } & Duke \\
\cline { 2 - 4 } & Wet & Dry & Avg. & Avg. \\
\hline I & $46.8 \%$ & $49.1 \%$ & $47.9 \%$ & $45.7 \%$ \\
II & $14.0 \%$ & $28.3 \%$ & $21.2 \%$ & $5.9 \%$ \\
III & $7.6 \%$ & $7.6 \%$ & $7.6 \%$ & $29.2 \%$ \\
IV & $3.8 \%$ & $3.7 \%$ & $3.75 \%$ & $1 \%$ \\
V & $27.8 \%$ & $11.3 \%$ & $19.6 \%$ & $18.2 \%$ \\
\hline
\end{tabular}

series since March 2012 is available for these quantities. In November 2012, the long-term measurement setup was upgraded to include measurements of ozone, aerosol scattering, aerosol size distribution, and aerosol number concentration. Due to the complex logistics at this remote site, there are a few large data gaps in some of these time series, but the data sets are almost complete from the middle of May to November 2013 and from February 2014 to now. Continuous measurements of aerosol chemical composition by an aerosol mass spectrometer were also initiated in February 2014. Furthermore, several intensive campaigns were conducted with additional measurements of aerosol properties, $\mathrm{VOC}, \mathrm{OH}$ reactivity, and $\mathrm{NO}_{x}$.

\subsection{1 $\mathrm{CO}_{2}, \mathrm{CH}_{4}$, and $\mathrm{CO}$}

Figure $17 \mathrm{a}-\mathrm{c}$ shows the diurnal cycles of the vertical distributions of $\mathrm{CO}_{2}, \mathrm{CH}_{4}$, and $\mathrm{CO}$ at the ATTO site. $\mathrm{CO}_{2}$ and $\mathrm{CO}$ show a nighttime accumulation in the sub-canopy space and a corresponding steepening of the vertical concentration gradient, which is greatly reduced during daytime due to the enhanced vertical mixing throughout the canopy. In addition, $\mathrm{CO}_{2}$ exhibits a clear minimum during daytime at mid-canopy level induced by photosynthesis. Interestingly, the build-up of the nighttime maximum of $\mathrm{CH}_{4}$ proceeds from above the canopy (Fig. 17b). The origin of this behavior, which seems to be linked to multiple processes, is under investigation. During daytime, $\mathrm{CO}_{2}, \mathrm{CH}_{4}$, and $\mathrm{CO}$ still exhibit a small vertical gradient below the canopy, indicating a local source near the ground.

Additional evidence for local surface sources are sporadic concurrent increases of $\mathrm{CH}_{4}$ and $\mathrm{CO}$, predominantly at the lowest measurement level. Examples are shown in Fig. 18. The origin of this local $\mathrm{CH}_{4}$ and $\mathrm{CO}$ source is not known. A remote source (e.g., from the large water reservoir behind the Balbina Dam, $60 \mathrm{~km}$ northwest of ATTO) seems unlikely, as such a signal would be vertically diluted before reaching the ATTO site. A combustion source also appears unlikely, as the observed $\mathrm{CH}_{4} / \mathrm{CO}$ ratios are several orders of magnitude higher than the values typical of combustion emissions.

Apart from these $\mathrm{CH}_{4}$ and $\mathrm{CO}$ peaks, we occasionally observe, mostly during nighttime, short $\mathrm{CH}_{4}$ peaks of up to more than $100 \mathrm{ppb}$ amplitude. These peaks last a few hours, they do not always concur with increases in $\mathrm{CO}$ concentrations, and often coincide with "bursts" of particles with a diameter of a few tens of nanometers.

Figure 19 shows the statistics of monthly daytime (defined as between 13:00-16:00 LT, or 17:00-20:00 UT) $30 \mathrm{~min}$ measurements of $\mathrm{CO}_{2}$ from three levels $(4,38$, and $79 \mathrm{~m})$. The values at the $4 \mathrm{~m}$ level are consistently higher than at the upper levels, while the $38 \mathrm{~m}$ level consistently shows lower values during daytime than the top level $(79 \mathrm{~m})$. This indicates that photosynthesis is active throughout the year. The record is still too short to reveal a clear seasonality. Nevertheless, it appears that $\mathrm{CO}_{2}$ from June to August is about $5 \mathrm{ppm}$ above the values during the months from December to February.

Statistics of monthly daytime $30 \mathrm{~min}$ measurements of $\mathrm{CH}_{4}$ and $\mathrm{CO}$ are shown in Fig. 20 (from the $79 \mathrm{~m}$ level only). Because of a large data gap due to a malfunctioning of the analyzer, a seasonal cycle is not discernible in the present $\mathrm{CH}_{4}$ 
Table 6. Distribution of Cava's classes associated with the turbulence regimes for the ATTO site nocturnal boundary layer.

\begin{tabular}{|c|c|c|c|c|c|c|}
\hline & \multicolumn{2}{|c|}{ Regime 1} & \multicolumn{2}{|c|}{ Regime 2} & \multicolumn{2}{|c|}{ Regime 3} \\
\hline & Wet & Dry & Wet & Dry & Wet & Dry \\
\hline Class I & $19.2 \%$ & $49 \%$ & $38.5 \%$ & $16 \%$ & $42.3 \%$ & $35 \%$ \\
\hline Class IV & $100 \%$ & $67 \%$ & $0 \%$ & $0 \%$ & $0 \%$ & $33 \%$ \\
\hline Class V & $25 \%$ & $50 \%$ & $25 \%$ & $27 \%$ & $50 \%$ & $23 \%$ \\
\hline
\end{tabular}
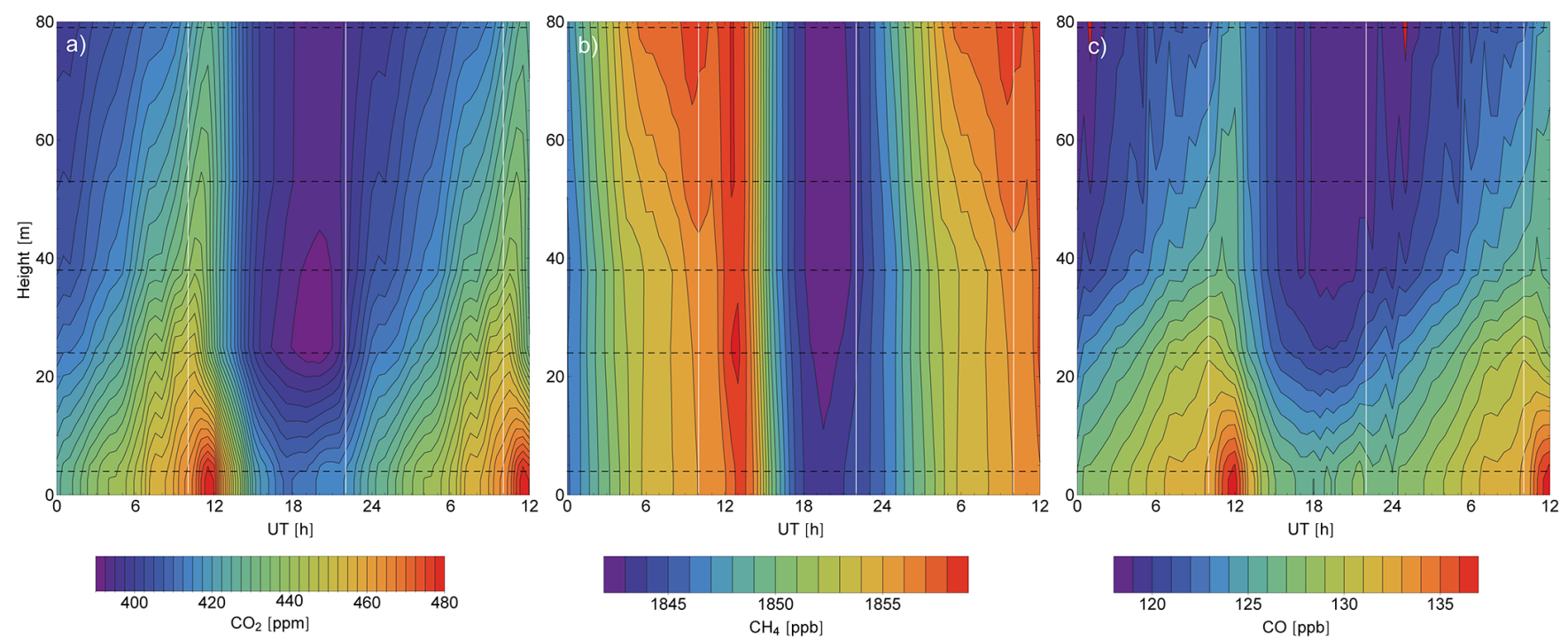

Figure 17. Diurnal cycle of (a) $\mathrm{CO}_{2}$, (b) $\mathrm{CH}_{4}$, and (c) $\mathrm{CO}$. The $\mathrm{CO}_{2}$ plot is computed from the measurements in January 2013 , the $\mathrm{CH}_{4}$ and $\mathrm{CO}$ plots from all available measurements until the end of 2014. Time is given in UT, with the first $12 \mathrm{~h}$ repeated for clarity. The white vertical lines indicate the times of local sunrise (10:00 UT) and sunset (22:00 UT), respectively. Black dashed horizontal lines show the heights of the five inlets.

record. CO does show a seasonal cycle at ATTO with concentrations higher by about $50 \mathrm{ppb}$ during the dry months with a significant fraction of air coming from the southeast (see Fig. 3), where vegetation fires are very active at this time.

Monthly daytime concentrations of $\mathrm{CO}_{2}, \mathrm{CH}_{4}$, and $\mathrm{CO}$ are compared in Fig. 21 with measurements upstream of ATTO: Cape Verde (green symbols) reflecting the subtropics of the Northern Hemisphere, and Ascension Island (brown symbols) representing conditions in the Southern Hemisphere. At least during the period of July to December, $\mathrm{CO}_{2}$ concentrations clearly reach lower values than at both upstream locations, reflecting the regional carbon sink in the Amazon domain. In contrast, $\mathrm{CH}_{4}$ levels at ATTO lie almost on Northern Hemisphere levels throughout the year, even when the ITCZ is north of ATTO in austral winter, and the site is in the atmospheric Southern Hemisphere with its lower background $\mathrm{CH}_{4}$ concentrations. This suggests the presence of regional $\mathrm{CH}_{4}$ emissions in the airshed of ATTO. The CO concentrations at ATTO during the wet season are close to those at Cape Verde, reflecting the absence of significant combustion sources in the South American part of the fetch during this season. In contrast, dry-season CO mixing ratios at ATTO are about $80 \mathrm{ppb}$ higher than those at Ascension Island, reflecting biomass burning emissions in the southeastern Amazon (Andreae et al., 2012).

\subsubsection{Biogenic volatile organic compounds and $\mathrm{OH}$ reactivity}

The first successful vertical gradients of biogenic VOCs and total $\mathrm{OH}$ reactivity were measured in November 2012 at the walk-up tower using the gradient system as described in Sect. 3.4. Diurnal fluctuations of isoprene are apparent at all heights (Fig. 22). Under daylight conditions, isoprene mixing ratios were always highest at the $24 \mathrm{~m}$ level, reaching up to $19.9 \pm 2.0 \mathrm{ppb}$ (average \pm standard deviation) and indicating a source at the canopy top. During nighttime, the lightdriven emissions of isoprene cease and the in-canopy mixing ratio fell to $1.1 \pm 0.5 \mathrm{ppb}$, which was lower than observed above the forest at $79 \mathrm{~m}(2.3 \pm 0.3 \mathrm{ppb})$. Measurements in the canopy $(24 \mathrm{~m})$ vary by a factor of 10 from day to night, while measurements close to the ground $(0.05 \mathrm{~m})$ vary only by a factor of two. This clearly demonstrates a canopy emission of isoprene, with a peak around noon, when light and 


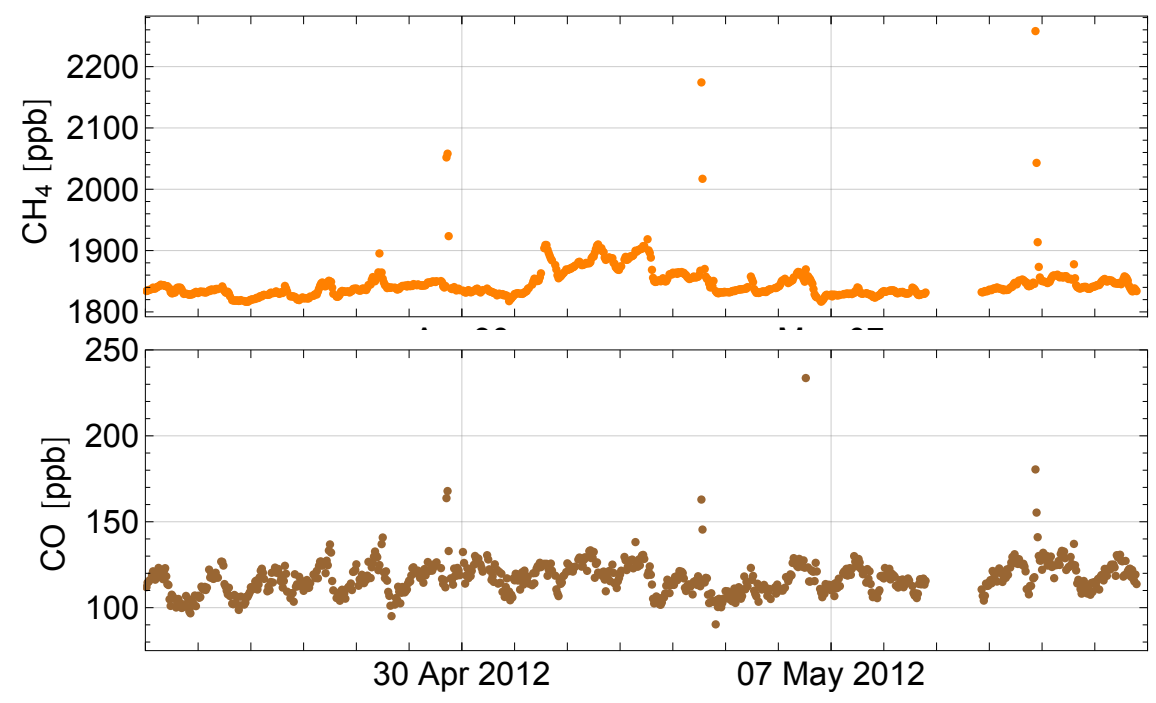

Figure 18. Examples of sporadic concurrent increases in $\mathrm{CH}_{4}$ and $\mathrm{CO}$ recorded at the lowermost (4 m) inlet in 2012.

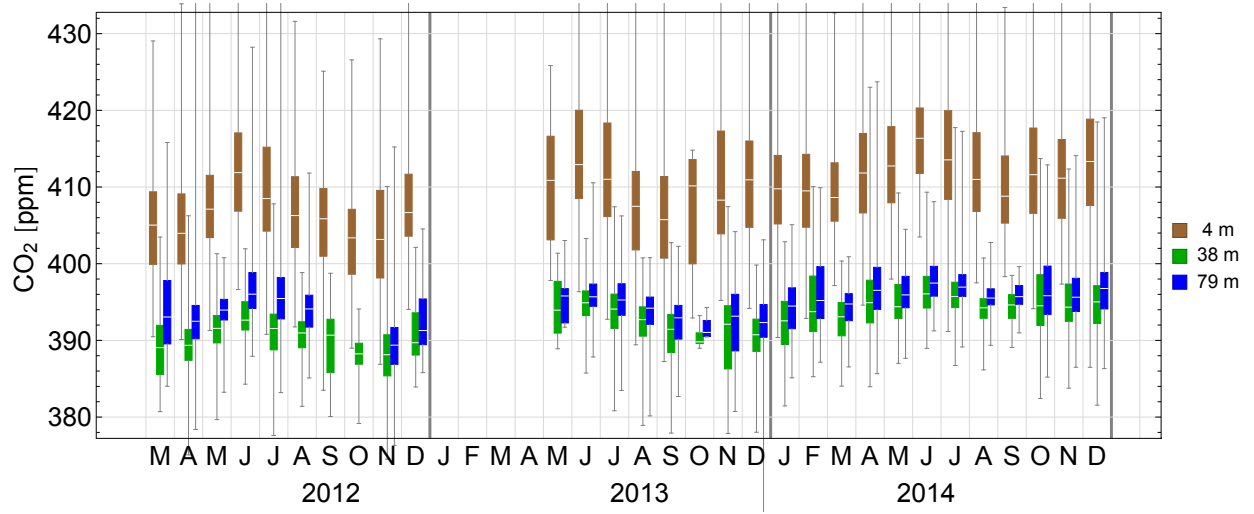

Figure 19. Statistics of monthly daytime (17:00-20:00 UT) 30 min measurements of $\mathrm{CO}_{2}$ at the $80 \mathrm{~m}$ walk-up tower. Shown are whisker plots indicating $\mathrm{min} / \mathrm{max}$ and quartiles of the monthly measurements. The white line in the box indicates the median. Brown: $4 \mathrm{~m}$ level, green: $38 \mathrm{~m}$ level, blue: $79 \mathrm{~m}$ level.

temperature are at their maximum. Isoprene mixing ratios at the ground level were always the lowest, indicating a potential sink at the soil/litter level or relatively slow downward mixing. A detailed discussion of measurements of isoprene and other biogenic VOC at ATTO was published recently (Yáñez-Serrano et al., 2015).

In November 2012, the high levels of isoprene measured above the canopy contributed significantly (on average about $85 \%)$ to the total $\mathrm{OH}$ reactivity. From Fig. 23, it can be seen that median isoprene mixing ratios of between $0.5 \mathrm{ppb}$ at 06:00 LT and $8 \mathrm{ppb}$ in the late afternoon above the canopy give an $\mathrm{OH}$ reactivity of about $1-20 \mathrm{~s}^{-1}$. The gap between the two curves is the fraction of total $\mathrm{OH}$ reactivity that is not due to isoprene. For most of the time this gap is small and within the uncertainty of the measurements. On two occasions, however, the total $\mathrm{OH}$ reactivity was significantly higher than the isoprene contribution, these being in the early morning (09:00 LT) coincident with a drop in light levels, and in the afternoon just after sunset (17:00 LT). For all other times in the course of the day, isoprene was the major sink for $\mathrm{OH}$ above the canopy. Overall, a distinct diel variability in total $\mathrm{OH}$ reactivity can be observed, similar to that of its major contributor, isoprene. The median lifetime of $\mathrm{OH}$ radicals during the dry-to-wet transition season above the forest canopy at $80 \mathrm{~m}$ varied from about $50 \mathrm{~ms}$ by day to $100 \mathrm{~ms}$ at night. Ongoing measurements will determine the seasonal variability in total $\mathrm{OH}$ reactivity and the relative contribution of isoprene.

\subsubsection{Ozone profiles}

The $\mathrm{O}_{3}$ mixing ratios (Fig. 24) show typical diurnal cycles for both seasons, with values increasing from the morning to the afternoon and subsequently decreasing due to deposition 

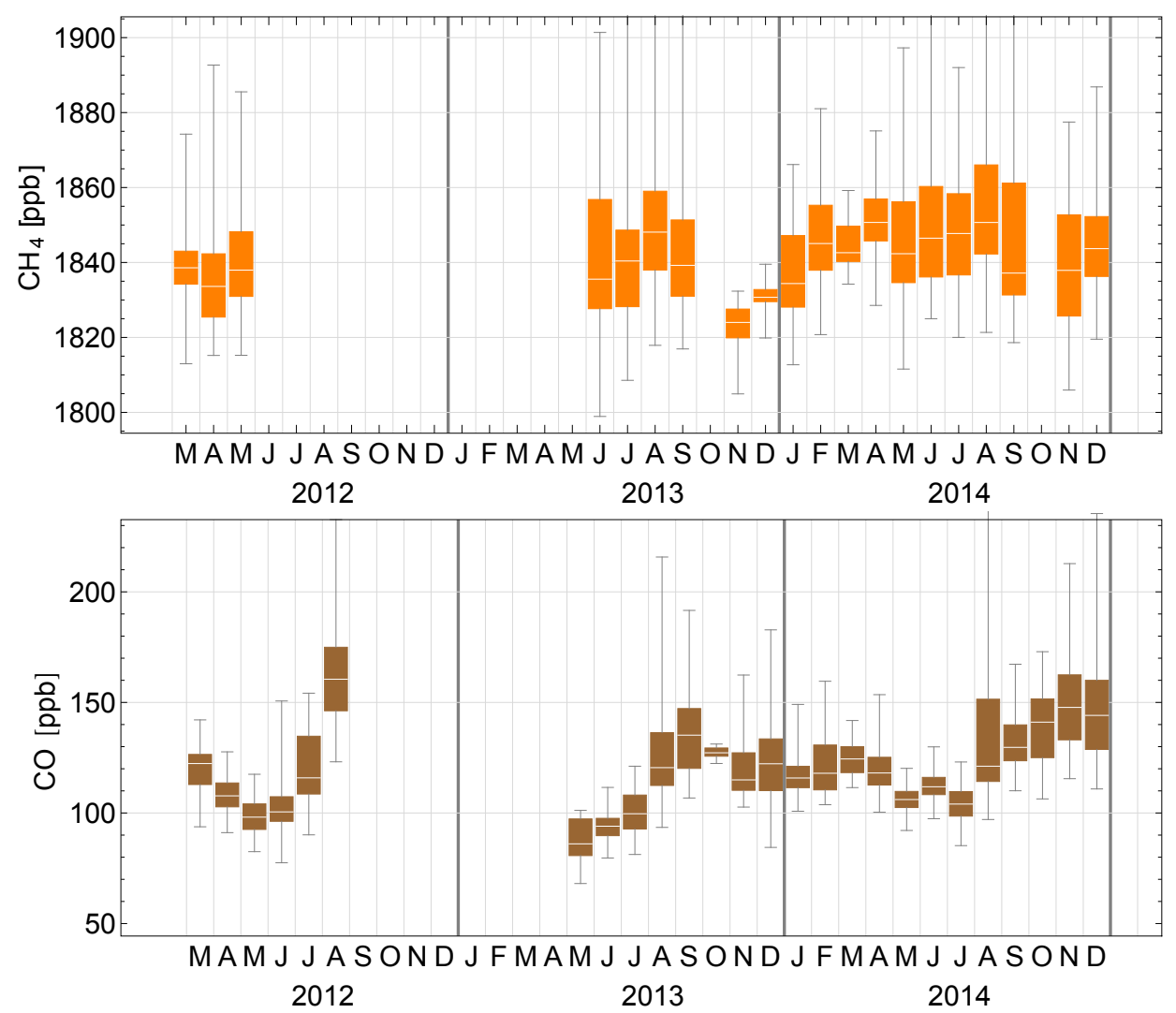

Figure 20. Statistics of monthly daytime (17:00-20:00 UT) $30 \mathrm{~min}$ measurements of $\mathrm{CH}_{4}$ and $\mathrm{CO}$ at the $79 \mathrm{~m}$ level of the $80 \mathrm{~m}$ walk-up tower. Shown are whisker plots indicating $\min / \max$ and quartiles of the monthly measurements. The white line in the box indicates the median.

and chemical reactions. The afternoon $\mathrm{O}_{3}$ maxima at the uppermost height $(79 \mathrm{~m})$ are about a factor of 1.4 higher during the dry season than during the wet season, averaging about $\sim 11$ and $\sim 8 \mathrm{ppb}$, respectively. As found in previous studies, its deposition to surfaces causes $\mathrm{O}_{3}$ to exhibit pronounced vertical gradients (Fig. 24), which makes a direct intercomparison to measurements at other sites difficult. However, the mixing ratios above the canopy from different studies in the Amazonian rain forest during the wet season are within a narrow range of 7 to $12 \mathrm{ppb}$, and the value measured at ATTO falls near the lower end of this range (Kirchhoff et al., 1990; Andreae et al., 2002; Rummel et al., 2007; Artaxo et al., 2013). A budget study by Jacob and Wofsy (1990) revealed that downward transport of $\mathrm{O}_{3}$ mainly controlled the losses near the surface, with only a minor contribution from photochemical formation above the canopy. This may explain the similar mixing ratios in the different studies. Furthermore, only small $\mathrm{O}_{3}$ differences were measured between $38 \mathrm{~m}$ (just above the canopy) and the top of the tower at $79 \mathrm{~m}$ during the wet season.

A different picture is observed during the dry season, with much higher $\mathrm{O}_{3}$ mixing ratios at more polluted sites ( $\sim 40$ ppb in Rondônia: Kirchhoff et al., 1989; Andreae et al., 2002; Rummel et al., 2007; Artaxo et al., 2013), which can be related to biomass burning emissions causing photochemical $\mathrm{O}_{3}$ formation (Crutzen and Andreae, 1990). A site comparable to the ATTO site is the ZF2 site, located about $60 \mathrm{~km}$ northwest of Manaus, which has been used extensively in the past (Artaxo et al., 2013), but which is occasionally affected by the Manaus urban plume (Kuhn et al., 2010; Trebs et al., 2012). At the $\mathrm{ZF} 2$ site, mean maximum $\mathrm{O}_{3}$ mixing ratios measured at $39 \mathrm{~m}$ from 2009-2012 (Artaxo et al., 2013) match exactly those measured at the ATTO site for the wet season, but are about a factor of 1.5 higher during the dry season. This may be attributed to the more pristine character of the ATTO site, but could also be related to the different measurement periods or different biogenic emissions at the sites. In order to distinguish these different influences, highquality long-term measurements are required, which are now being generated within the ATTO project.

During the wet season, the amplitude of the mean diurnal cycle at $79 \mathrm{~m}$ is only about $2 \mathrm{ppb}$, whereas it is $3-4 \mathrm{ppb}$ during the dry season. The highest amplitudes are observed within the canopy and the understory with up to $5 \mathrm{ppb}(24 \mathrm{~m})$ in the dry season. These variations can be attributed to downward mixing of $\mathrm{O}_{3}$, which is "stored" within the canopy (so called storage flux, see Rummel et al., 2007). It is subsequently depleted by chemical reactions, mostly with soil bio- 

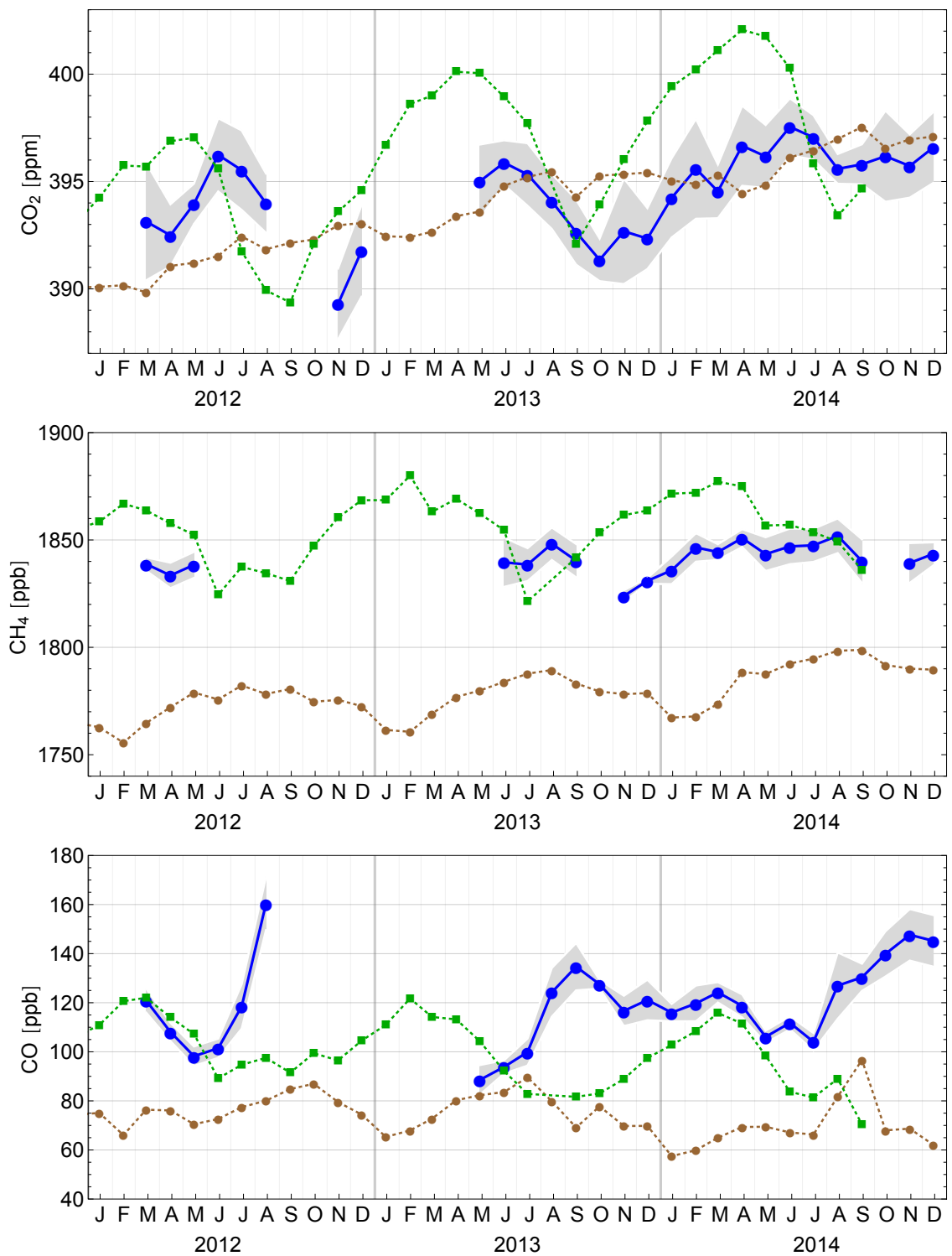

Figure 21. Monthly averaged daytime (17:00-20:00 UT) measurements of $\mathrm{CO}_{2}, \mathrm{CH}_{4}$ and $\mathrm{CO}$ at the 79 m level of the ATTO tower (blue line, standard deviation indicated by shading) in comparison with monthly averaged concentration measurements from Ascension Island (brown; data for 2014 are preliminary; Dlugokencky et al., 2014; Novelli and Masarie, 2014) and Cape Verde (green: Carpenter et al., 2010, updated).

genic NO, and deposition after the forest canopy becomes decoupled from the atmosphere above at nighttime. During the wet season, the largest decrease in $\mathrm{O}_{3}$ mixing ratios occurs at the canopy top. This might be attributed to a lower canopy resistance to $\mathrm{O}_{3}$ deposition due to enhanced stomatal aperture during the wet season as proposed by Rummel et al. (2007) and will be the subject of future work. Further investigations will also focus on the interactions between turbulence (supply of $\mathrm{O}_{3}$ ) and trace gases that react with $\mathrm{O}_{3}$, especially nitric oxide $(\mathrm{NO})$.

\subsubsection{Aerosol optical properties}

The aerosol optical properties measured at the ATTO site are shown as a time series in Fig. 25 and summarized in Table 7. The averages were calculated for the dry season, August-October, and the wet season, February-May (20122013 for the absorption measurements and 2013 for the scattering measurements). The transition periods between these two seasons are not included in the summary, in order to show the contrast between the cleanest and "more polluted" periods. The scattering coefficients are similar to those reported by Rizzo et al. (2013) from measurements performed at the ZF2 site ( $60 \mathrm{~km} \mathrm{~N}$ of Manaus). The regional transport 


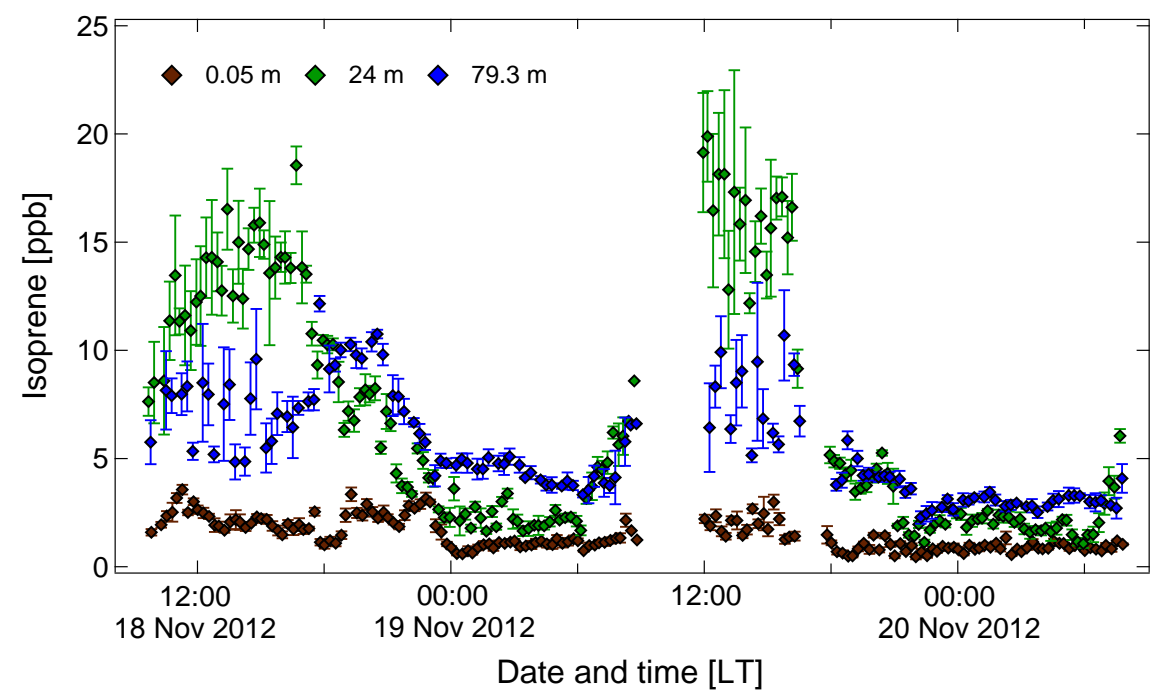

Figure 22. Profiles of isoprene derived from measurements at three different heights $(0.05,24$, and $79.3 \mathrm{~m})$ below, within, and above the canopy, respectively, in November 2012 (transition period from dry to wet season).

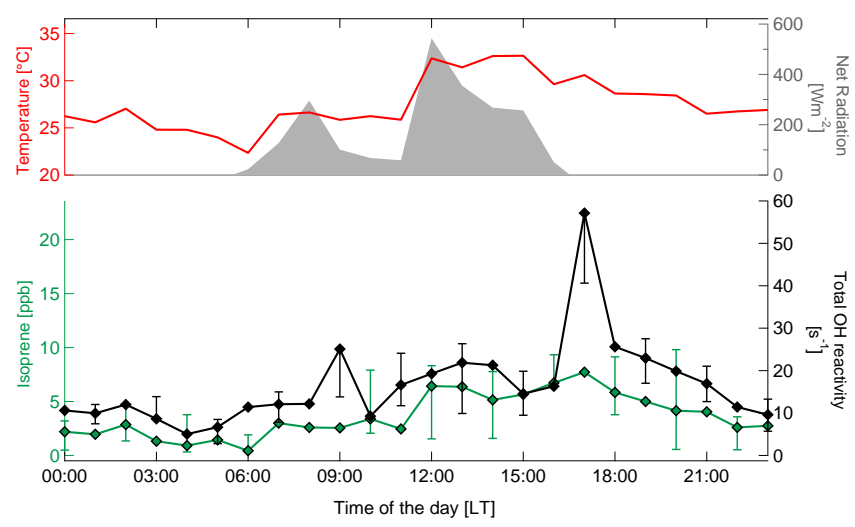

Figure 23. Isoprene and total $\mathrm{OH}$ reactivity measurements during November 2012 at the highest point above the canopy $(79 \mathrm{~m})$, binned as 60 min medians for all periods when both data were available (about 4 days). The isoprene mixing ratio scale (left axis) was set to match its contribution to the total $\mathrm{OH}$ reactivity ( $1 \mathrm{ppb}$ isoprene $=2.46 \mathrm{~s}^{-1}$ isoprene $\mathrm{OH}$ reactivity), which is presented on the right axis. The upper panel shows the diel variation of temperature (measured at $81 \mathrm{~m}$ ) and the net radiation.

of biomass burning emissions and fossil-fuel derived pollution is the main source of particles during the dry season. Its influence is pronounced, as can be seen by comparing the scattering and absorption coefficients from both seasons, which average about 3-6 times higher during the dry than during the wet season. During the wet season, ATTO is meteorologically located in the $\mathrm{NH}$ and the scattering and absorption coefficients reach their minimum values; however, episodes of long-range transport of aerosols from the Atlantic Ocean and Africa still lead to episodically elevated values.
The contrast between the wet and dry seasons can be attributed to a combination of higher removal rates by wet deposition during the wet season and the dominant influence from biomass burning and fossil fuel emissions during the dry season, which are the main sources of submicron particles at that time. The scattering Ångström exponent $\left(\stackrel{\circ}{\mathrm{s}}_{\mathrm{s}}\right)$ averages 1.25 during the wet season, lower than the $1.62 \mathrm{ob}-$ tained for the dry season. This behavior results from the high relative proportion of larger particles (mostly primary biogenic particles, but also dust and seaspray) during the wet season, because in contrast to the large seasonal variability of the submicron particles, the supermicron fraction shows less intense seasonal changes.

The seasonality of the absorption coefficient, $\sigma_{\mathrm{a}}$, is comparable to that of the scattering coefficient. The regional transport of biomass burning emissions, most important between August and October, produces a rise in the $\sigma_{\mathrm{a}}$ values, reaching an average of $3.46 \mathrm{Mm}^{-1}$ during this period. In contrast, during the wet season, $\sigma_{a}$ is very low, around $0.52 \mathrm{Mm}^{-1}$ on average.

The absorption Ångström exponent $\left(\stackrel{a}{a}_{a}\right)$ is often used to estimate the composition of light absorbing aerosols. An $a_{a} \sim 1$ indicates the aerosol is in the Rayleigh regime, and the absorption is dominated by soot-like carbon and is therefore wavelength independent (Moosmüller et al., 2011). Higher $\stackrel{\circ}{a}_{a}$ values indicate the presence of additional light absorbing material, like brown carbon $(\mathrm{BrC})$ (Andreae and Gelencsér, 2006). This kind of yellowish or brown organic material, abundant in biomass burning aerosols, usually has an $\stackrel{\circ}{a}_{a}$ $\sim 2.0$ or greater (Bond et al., 1999). Our measurements show only relatively minor seasonal differences in $\stackrel{a}{a}_{a}$, with somewhat higher values during the wet season (1.53) than in the dry season (1.40), suggesting that soot carbon is the most im- 

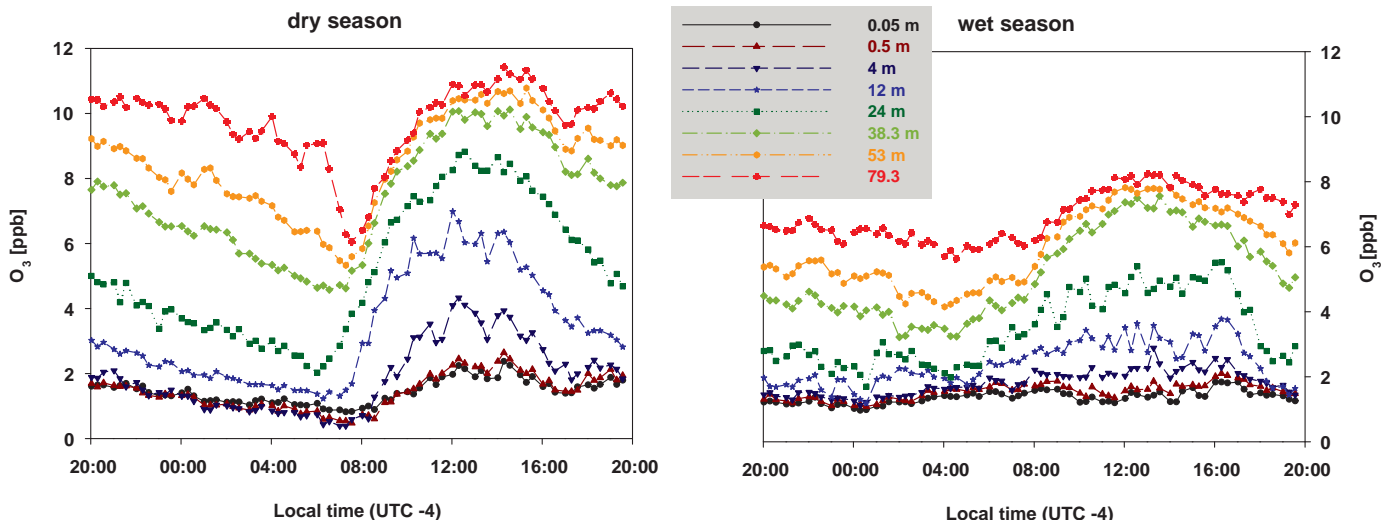

Figure 24. Mean diurnal profiles of $\mathrm{O}_{3}$ mixing ratios measured on the walk-up tower during the dry season (left panel, 15 August to 14 September 2013) and the wet season (right panel, 1 February to 3 March 2014).

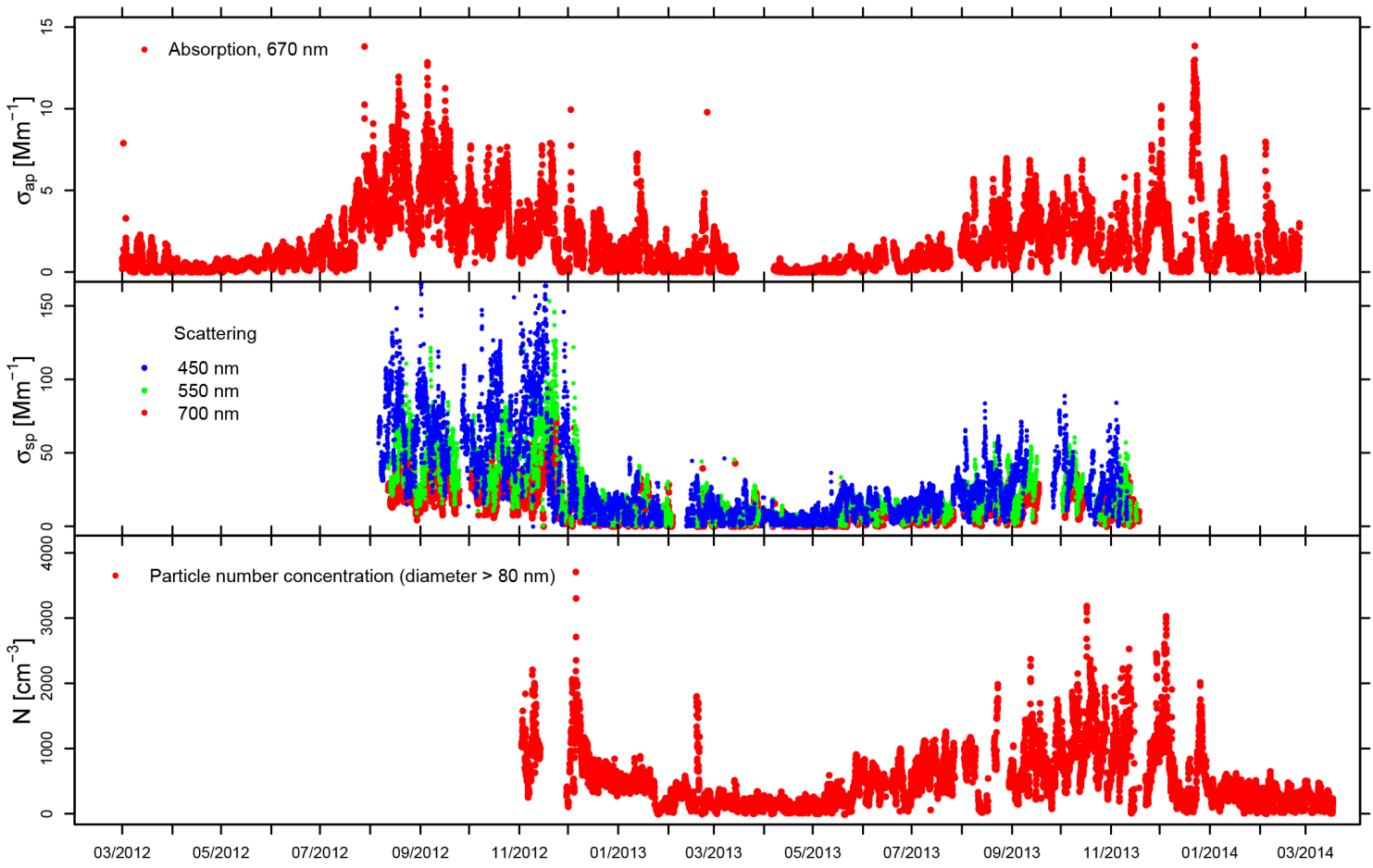

Figure 25. Time series of scattering and absorption coefficients and particle number concentration (diameter $>80 \mathrm{~nm}$ ).

portant contributor to aerosol light absorption throughout the year. The contribution of the different light absorbing components of the aerosol to the total observed aerosol absorption is currently being investigated.

We conducted the first long-term refractory black carbon (rBC) measurements by an SP2 instrument at a remote Amazonian site. The mass absorption cross section $\left(\alpha_{\mathrm{a}}\right)$ has been calculated by applying an orthogonal regression to the MAAP absorption coefficient measurements at $637 \mathrm{~nm}$ vs. the $\mathrm{rBC}$ mass concentrations measured by the SP2. The average $\alpha_{\mathrm{a}}$ obtained for the 2013-2014 wet season measurements was $13.5 \mathrm{~m}^{2} \mathrm{~g}^{-1}$, which is much higher than the $4.7 \mathrm{~m}^{2} \mathrm{~g}^{-1}$ reported previously for another Amazonian forest site (Gilardoni et al., 2011), who used a thermal-optical method to determine the apparent elemental carbon content. The high apparent $\alpha_{\mathrm{a}}$ could be partly explained by the fact that the SP2 size dynamic range was $70-280 \mathrm{~nm}$ and thus the technique did not account for $\mathrm{rBC}$ particles larger than $280 \mathrm{~nm}$. However, it is also likely related to an enhancement of light absorption by coatings on the rBC particles, or to the presence of additional light-absorbing substances besides $\mathrm{rBC}$ (Bueno et al., 2011; McMeeking et al., 2014). Single-particle studies (Sect. 4.3.7) on aerosols from the ATTO site consistently show thick coatings on the soot carbon particles. Our pre- 


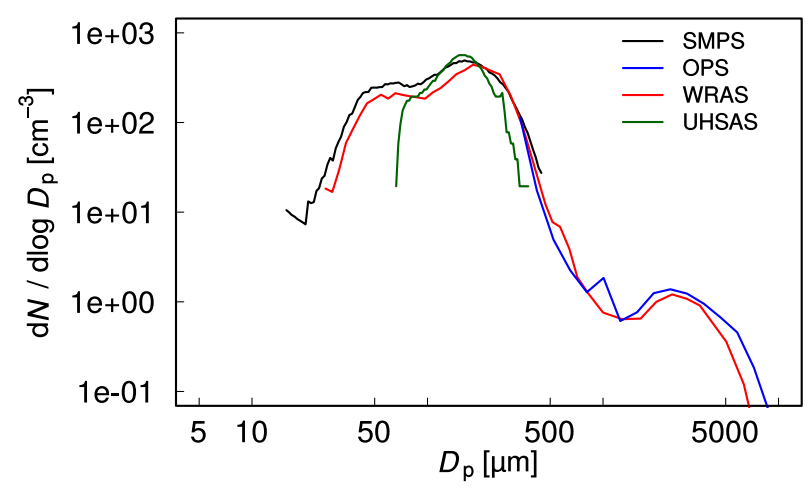

Figure 26. Intercomparison of the median particle number size distributions from the SMPS, OPS, WRAS, and UHSAS instruments. Instruments were operated for $6 \mathrm{~h}$ using the same inlet line during clean rainy-season conditions (26 January 2015).

liminary results indicate that the constant $\alpha_{\mathrm{a}}\left(6.6 \mathrm{~m}^{2} \mathrm{~g}^{-1}\right)$, implemented by the MAAP in order to retrieve the $\mathrm{BC}$ mass concentration, is not representative of the true optical properties of Amazonian aerosol particles.

\subsubsection{Aerosol number concentrations and size distributions}

Continuous measurements of aerosol particle size and concentration have been conducted at the ATTO site since March 2012. Over the last years, the extent of the sizing instrumentation has been increased stepwise to provide uninterrupted and redundant aerosol size and concentration time series. Figure 26 shows one of the frequent instrument intercomparisons, including four different instruments that are based on optical and electromobility sizing. It confirms the overall consistency and comparability of the different sizing techniques. Integrated particle number concentrations agree within $15 \%$ with measurements of total particle number concentrations by a CPC. The sample air for this intercomparison was collected through the main aerosol inlet at $60 \mathrm{~m}$ height, which is also used for instruments measuring aerosol scattering, absorptivity, hygroscopicity, and chemical composition.

At the ATTO site, the atmospheric aerosol burden shows remarkable differences in terms of size distribution and concentration depending on the seasons. Figure 27 displays the average particle number and volume size distributions for typical wet (6-13 May 2014) and dry season (13-20 September 2014) conditions, covering an aerosol size range from $10 \mathrm{~nm}$ to $10 \mu \mathrm{m}$. The wet season is characterized by clean air masses from NE directions (Fig. 3), which result in a near-pristine atmospheric state at the ATTO site. Total particle concentrations typically range from $100-400 \mathrm{~cm}^{-3}$ and aerosol size spectra reveal the characteristic "wet season shape". A representative example is shown in Fig. 27. The size spectrum is characterized by a three-modal shape with
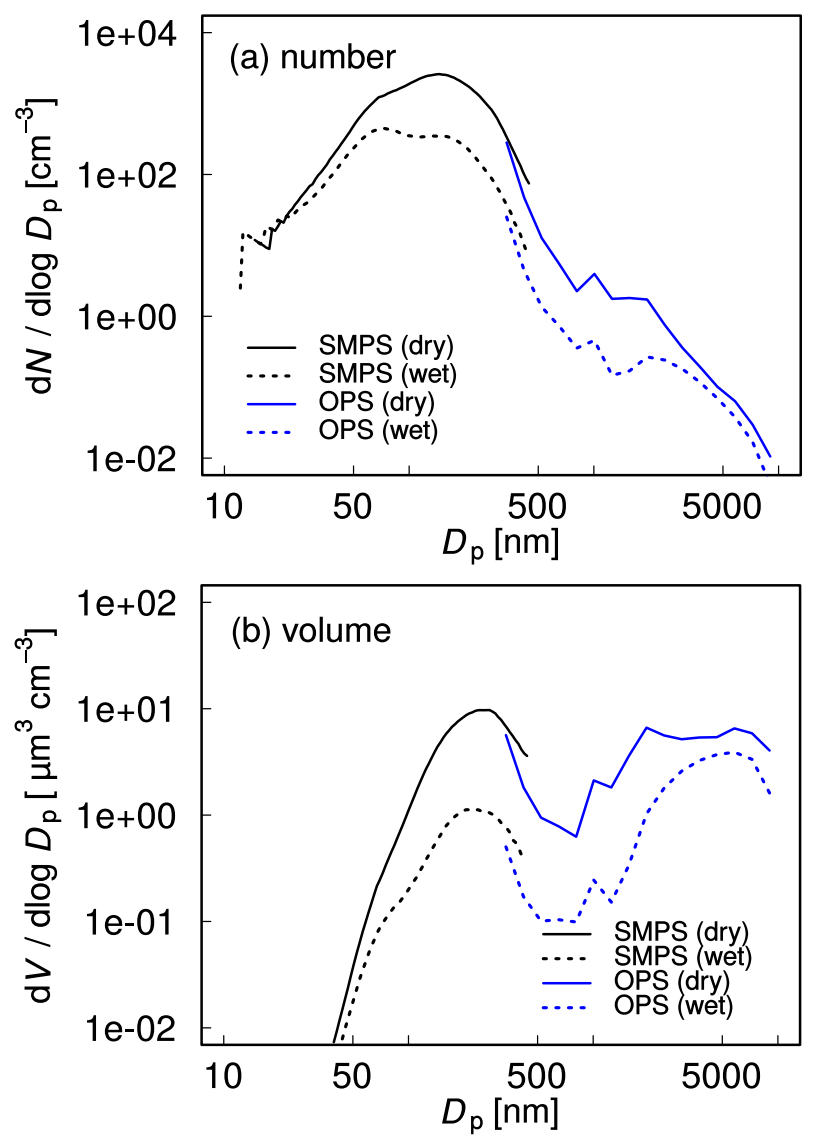

Figure 27. Median particle number (a) and volume (b) size distributions from the SMPS and OPS instruments, representative for conditions during the wet (dashed lines) and dry (solid lines) seasons. Plotted data sets comprise continuous SMPS and OPS data covering 7-day periods for wet (6-13 May 2014) and dry (13-20 September 2014) season conditions. Integrated number and volume concentrations for the selected wet season period: $\quad N_{\text {Ait,wet }}=141 \mathrm{~cm}^{-3}, \quad N_{\text {Acc,wet }}=130 \mathrm{~cm}^{-3}$, $N_{\text {Total,wet }}=282 \mathrm{~cm}^{-3} ; \quad V_{\text {sub}-\mu, \text { wet }}=0.5 \mu \mathrm{m}^{3} \mathrm{~cm}^{-3}$, $V_{\text {super }-\mu, \text { wet }}=1.5 \mu \mathrm{m}^{3} \mathrm{~cm}^{-3}, \quad V_{\text {Total,wet }}=2.0 \mu \mathrm{m}^{3} \mathrm{~cm}^{-3} . \quad$ Integrated number and volume concentrations for the selected dry season period: $N_{\text {Ait,dry }}=395 \mathrm{~cm}^{-3}, \quad N_{\text {Acc,dry }}=967 \mathrm{~cm}^{-3}$, $N_{\text {Total,dry }}=1398 \mathrm{~cm}^{-3} ; \quad V_{\text {sub }-\mu, \text { dry }}=4.0 \mu \mathrm{m}^{3} \mathrm{~cm}^{-3}$, $V_{\text {super }-\mu, \text { dry }}=3.5 \mu \mathrm{m}^{3} \mathrm{~cm}^{-3}, V_{\text {Total,dry }}=7.5 \mu \mathrm{m}^{3} \mathrm{~cm}^{-3}$.

pronounced Aitken and accumulation modes as well as a noticeable coarse mode. Aitken (maximum at $\sim 70 \mathrm{~nm}$ ) and accumulation (maximum at $\sim 150 \mathrm{~nm}$ ) modes are separated by the so called Hoppel minimum (at $\sim 110 \mathrm{~nm}$ ), which is thought to be caused by cloud processing (e.g., Zhou et al., 2002; Rissler et al., 2004; Artaxo et al., 2013).

The near-pristine conditions that prevail at the ATTO site during the wet season, when the aerosol concentrations are remarkably low and dominated by local and/or regional biogenic sources, are episodically interrupted by long-range transport of sea spray, Saharan dust, and/or African biomass 

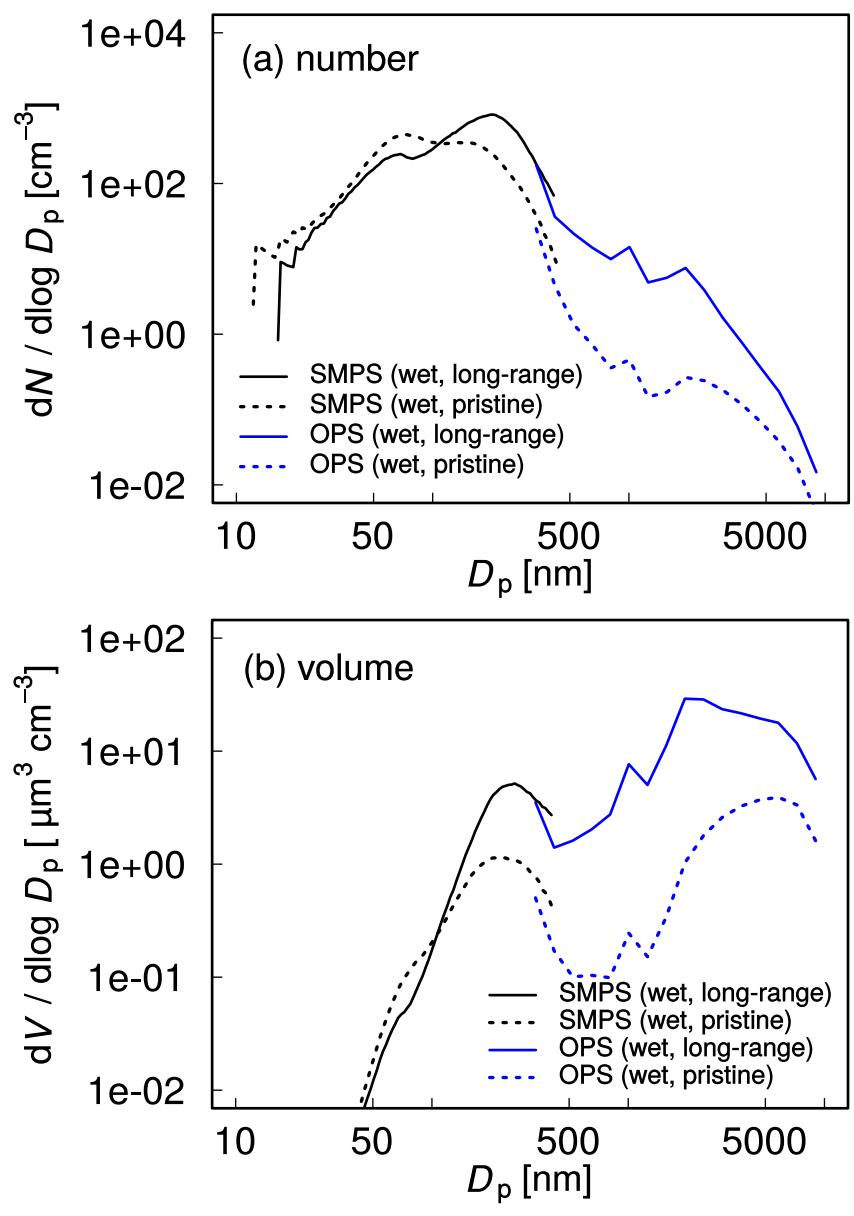

Figure 28. Median particle number (a) and volume (b) size distributions from the SMPS and OPS instruments, showing the contrast between pristine wet season conditions and episodes with long-range transport influence (i.e., Saharan dust, African biomass burning, and sea salt). Wet season number and volume size spectra are taken from Fig. 27. The long-range transport size spectrum is averaged from three selected episodes in Feb and Mar 2014. Integrated number and volume concentrations for the long-range transport episodes: $N_{\text {Ait,long }}=80 \mathrm{~cm}^{-3}, N_{\text {Acc,long }}=$ $308 \mathrm{~cm}^{-3}, N_{\text {Total, long }}=409 \mathrm{~cm}^{-3} ; V_{\text {sub }-\mu, \text { long }}=2.3 \mu \mathrm{m}^{3} \mathrm{~cm}^{-3}$, $V_{\text {super }-\mu, \text { long }}=12.7 \mu \mathrm{m}^{3} \mathrm{~cm}^{-3}, V_{\text {Total,long }}=15.0 \mu \mathrm{m}^{3} \mathrm{~cm}^{-3}$.

burning and fossil fuel combustion aerosol (e.g., Talbot et al., 1990; Martin et al., 2010a; Martin et al., 2010b; Baars et al., 2011). Figure 28 displays characteristic changes in the wet season size distribution during selected episodes with longrange transport intrusions. Typically, the aerosol abundance in the accumulation and coarse mode size range is substantially increased, and the Hoppel minimum almost completely disappears. The aerosol volume distribution clearly indicates a pronounced enhancement of coarse particles, which increases the integrated particle volume concentration by almost 1 order of magnitude (Fig. 28b).
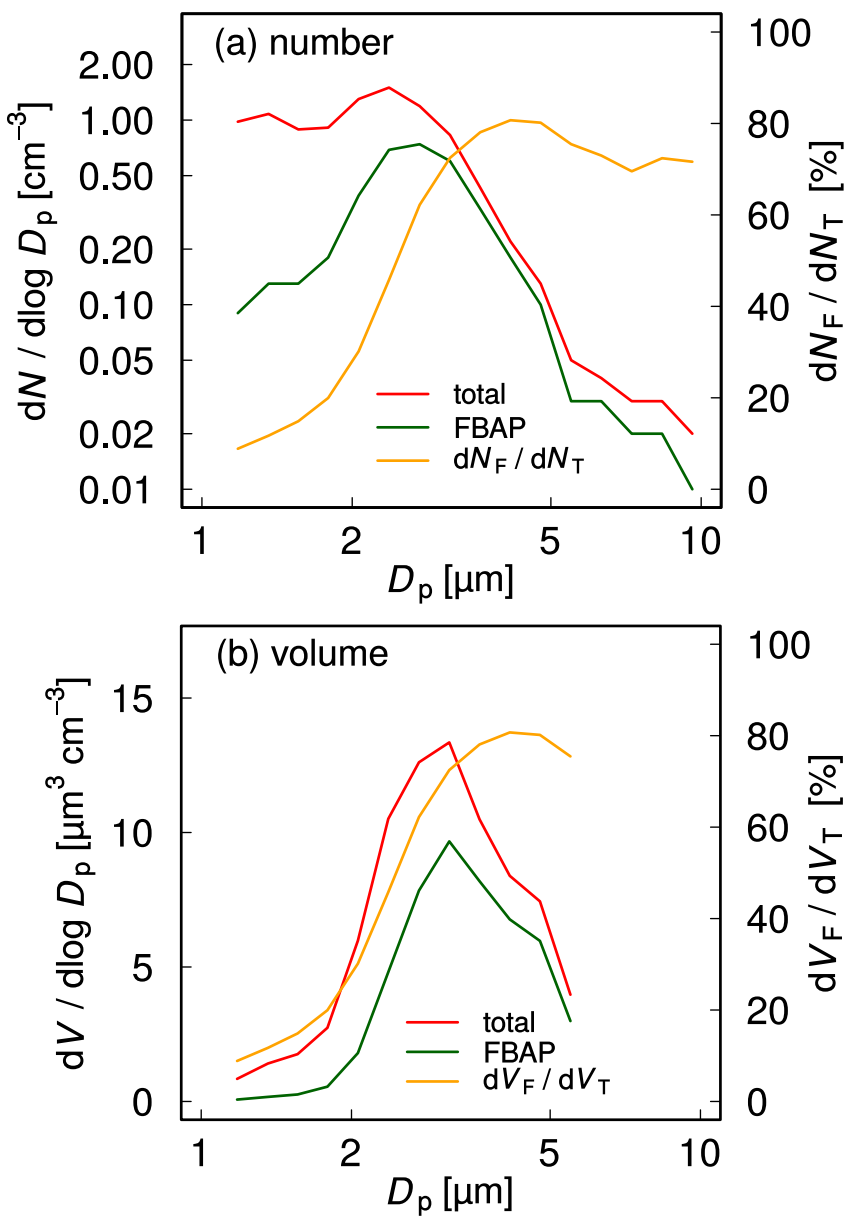

Figure 29. Average number (a) and volume (b) size distributions of the total and fluorescent aerosol particles measured by WIBS. Orange lines refer to the size-resolved fraction of FBAP.

During the dry season, the dominant wind direction is $\mathrm{E}$ to SE (Fig. 3), which brings polluted air from urban sources and deforestation and pasture fires in the southeastern Amazon and the Brazilian Nordeste to the ATTO site. Dry season aerosol number concentrations typically range from 500 $2000 \mathrm{~cm}^{-3}$. A characteristic dry season size spectrum is illustrated in Fig. 27, which shows increased particle concentrations across the entire size range. Typically, the accumulation mode (maximum at $\sim 140 \mathrm{~nm}$ ) shows the highest relative increase and therefore partly "swamps" the Aitken mode (shoulder at $\sim 70 \mathrm{~nm}$ ).

Besides the Aitken and accumulation modes, which dominate the total aerosol number concentration, a persistent coarse mode is observed at about $3 \mu \mathrm{m}$, which accounts for a significant fraction of the total aerosol mass (Fig. 27). The coarse mode peak occurs throughout the year, with higher abundance in the dry season. In the absence of long-range transport, primary biological aerosol particles (PBAP) are assumed to dominate the coarse mode (Pöschl et al., 2010; Huffman et al., 2012). 
Autofluorescence-based techniques such as the Wideband Integrated Bioaerosol Sensor, WIBS-4A) are an efficient approach to probe fluorescent biological aerosol particles (FBAP) in online measurements (Kaye et al., 2005; Healy et al., 2014). Figure 29 shows the first measurements of the FBAP number and volume size distributions from the WIBS instrument at the ATTO site. The FBAP size distributions are dominated in number by a narrow peak at $2.7 \mu \mathrm{m}$ and in volume by a broad peak from 2 to $5 \mu \mathrm{m}$ (Fig. 29). For particles larger than $1 \mu \mathrm{m}$, the mean integral FBAP number concentration is $0.22 \mathrm{~cm}^{-3}$ (40\% of the concentration of supermicron particles), and the corresponding volume concentration is calculated to be $3.0 \mu^{3} \mathrm{~cm}^{-3}(62 \%)$. The ratio of FBAP to total particles (number concentration) shows a clear size dependence, starting from $10 \%$ at $1 \mu \mathrm{m}$ and rising to a peak value $\sim 70-80 \%$ in the size range of $3-10 \mu \mathrm{m}$. These observations are consistent with FBAP measurements made with an alternative instrument (UVAPS) during the AMAZE-08 campaign at the ZF2 rainforest site north of Manaus (Pöschl et al., 2010; Huffman et al., 2012).

$\mathrm{CCN}$ size/supersaturation spectra have been measured since 2014 and are being continued. The long-term data set provides unique information on the size dependent hygroscopicity of Amazonian aerosol particles throughout the seasons. The results will complement and extend the results from previous campaigns (e.g., Gunthe et al., 2009; Rose et al., 2011; Levin et al., 2014). The measurements of CCN and other aerosol properties at the ATTO site will also be an important reference for the analysis of the results from the ACRIDICON-CHUVA aircraft campaign, which took place in central Amazonia in September 2014 (Wendisch et al., 2015).

\subsubsection{Aerosol chemical composition}

For the continuous determination of aerosol composition, an Aerosol Chemical Speciation Monitor (ACSM) was installed at the ATTO site in February 2014 with the objective of making long-term measurements. The data reported here summarize the annual cycle of aerosol concentrations and composition from May 2014 to April 2015 (Fig. 30).

During the middle of the rainy season (March to May), the aerosol concentrations at ATTO reach their annual minimum and are in relatively good agreement with previous wet season studies, including those conducted at the ZF2 site, ca. $140 \mathrm{~km}$ SW of ATTO (Chen et al., 2009; Pöschl et al., 2010; Artaxo et al., 2013). With the onset of the dry season, the shift of air mass origins to the southeast, and the transition of ATTO into the atmospheric Southern Hemisphere (Fig. 3), aerosol concentrations increase sharply and remain high until the end of December, well into the rainy season. Trajectory analyses suggest that burning in Africa may contribute significantly to pollution levels at ATTO during this part of the year. Only when the rainy conditions in the Amazon combine again with dominant air mass origins in the tropical and subtropical North Atlantic and with the waning of biomass burning in West Africa can aerosol concentrations at ATTO drop again to their seasonal lows.

The composition of the aerosol at ATTO shows surprisingly little variation throughout the year in spite of the huge change in total concentrations between seasons. Organic aerosol is always the dominant mass fraction at about $70 \%$, sulfate comprises about $10-15 \%$, followed by $\mathrm{BC}_{\mathrm{e}}(5-$ $11 \%)$, ammonium $(\sim 5 \%)$, nitrate $(\sim 4 \%)$ and chloride. Elevated concentrations of chloride were observed during a few episodes, when this species represented up to $13 \%$ of the total submicron particulate mass, which is consistent with earlier observations of long-range transport of sea salt, going back to the ABLE-2B campaign (Talbot et al., 1990).

The ionic mass balance indicates that the aerosol was approximately acid-base neutral. While sulfate is mostly in the form of ammonium sulfate, there is some indication that part of the nitrate could be present in the form of organic nitrate. This is because the ratio between the fragments $\mathrm{NO}^{+}$ and $\mathrm{NO}_{2}^{+}$(main nitrate fragments measured by the ACSM at mass-to-charge ratios 30 and 46) is expected to be large $(\sim 10)$ when this ion is in organic forms, and low (2-3) when in inorganic forms, such as ammonium nitrate (Alfarra et al., 2006; Fry et al., 2009). Large values for this ratio were often observed during this period and may indicate the presence of organic nitrate.

The bulk composition of $\mathrm{PM}_{2.5}$ was measured for up to 10 elements by EDXRF analysis on a set of samples obtained in March/April 2012. The analysis showed a high abundance of crustal elements, illustrating one exemplary episode of longrange dust transport from Africa (Fig. 31). Back trajectories indicate that this period was indeed influenced by dust transport from Africa, which is a phenomenon observed annually and particularly pronounced in February, March, and April (Prospero et al., 1981; Swap et al., 1992; Ben-Ami et al., 2012). Local sources of mineral dust aerosol can be excluded, especially during the wet season, because of the wetness of the soils. The prevalence of mineral dust aerosols during the wet season, when airmass trajectories reach from the North African deserts to the Amazon Basin, in combination with observations of transatlantic dust plumes by lidar, is strong evidence for the long-range origin of the observed crustal elements.

To explore the bioavailability of important trace elements, the oxidation state and solubility of iron $(\mathrm{Fe})$ in the $\mathrm{PM}_{2.5}$ aerosols were analyzed. The soluble (and therefore bioavailable) fraction of $\mathrm{Fe}$ is an important parameter in the overall biogeochemical cycles, with impact on the phosphorus cycle and biomass production (Liptzin and Silver, 2009). A soluble fraction of only $1.5 \%\left(1.8 \mathrm{ng} \mathrm{m}^{-3} \mathrm{Fe}\right.$ (III) of $120 \mathrm{ng} \mathrm{m}^{-3}$ of total $\mathrm{Fe}$ ) was found, suggesting that aeolian transport of $\mathrm{Fe}$ is not likely to make a significant contribution of bioavailable Fe to the ecosystem at ATTO.

The extended measurements of aerosol composition at the ATTO site, now reaching well over a full year, suggest 


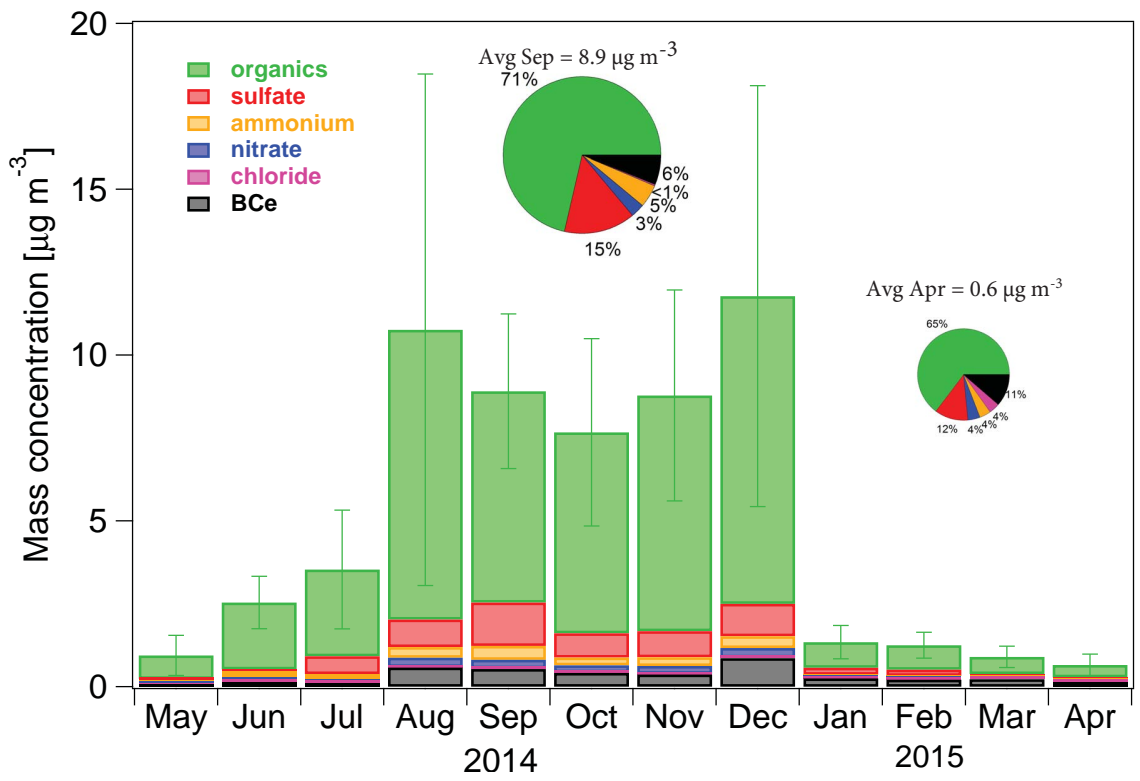

Figure 30. Time series of monthly mean aerosol mass concentrations and chemical speciation at the ATTO site, measured by ACSM from May 2014 to April 2015.
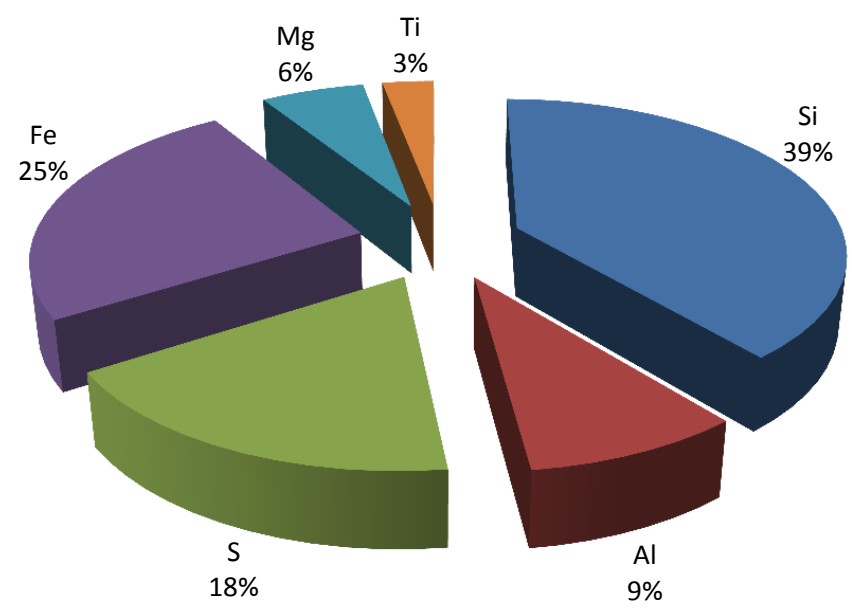

Figure 31. Average bulk elemental concentrations (in weightpercent) of $\mathrm{PM}_{2.5}$ aerosols collected at $80 \mathrm{~m}$ height between 7 March and 21 April 2012.

the need for a reassessment of the relative contributions of biogenic and anthropogenic sources even in this very remote region. Black carbon, a unique tracer of combustion, is present in a roughly equal fraction throughout the year. Sulfate, which has a more complex mixture of sources, also contributes a fairly constant fraction. In the rainy season, much of this sulfate could come from biogenic or marine sources (Andreae et al., 1990), but the high concentrations during the August to December period suggest substantial contributions from fossil fuel burning. Periods with aerosol compositions suggesting pristine conditions (low $\mathrm{BC}_{\mathrm{e}}$ and sulfate, dominant organic matter) occur more as episodes at ATTO than as seasonal characteristics, similar to what is observed at the remote ZOTTO site in Siberia (Chi et al., 2013).

\subsubsection{Microspectroscopic analysis of single aerosol particles}

The microspectroscopic analysis of aerosol samples can be seen as a "snapshot" of the aerosol population at a given time. In combination with the long-term aerosol measurements at the ATTO site, single particle characterization provides detailed insights into the highly variable aerosol cycling in the rain forest ecosystem. In the soft X-ray regime, STXMNEXAFS is a powerful microscopic tool with high spectroscopic sensitivity for the light elements carbon (C), nitrogen $(\mathrm{N})$, and oxygen $(\mathrm{O})$ as well as a variety of other atmospherically relevant elements (e.g., K, Ca, Fe, S, and Na). The technique allows analyzing the microstructure, mixing state, and the chemical composition of individual aerosol particles. As an example, Fig. 32 displays the STXM-NEXAFS analysis of an aerosol sample with substantial anthropogenic pollution, collected at the ATTO site during the dry season. X-ray microspectroscopy reveals a substantial fraction of internally mixed particles with soot cores (strong $\pi$-bond signals) and organic coatings of variable thickness. The spectral signature of the organic coating is characteristic for secondary organic material (SOM) (Pöhlker et al., 2014). These observations underline the dominance of aged pyrogenic aerosols at the ATTO site during the dry season. During the rainy season, when biomass burning is absent and undisturbed biosphereatmosphere interactions prevail in the region, the aerosol population is dominated by biogenic aerosol, such as primary biological aerosol particles (PBAP), biogenic SOA, and bio- 
a) Carbon post-edge image

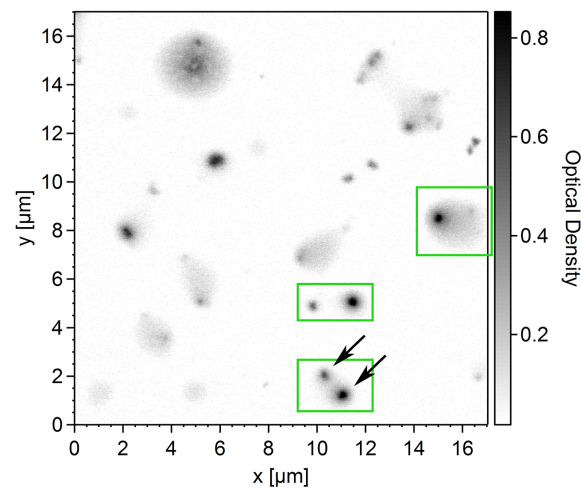

b) Carbon map

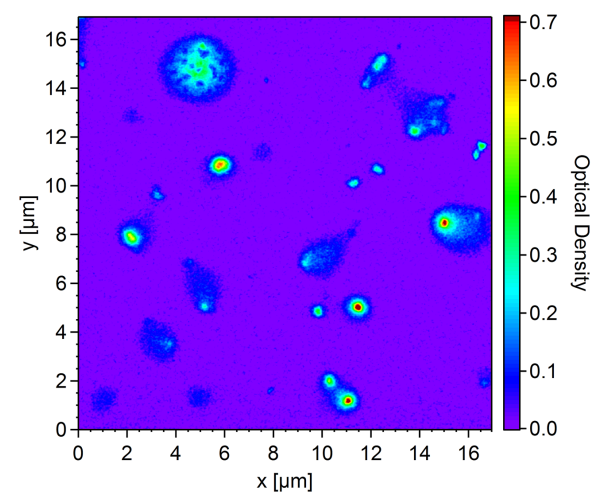

c) NEXAFS spectra

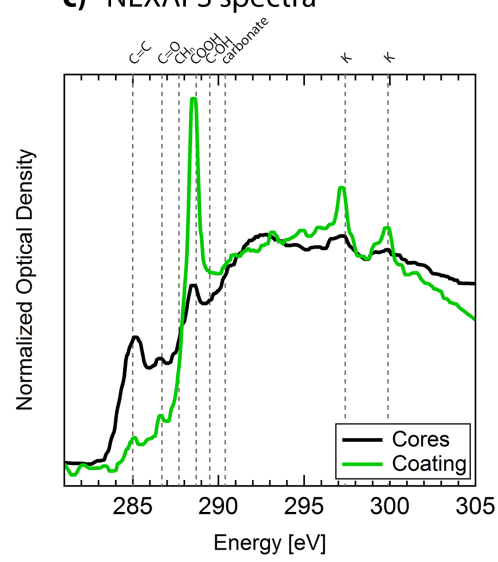

Figure 32. STXM images and elemental maps with corresponding NEXAFS spectra of aerosol particles collected at the ATTO site during a period with anthropogenic pollution. (a) Carbon post-edge image $(293 \mathrm{eV})$ of a characteristic region showing internally mixed droplet-like particles with cores (black arrows) and coatings of variable thickness (green boxes). (b) Carbon elemental map (pre-edge $280 \mathrm{eV}$, post-edge $293 \mathrm{eV}$ ) showing the distribution of carbonaceous material. (c) NEXAFS spectra showing high abundance of pi- $(\mathrm{C}=\mathrm{C})$ and keto $(\mathrm{O}=\mathrm{C})$ functional groups in cores. Coating reveals high abundance of carboxylic acid groups $(\mathrm{CCOH})$ and weaker signals for keto and pi groups.

genic salts (Pöhlker et al., 2012). Figure 33 displays STXM elemental maps of this typical rainy season aerosol population.

As mentioned in the previous section, the biogenic background aerosol in the wet season (i.e., February to April) is episodically superimposed by transatlantic dust and smoke events. Statistical analysis of the electron microscope (EPMA) results by hierarchical clustering reveals the abundance of the various particle types observed at the ATTO tower in this season (Table 8). In order to determine the sources and possible chemical interactions, particles were classified into representative groups according to their chemical composition. They are classified as "mineral" when Al, $\mathrm{Si}, \mathrm{O}$, and $\mathrm{Ca}$ are dominant, and also contain minor elements like $\mathrm{K}, \mathrm{Na}, \mathrm{Mg}$, and $\mathrm{Fe}$. Particles are identified as being "organic", when the concentrations of $\mathrm{C}$ and $\mathrm{O}$ in the particles are similar and when they also contain some $\mathrm{P}$ and $\mathrm{S}(<10 \mathrm{wt} \%)$. "Biogenic" particles occur in the larger size classes; they have smooth boundaries and always contain C, $\mathrm{O}, \mathrm{S}, \mathrm{N}, \mathrm{P}$, and $\mathrm{K}$. Irregular crystallized particles with $\mathrm{Na}$, $\mathrm{Mg}, \mathrm{S}, \mathrm{O}$ and $\mathrm{C}$ are classified as "salt" particles. Soot particles can be distinguished by their morphology, and always contain the elements $\mathrm{C}$ and $\mathrm{O}$.

With single particle analysis, important information was obtained concerning the contribution from organic aerosol particles and the agglomeration of various types of particles. The majority of particles in the fine fraction consist of organic matter with traces of $\mathrm{S}$ and $\mathrm{K}$. This observation corroborates that small biogenic potassium and sulfur-containing particles from primary emissions can act as seeds for the condensation of organic material (Pöhlker et al., 2012).

\subsubsection{Chemical composition of secondary organic aerosol}

Measurements of the organic chemical composition of the aerosol over the Amazon rainforest are rare. Levoglucosan, several mono- di- and polycarboxylic acids, as well as isoprene tracer compounds have been identified in the aerosol phase (Mayol-Bracero et al., 2002; Claeys et al., 2004, 2010; Schkolnik et al., 2005), whereas the contribution of highly reactive compounds, such as monoterpenes and sesquiterpenes, to SOA in this region is still largely unknown.

The concentrations of monoterpene and sesquiterpene oxidation products in ambient aerosol collected in November 2012 at the ATTO research site are shown in Fig. 34. A median concentration of $102 \mathrm{ng} \mathrm{m}^{-3}$ was measured for the sum of terpene oxidation products in the aerosol sampled over the Amazon rain forest. As can be seen in Fig. 34, monoterpene oxidation products accounted for the major part of the terpene oxidation products. Their concentration showed a high variance during November ranging between 23 and $146 \mathrm{ng} \mathrm{m}^{-3}$. The oxidation products derived from the pinene skeleton ( $\alpha$ - and $\beta$-pinene) were most abundant in the sampled aerosols, followed by limonene oxidation products. Among the pinene derived oxidation products, MBTCA (3-methyl-1,2,3-butanetricarboxylic acid) was observed to be the most abundant individual monoterpene oxidation product, with concentrations of up to $73 \mathrm{ng} \mathrm{m}^{-3}$, followed by pinonic acid with a maximum concentration of $46 \mathrm{ng} \mathrm{m}^{-3}$ (van Eijck, 2013). Interestingly, these concentrations are in the same range as monoterpene oxidation products measured during summertime in boreal forest environments (Vestenius et al., 2014), ecosystems which are known to strongly emit monoterpenes. However, these observations of high monoter- 
a) SEM image

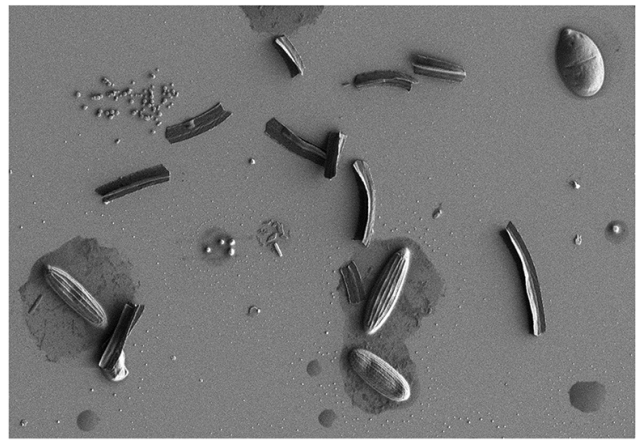

c) STXM carbon map

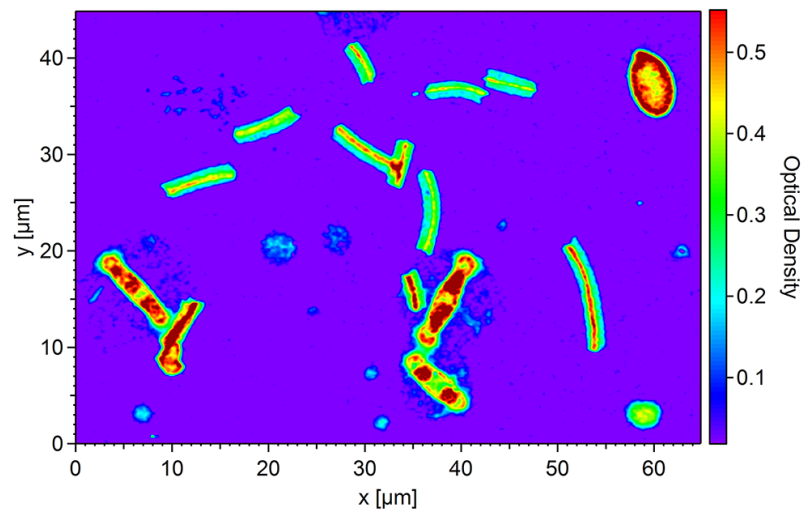

e) STXM nitrogen map

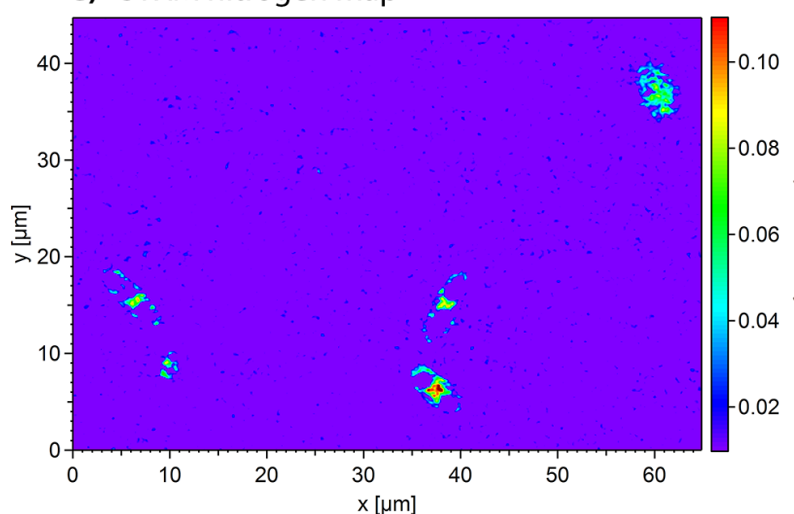

b) STXM carbon post-edge image

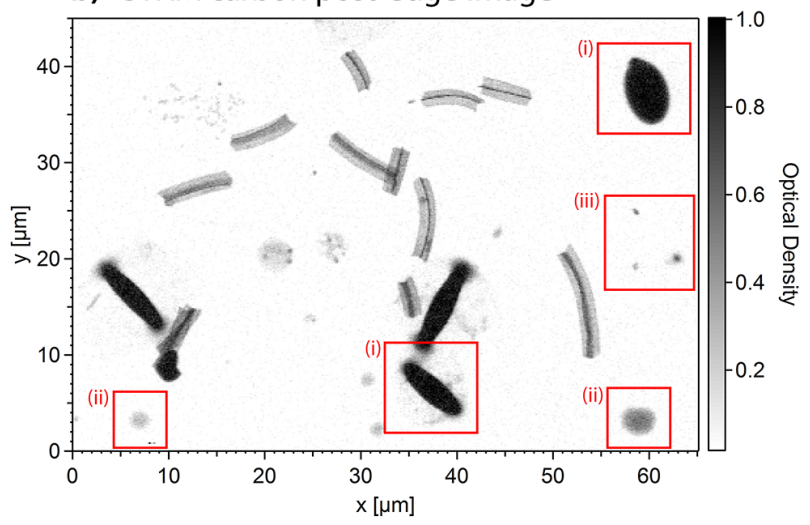

d) STXM potassium map

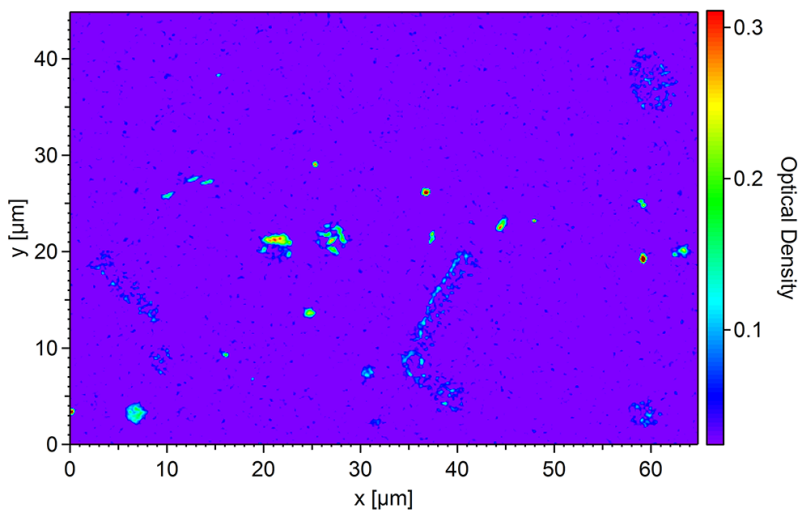

f) STXM oxygen map

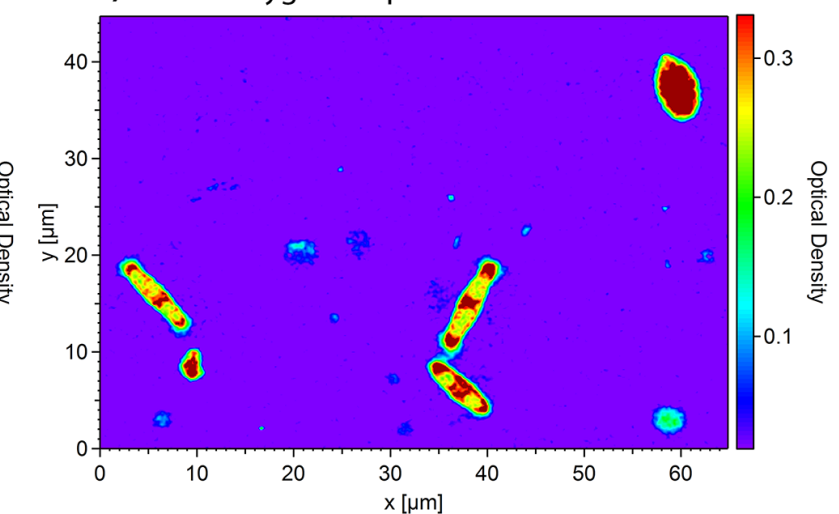

Figure 33. Microscopic images of aerosol particles during rainy season. (a) SEM images of representative region. (b) STXM carbon postedge image $(293 \mathrm{eV})$ and $(\mathbf{c - f})$ STXM elemental maps of same region. The particle types are indicated in panel (b): primary biological aerosol particles (region i), droplet-like SOA particles (region ii), and potassium-rich biogenic salts (region iii).

pene product concentrations match with the high monoterpene mixing ratios measured at the same site (Yáñez-Serrano et al., 2015).

The products from sesquiterpene oxidation showed much lower concentrations (Fig. 34). On average the sesquiterpene oxidation products reached about $10 \%$ of the monoterpene oxidation product concentration; however, on some days they were as high as $26 \%$ of the total monoterpene oxidation product concentration. Overall, 23 individual ox- idation products of sesquiterpenes were identified in the aerosol collected in the Amazonian rainforest. The total concentration of these sesquiterpene oxidation products ranged from 6 to $12 \mathrm{ng} \mathrm{m}^{-3}$. The oxidation products could be assigned to four sesquiterpene precursors: $\beta$-caryophyllene, aromadendrene, cedrene, and isolongifolene. Among them, the products from the oxidation of $\beta$-caryophyllene were the most abundant (van Eijck, 2013). Very few measurements exist of sesquiterpene oxidation product concentra- 
Table 7. Summary of aerosol optical parameters for the dry and wet seasons. Average and standard deviations are calculated from 60 min data.

\begin{tabular}{|c|c|c|c|c|c|}
\hline & & \multicolumn{2}{|c|}{ Dry season } & \multicolumn{2}{|c|}{ Wet season } \\
\hline & & Mean & SD & Mean & SD \\
\hline \multirow{3}{*}{ Scattering coefficient $\left(\sigma_{\mathrm{s}}, \mathrm{Mm}^{-1}\right)$} & $450 \mathrm{~nm}$ & 31 & 15 & 8.0 & 7.4 \\
\hline & $550 \mathrm{~nm}$ & 23 & 11 & 6.4 & 6.5 \\
\hline & $700 \mathrm{~nm}$ & 15 & 8 & 4.8 & 5.3 \\
\hline Scattering Ångström exponent $\left(a_{\mathrm{s}}\right)$ & $450 / 700$ & 1.62 & 0.26 & 1.25 & 0.71 \\
\hline Absorption coefficient $\left(\sigma_{\mathrm{a}}, \mathrm{Mm}^{-1}\right)$ & $637 \mathrm{~nm}$ & 3.46 & 2.32 & 0.52 & 1.25 \\
\hline Absorption Ångström exponent $\left(\stackrel{a}{a}_{a}\right)$ & $470 / 960$ & $1.40^{\mathrm{a}}$ & 0.26 & $1.53^{\mathrm{a}}$ & 0.36 \\
\hline Mass absorption cross-section $\left(\alpha_{\mathrm{a}}, \mathrm{m}^{2} \mathrm{~g}^{-1}\right)$ & $637 \mathrm{~nm}$ & & & $13.5^{\mathrm{b}}$ & \\
\hline
\end{tabular}

Table 8. Relative abundance of single particle types obtained at top of the walk-up tower in April 2012 (in percent).

\begin{tabular}{rrrrrrrr}
\hline $\begin{array}{r}\text { Date } \\
\text { April 2012 }\end{array}$ & $\begin{array}{r}\text { Size fraction } \\
(\mu \mathrm{m})\end{array}$ & Organic & $\begin{array}{r}\text { Organic } \\
\text { with S, K }\end{array}$ & Mineral & Biogenic & Salts & Soot \\
\hline 1 & $0.2-0.5$ & 70 & 13 & 17 & 0 & 0 & 0 \\
& $0.5-1.0$ & 0 & 27 & 71 & 1.2 & 0 & 0 \\
& $1.0-2.0$ & 24 & 28 & 47 & 1.7 & 0 & 0 \\
\hline 16 & $0.25-0.5$ & 42 & 58 & 0 & 0 & 0 & 0 \\
& $0.5-1.0$ & 60 & 32 & 8 & 0 & 0 & 0 \\
& $1.0-2.0$ & 50 & 5.3 & 16 & 13 & 16 & 0 \\
\hline \multirow{2}{*}{17} & $0.25-0.5$ & 82 & 6.1 & 3 & 9.1 & 0 & 0 \\
& $0.5-1.0$ & 37 & 27 & 6.7 & 17 & 13 & 0 \\
& $1.0-2.0$ & 0 & 79 & 21 & 0 & 0 & 0 \\
\hline 18 & $0.25-0.5$ & 72 & 28 & 0 & 0 & 0 & 0 \\
& $0.5-1.0$ & 41 & 36 & 21 & 2.4 & 0 & 0 \\
& $1.0-2.0$ & 34 & 31 & 17 & 5.7 & 0 & 11 \\
\hline
\end{tabular}

tions and actually none in tropical forests, which complicates a comparison. Measurements in boreal ecosystems (Vestenius et al., 2014) showed mean summertime concentrations of caryophyllinic acid (one of the $\beta$-caryophyllene oxidation products) of about $8 \mathrm{ng} \mathrm{m}^{-3}$, which is a high concentration for a single compound compared to the concentrations measured at ATTO, where the measured concentration range of caryophyllinic acid is $0.26-1.38 \mathrm{ng} \mathrm{m}^{-3}$.

In summary, the contribution of monoterpene oxidation products to SOA at ATTO is relatively high and essentially comparable with their contribution to boreal forest SOA, whereas the contribution of sesquiterpene products is much less (about 1/10) than in boreal forest ecosystems.

\section{Summary and future outlook}

Our initial ecological studies have shown the ATTO site to be located in an area of high biodiversity, containing forest and wetland ecosystems that are representative of many regions in the central Amazon Basin. The meteorological measurements reflect rainfall, temperature, and wind conditions typical of the region, with pronounced seasonality in rainfall and airmass origins, but they also show substantial interannual variability. Early micrometeorological studies have characterized the nocturnal boundary layer and its coupling with the overlying atmosphere, the properties of turbulence structures in the boundary layer, and the formation of orographically induced gravity waves.

Continuous measurements of the carbon gases $\mathrm{CO}_{2}, \mathrm{CO}$, and $\mathrm{CH}_{4}$ at five heights reveal the effects of photosynthesis and respiration on the vertical distribution of $\mathrm{CO}_{2}$, the presence of a source of $\mathrm{CO}$ at the forest floor, and yet unidenti- 


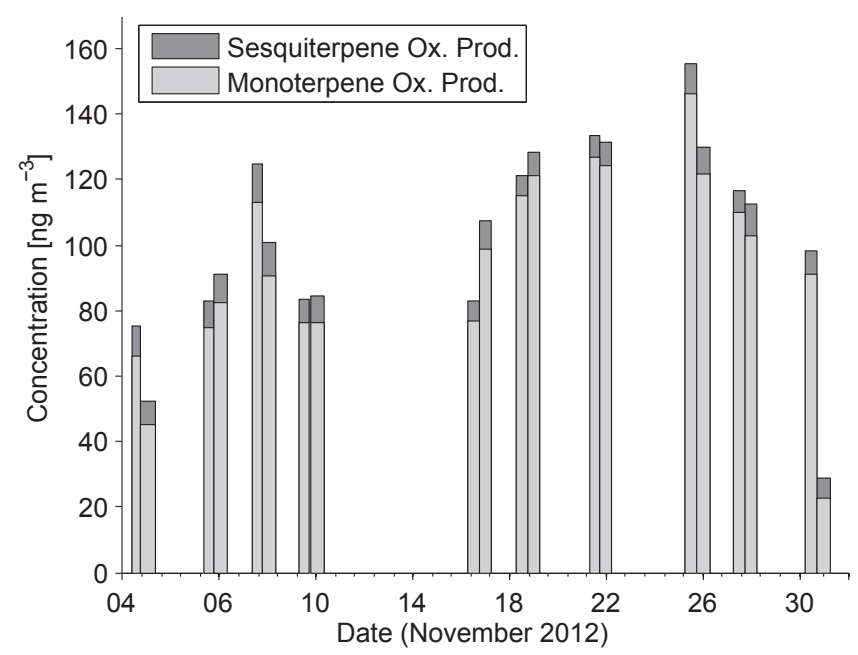

Figure 34. Concentration of monoterpene and sesquiterpene oxidation products in ambient aerosol collected in November 2012 over the Amazon rain forest.

fied intensive and episodic sources of $\mathrm{CH}_{4}$. Ozone, $\mathrm{VOC}$, and $\mathrm{OH}$ reactivity measurements indicate an active photochemical cycle in the tropical boundary layer and a strong forest sink for ozone.

The Amazonian aerosol is strongly influenced by seasonal variations in airmass origins. In the rainy season, when air masses come from the northeast across almost undisturbed rain forest, there are long periods when natural, biogenic aerosols prevail, characterized by low particle number concentrations and a very large fraction of organic matter. In spite of considerable research efforts, the mode of formation of these aerosols remains enigmatic. Nucleation and new particle formation events are almost never observed in clean air over Amazonia. The deployment of instrumentation that explores the size range at the border between gases and particles, and the measurement of species that are involved in the formation and growth of aerosol particles, such as $\mathrm{H}_{2} \mathrm{SO}_{4}$, extremely low volatility organic compounds (ELVOCs), ammonia, and amines may shed light on the processes responsible for the formation of biogenic aerosols over the tropical forest (Kulmala et al., 2014).

During the rainy season, the biogenic aerosol over Amazonia is overprinted periodically by episodes of intense transatlantic transport, which bring Saharan dust, smoke from fires in West Africa, Atlantic marine aerosols, and possibly pollution from fossil fuel burning in Africa, Europe, and North America to the site. In contrast, during the dry season the dominant airmass source regions lie to the east and southeast, where biomass and fossil fuel combustion result in persistent and substantial production of pollution aerosols.

Overall, our measurements at ATTO support the view that there is no longer any place on Earth that can be considered truly pristine. Even at this remote site, trace gas and aerosol concentrations show the impact of anthropogenic emissions.
For long-lived species, like $\mathrm{CO}_{2}$ and $\mathrm{CH}_{4}$, this reflects the secular increase in concentrations as a result of global emissions. For shorter-lived trace gases and aerosols, the effects of regional sources and long range transport can be detected almost at all times, even though they may be very small during the cleanest periods.

During 2015, we expect that many measurements will be relocated from the $80 \mathrm{~m}$ towers to the $325 \mathrm{~m}$ tall tower. This will significantly enlarge the footprint of the measurements of long-lived trace gases, especially $\mathrm{CO}_{2}$. Integration of ATTO into networks for the study of carbon cycling, such as the proposed long-term, pantropical network that assesses NPP using multiple approaches (Cleveland et al., 2015) could significantly increase the knowledge that can be gained from this site. The challenge for the future will be to maintain these measurements over the coming decades so that they can reveal secular trends in atmospheric composition and the health of the Amazonian ecosystem.

Acknowledgements. We thank the Max Planck Society and the Instituto Nacional de Pesquisas da Amazonia for continuous support. We acknowledge the support by the German Federal Ministry of Education and Research (BMBF contract 01LB1001A) and the Brazilian Ministério da Ciência, Tecnologia e Inovação (MCTI/FINEP contract 01.11.01248.00) as well as the Amazon State University (UEA), FAPEAM, LBA/INPA and SDS/CEUC/RDS-Uatumã. Leonardo Sá thanks CNPq for his Productivity in Research Grant, Process 303728/2010-8. Cléo Dias-Júnior thanks CAPES for his Ph.D. grant. Maria Teresa F. Piedade thanks CNPq and FAPEAM for research grants (PELDProject, Process 403792/2012-6). The ALS is supported by the Director, Office of Science, Office of Basic Energy Sciences, of the US Department of Energy under Contract DE-AC02-05CH11231. We thank the Helmholtz-Zentrum Berlin for the allocation of synchrotron radiation beamtime at BESSY II. We also thank M. Weigand, M. Bechtel, and A. L. D. Kilcoyne for their constant support during the beamtime sessions. We would like to especially thank all the people involved in the technical and logistical support of the ATTO project, in particular Thomas Disper, Andrew Crozier, Uwe Schulz, Steffen Schmidt, Alcides Camargo Ribeiro, Hermes Braga Xavier, Elton Mendes da Silva, Nagib Alberto de Castro Souza, Adi Vasconcelos Brandão, Amauri Rodriguês Perreira, Thiago de Lima Xavier, Josué Ferreira de Souza, Roberta Pereira de Souza, and Wallace Rabelo Costa. We acknowledge the micrometeorological group of INPA/LBA for their collaboration concerning the meteorological parameters, with special thanks to Antonio Huxley Melo Nascimento and Leonardo Ramos de Oliveira. The aerosol team thanks Isabella Hrabe de Angelis and Sachin S. Gunthe for their help with instrument maintenance and I. Lieberwirth and G. Glaßer (Max Planck Institute for Polymer Research, Mainz, Germany) for kind support with SEM imaging. We thank Tracey W. Andreae for help with copy-editing the manuscript. This paper contains results of research conducted under the Technical/Scientific Cooperation Agreement between the National Institute for Amazonian Research, the State University of Amazonas, and the Max-Planck-Gesellschaft e.V.; the opinions expressed are the entire responsibility of the authors and not of the 
participating institutions.

The article processing charges for this open-access publication were covered by the Max Planck Society.

Edited by: M. Kulmala

\section{References}

Abril, G., Martinez, J. M., Artigas, L. F., Moreira-Turcq, P., Benedetti, M. F., Vidal, L., Meziane, T., Kim, J. H., Bernardes, M. C., Savoye, N., Deborde, J., Souza, E. L., Alberic, P., de Souza, M. F. L., and Roland, F.: Amazon River carbon dioxide outgassing fuelled by wetlands, Nature, 505, 395-398, doi:10.1038/nature12797, 2014.

Acevedo, O. C., Costa, F. D., Oliveira, P. E. S., Puhales, F. S., Degrazia, G. A., and Roberti, D. R.: The influence of submeso processes on stable boundary layer similarity relationships, J. Atmos. Sci., 71, 207-225, doi:10.1175/jas-d-13-0131.1, 2014.

Alfarra, M. R., Paulsen, D., Gysel, M., Garforth, A. A., Dommen, J., Prévôt, A. S. H., Worsnop, D. R., Baltensperger, U., and Coe, H.: A mass spectrometric study of secondary organic aerosols formed from the photooxidation of anthropogenic and biogenic precursors in a reaction chamber, Atmos. Chem. Phys., 6, 52795293, doi:10.5194/acp-6-5279-2006, 2006.

Allan, J. D., Delia, A. E., Coe, H., Bower, K. N., Alfarra, M. R., Jimenez, J. L., Middlebrook, A. M., Drewnick, F., Onasch, T. B., Canagaratna, M. R., Jayne, J. T., and Worsnop, D. R.: A generalised method for the extraction of chemically resolved mass spectra from aerodyne aerosol mass spectrometer data, J. Aerosol Sci., 35, 909-922, doi:10.1016/j.jaerosci.2004.02.007, 2004.

Anderson, T. L. and Ogren, J. A.: Determining aerosol radiative properties using the TSI 3563 integrating nephelometer, Aerosol Sci. Tech., 29, 57-69, 1998.

Anderson, T. L., Covert, D. S., Marshall, S. F., Laucks, M. L., Charlson, R. J., Waggoner, A. P., Ogren, J. A., Caldow, R., Holm, R. L., Quant, F. R., Sem, G. J., Wiedensohler, A., Ahlquist, N. A., and Bates, T. S.: Performance characteristics of a high-sensitivity, three- wavelength, total scatter/backscatter nephelometer, J. Atmos. Ocean. Technol., 13, 967-986, 1996.

Andreae, M. O.: The Biosphere: Pilot or Passenger on Spaceship Earth?, in: Contributions to Global Change Research, edited by: Heinen, D., Hoch, S., Krafft, T., Moss, C., Scheidt, P., and Welschhoff, A., German National Committee on Global Change Research, Bonn, 59-66, 2001.

Andreae, M. O.: Correlation between cloud condensation nuclei concentration and aerosol optical thickness in remote and polluted regions, Atmos. Chem. Phys., 9, 543-556, doi:10.5194/acp-9-543-2009, 2009.

Andreae, M. O. and Gelencsér, A.: Black carbon or brown carbon? The nature of light-absorbing carbonaceous aerosols, Atmos. Chem. Phys., 6, 3131-3148, doi:10.5194/acp-6-3131-2006, 2006.

Andreae, M. O., Berresheim, H., Bingemer, H., Jacob, D. J., Lewis, B. L., Li, S.-M., and Talbot, R. W.: The atmospheric sulfur cycle over the Amazon Basin, 2. Wet Season, J. Geophys. Res., 95, 16813-16824, 1990.
Andreae, M. O., Artaxo, P., Brandão, C., Carswell, F. E., Ciccioli, P., da Costa, A. L., Culf, A. D., Esteves, J. L., Gash, J. H. C., Grace, J., Kabat, P., Lelieveld, J., Malhi, Y., Manzi, A. O., Meixner, F. X., Nobre, A. D., Nobre, C., Ruivo, M. d. L. P., Silva-Dias, M. A., Stefani, P., Valentini, R., von Jouanne, J., and Waterloo, M. J.: Biogeochemical cycling of carbon, water, energy, trace gases and aerosols in Amazonia: The LBA-EUSTACH experiments, J. Geophys. Res., 107, 8066, doi:10.1029/2001JD000524, 2002.

Andreae, M. O., Rosenfeld, D., Artaxo, P., Costa, A. A., Frank, G. P., Longo, K. M., and Silva-Dias, M. A. F.: Smoking rain clouds over the Amazon, Science, 303, 1337-1342, 2004.

Andreae, M. O., Artaxo, P., Beck, V., Bela, M., Freitas, S., Gerbig, C., Longo, K., Munger, J. W., Wiedemann, K. T., and Wofsy, S. C.: Carbon monoxide and related trace gases and aerosols over the Amazon Basin during the wet and dry seasons, Atmos. Chem. Phys., 12, 6041-6065, doi:10.5194/acp-12-6041-2012, 2012.

Andrews, A. E., Kofler, J. D., Trudeau, M. E., Williams, J. C., Neff, D. H., Masarie, K. A., Chao, D. Y., Kitzis, D. R., Novelli, P. C., Zhao, C. L., Dlugokencky, E. J., Lang, P. M., Crotwell, M. J., Fischer, M. L., Parker, M. J., Lee, J. T., Baumann, D. D., Desai, A. R., Stanier, C. O., De Wekker, S. F. J., Wolfe, D. E., Munger, J. W., and Tans, P. P.: $\mathrm{CO}_{2}, \mathrm{CO}$, and $\mathrm{CH}_{4}$ measurements from tall towers in the NOAA Earth System Research Laboratory's Global Greenhouse Gas Reference Network: instrumentation, uncertainty analysis, and recommendations for future high-accuracy greenhouse gas monitoring efforts, Atmos. Meas. Tech., 7, 647-687, doi:10.5194/amt-7-647-2014, 2014.

Ansmann, A., Baars, H., Tesche, M., Muller, D., Althausen, D., Engelmann, R., Pauliquevis, T., and Artaxo, P.: Dust and smoke transport from Africa to South America: Lidar profiling over Cape Verde and the Amazon rainforest, Geophys. Res. Lett., 36, L11802, doi:10.1029/2009GL037923, 2009.

Artaxo, P., Martins, J. V., Yamasoe, M. A., Procópio, A. S., Pauliquevis, T. M., Andreae, M. O., Guyon, P., Gatti, L. V., and Leal, A. M. C.: Physical and chemical properties of aerosols in the wet and dry season in Rondonia, Amazonia, J. Geophys. Res., 107, 8081, doi:10.1029/2001JD000666, 2002.

Artaxo, P., Rizzo, L. V., Brito, J. F., Barbosa, H. M. J., Arana, A., Sena, E. T., Cirino, G. G., Bastos, W., Martin, S. T., and Andreae, M. O.: Atmospheric aerosols in Amazonia and land use change: from natural biogenic to biomass burning conditions, Faraday Discuss., 165, 203-235, doi:10.1039/C3FD00052D, 2013.

Aubinet, M., Grelle, A., Ibrom, A., Rannik, U., Moncrieff, J., Foken, T., Kowalski, A. S., Martin, P. H., Berbigier, P., Bernhofer, C., Clement, R., Elbers, J., Granier, A., Grunwald, T., Morgenstern, K., Pilegaard, K., Rebmann, C., Snijders, W., Valentini, R., and Vesala, T.: Estimates of the annual net carbon and water exchange of forests: The EUROFLUX methodology, Adv. Ecol. Res., 30, 113-175, 2000.

Baars, H., Ansmann, A., Althausen, D., Engelmann, R., Artaxo, P., Pauliquevis, T., and Souza, R.: Further evidence for significant smoke transport from Africa to Amazonia, Geophys. Res. Lett., 38, L20802, doi:10.1029/2011GL049200, 2011.

Baccini, A., Goetz, S. J., Walker, W. S., Laporte, N. T., Sun, M., Sulla-Menashe, D., Hackler, J., Beck, P. S. A., Dubayah, R., Friedl, M. A., Samanta, S., and Houghton, R. A.: Estimated carbon dioxide emissions from tropical deforestation improved by carbon-density maps, Nature Climate Change, 2, 182-185, doi:10.1038/nclimate1354, 2012. 
Bakwin, P. S., Tans, P. P., Hurst, D. F., and Zhao, C. L., Measurements of carbon dioxide on very tall towers: results of the NOAA/CMDL program: Tellus Ser. B, 50, 401-415, 1998.

Balch, J. K.: Drought and fire change sink to source, Nature, 506, 41-42, doi:10.1038/506041a, 2014.

Baldocchi, D. D.: Assessing the eddy covariance technique for evaluating carbon dioxide exchange rates of ecosystems: past, present and future, Global Change Biol., 9, 479-492, doi:10.1046/j.1365-2486.2003.00629.x, 2003.

Beck, V., Chen, H., Gerbig, C., Bergamaschi, P., Bruhwiler, L., Houweling, S., Röckmann, T., Kolle, O., Steinbach, J., Koch, T., Sapart, C. J., van der Veen, C., Frankenberg, C., Andreae, M. O., Artaxo, P., Longo, K. M., and Wofsy, S. C.: Methane airborne measurements and comparison to global models during BARCA, J. Geophys. Res., 117, D15310, doi:10.1029/2011JD017345, 2012.

Ben-Ami, Y., Koren, I., Rudich, Y., Artaxo, P., Martin, S. T., and Andreae, M. O.: Transport of North African dust from the Bodélé depression to the Amazon Basin: a case study, Atmos. Chem. Phys., 10, 7533-7544, doi:10.5194/acp-10-7533-2010, 2010.

Ben-Ami, Y., Koren, I., Altaratz, O., Kostinski, A., and Lehahn, Y.: Discernible rhythm in the spatio/temporal distributions of transatlantic dust, Atmos. Chem. Phys., 12, 2253-2262, doi:10.5194/acp-12-2253-2012, 2012.

Betts, A. K., Fisch, G., von Randow, C., Dias, M. A. F. S., Cohen, J. C. P., da Silva, R., and Fitzjarrald, D. R.: The Amazonian boundary layer and mesoscale circulations, in: $t$ Amazonia and Global Change, edited by: Keller, M., Bustamante, M., Gash, J., and Dias, P., American Geophysical Union, Washington, DC, 163-181, 2009.

Bevan, S. L., North, P. R. J., Grey, W. M. F., Los, S. O., and Plummer, S. E.: Impact of atmospheric aerosol from biomass burning on Amazon dry-season drought, J. Geophys. Res., 114, D09204, doi:10.1029/2008jd011112, 2009.

Boisier, J. P., Ciais, P., Ducharne, A., and Guimberteau, M.: Projected strengthening of Amazonian dry season by constrained climate model simulations, Nature Climate Change, 5, 656-660, doi:10.1038/nclimate2658, 2015.

Bond, T. C., Bussemer, M., Wehner, B., Keller, S., Charlson, R. J., and Heintzenberg, J.: Light absorption by primary particle emissions from a lignite burning plant, Environ. Sci. Technol., 33, 3887-3891, 1999.

Bond, T. C., Covert, D. S., and Müller, T.: Truncation and angular-scattering corrections for absorbing aerosol in the TSI 3563 nephelometer, Aerosol Sci. Tech., 43, 866-871, doi:10.1080/02786820902998373, 2009.

Bou-Zeid, E., Meneveau, C., and Parlange, M. B.: Large-eddy simulation of neutral atmospheric boundary layer flow over heterogeneous surfaces: Blending height and effective surface roughness, Water Resour. Res., 40, W02505, doi:10.1029/2003wr002475, 2004.

Brienen, R. J. W., Phillips, O. L., Feldpausch, T. R., Gloor, E., Baker, T. R., Lloyd, J., Lopez-Gonzalez, G., MonteagudoMendoza, A., Malhi, Y., Lewis, S. L., Vasquez Martinez, R., Alexiades, M., Alvarez Davila, E., Alvarez-Loayza, P., Andrade, A., Aragao, L. E. O. C., Araujo-Murakami, A., Arets, E. J. M. M., Arroyo, L., Aymard C., G. A., Banki, O. S., Baraloto, C., Barroso, J., Bonal, D., Boot, R. G. A., Camargo, J. L. C., Castilho, C. V., Chama, V., Chao, K. J., Chave, J., Comiskey, J. A., Cornejo
Valverde, F., da Costa, L., de Oliveira, E. A., Di Fiore, A., Erwin, T. L., Fauset, S., Forsthofer, M., Galbraith, D. R., Grahame, E. S., Groot, N., Herault, B., Higuchi, N., Honorio Coronado, E. N., Keeling, H., Killeen, T. J., Laurance, W. F., Laurance, S., Licona, J., Magnussen, W. E., Marimon, B. S., Marimon-Junior, B. H., Mendoza, C., Neill, D. A., Nogueira, E. M., Nunez, P., Pallqui Camacho, N. C., Parada, A., Pardo-Molina, G., Peacock, J., Pena-Claros, M., Pickavance, G. C., Pitman, N. C. A., Poorter, L., Prieto, A., Quesada, C. A., Ramirez, F., Ramirez-Angulo, H., Restrepo, Z., Roopsind, A., Rudas, A., Salomao, R. P., Schwarz, M., Silva, N., Silva-Espejo, J. E., Silveira, M., Stropp, J., Talbot, J., ter Steege, H., Teran-Aguilar, J., Terborgh, J., ThomasCaesar, R., Toledo, M., Torello-Raventos, M., Umetsu, R. K., van der Heijden, G. M. F., van der Hout, P., Guimaraes Vieira, I. C., Vieira, S. A., Vilanova, E., Vos, V. A., and Zagt, R. J.: Longterm decline of the Amazon carbon sink, Nature, 519, 344-348, doi:10.1038/nature14283, 2015.

Brown, A. R. and Wood, N.: Properties and parameterization of the stable boundary layer over moderate topography, J. Atmos. Sci., 60, 2797-2808, 2003.

Bueno, P. A., Havey, D. K., Mulholland, G. W., Hodges, J. T., Gillis, K. A., Dickerson, R. R., and Zachariah, M. R.: Photoacoustic measurements of amplification of the absorption cross section for coated soot aerosols, Aerosol Sci. Tech., 45, 1217 1230, doi:10.1080/02786826.2011.587477, 2011.

Cai, Y., Montague, D. C., Mooiweer-Bryan, W., and Deshler, T.: Performance characteristics of the ultra high sensitivity aerosol spectrometer for particles between 55 and $800 \mathrm{~nm}$ : Laboratory and field studies, J. Aerosol Sci., 39, 759-769, doi:10.1016/j.jaerosci.2008.04.007, 2008.

Campanharo, A., Ramos, F. M., Macau, E. E. N., Rosa, R. R., Bolzan, M. J. A., and Sa, L. D. A.: Searching chaos and coherent structures in the atmospheric turbulence above the Amazon forest, Phil. Trans. R. Soc. A, 366, 579-589, doi:10.1098/rsta.2007.2118, 2008.

Camponogara, G., Silva Dias, M. A. F., and Carrió, G. G.: Relationship between Amazon biomass burning aerosols and rainfall over the La Plata Basin, Atmos. Chem. Phys., 14, 4397-4407, doi:10.5194/acp-14-4397-2014, 2014.

Cancelli, D. M., Dias, N. L., and Chamecki, M.: Dimensionless criteria for the production-dissipation equilibrium of scalar fluctuations and their implications for scalar similarity, Water Resour. Res., 48, W10522, doi:10.1029/2012wr012127, 2012.

Carpenter, L. J., Fleming, Z. L., Read, K. A., Lee, J. D., Moller, S. J., Hopkins, J. R., Purvis, R. M., Lewis, A. C., Mueller, K., Heinold, B., Herrmann, H., Fomba, K. W., van Pinxteren, D., Mueller, C., Tegen, I., Wiedensohler, A., Mueller, T., Niedermeier, N., Achterberg, E. P., Patey, M. D., Kozlova, E. A., Heimann, M., Heard, D. E., Plane, J. M. C., Mahajan, A., Oetjen, H., Ingham, T., Stone, D., Whalley, L. K., Evans, M. J., Pilling, M. J., Leigh, R. J., Monks, P. S., Karunaharan, A., Vaughan, S., Arnold, S. R., Tschritter, J., Poehler, D., Friess, U., Holla, R., Mendes, L. M., Lopez, H., Faria, B., Manning, A. J., and Wallace, D. W. R.: Seasonal characteristics of tropical marine boundary layer air measured at the Cape Verde Atmospheric Observatory, J. Atmos. Chem., 67, 87-140, doi:10.1007/s10874-011-9206-1, 2010.

Carswell, F. E., Costa, A. L., Palheta, M., Malhi, Y., Meir, P., Costa, J. d. P. R., Ruivo, M. D. L., Leal, L. D. S. M., Costa, J. M. N., Clement, R. J., and Grace, J.: Seasonality in $\mathrm{CO}_{2}$ and $\mathrm{H}_{2} \mathrm{O}$ flux 
at an eastern Amazonian rain forest, J. Geophys. Res., 107, LBA 43-1-LBA 43-15, doi:10.1029/2000JD000284, 2002.

Cava, D., Giostra, U., Siqueira, M., and Katul, G.: Organised motion and radiative perturbations in the nocturnal canopy sublayer above an even-aged pine forest, Bound.-Lay. Meteorol., 112, 129-157, doi:10.1023/B:BOUN.0000020160.28184.a0, 2004.

Chambers, J. Q., Negron-Juarez, R. I., Marra, D. M., Di Vittorio, A., Tews, J., Roberts, D., Ribeiro, G. H. P. M., Trumbore, S. E., and Higuchi, N.: The steady-state mosaic of disturbance and succession across an old-growth Central Amazon forest landscape, Proc. Natl. Acad. Sci., 110, 3949-3954, doi:10.1073/pnas.1202894110, 2013.

Chauvel, A., Lucas, Y., and Boulet, R.: On the genesis of the soil mantle of the region of Manaus, Central Amazonia, Brazil, Experientia, 43, 234-241, doi:10.1007/bf01945546, 1987.

Chave, J., Andalo, C., Brown, S., Cairns, M. A., Chambers, J. Q., Eamus, D., Folster, H., Fromard, F., Higuchi, N., Kira, T., Lescure, J. P., Nelson, B. W., Ogawa, H., Puig, H., Riera, B., and Yamakura, T.: Tree allometry and improved estimation of carbon stocks and balance in tropical forests, Oecologia, 145, 87-99, doi:10.1007/s00442-005-0100-x, 2005.

Chave, J., Coomes, D., Jansen, S., Lewis, S. L., Swenson, N. G., and Zanne, A. E.: Towards a worldwide wood economics spectrum, Ecol. Lett., 12, 351-366, doi:10.1111/j.14610248.2009.01285.x, 2009.

Chen, B., Coops, N. C., Fu, D., Margolis, H. A., Amiro, B. D., Black, T. A., Arain, M. A., Barr, A. G., Bourque, C. P. A., Flanagan, L. B., Lafleur, P. M., McCaughey, J. H., and Wofsy, S. C.: Characterizing spatial representativeness of flux tower eddycovariance measurements across the Canadian Carbon Program Network using remote sensing and footprint analysis: Remote Sens. Environ., 124, 742-755, doi:10.1016/j.rse.2012.06.007, 2012.

Chen, Q., Farmer, D. K., Schneider, J., Zorn, S. R., Heald, C. L., Karl, T., Guenther, A., Allan, J. D., Robinson, N., Coe, H., Kimmel, J. R., Pauliquevis, T., Borrmann, S., Pöschl, U., Andreae, M. O., Artaxo, P., Jimenez, J. L., and Martin, S. T.: Mass spectral characterization of submicron biogenic organic particles in the Amazon Basin, Geophys. Res. Lett., 36, L20806, doi:10.1029/2009GL039880, 2009.

Chen, Q., Farmer, D. K., Rizzo, L. V., Pauliquevis, T., Kuwata, M., Karl, T. G., Guenther, A., Allan, J. D., Coe, H., Andreae, M. O., Pöschl, U., Jimenez, J. L., Artaxo, P., and Martin, S. T.: Submicron particle mass concentrations and sources in the Amazonian wet season (AMAZE-08), Atmos. Chem. Phys., 15, 3687-3701, doi:10.5194/acp-15-3687-2015, 2015.

Chi, X., Winderlich, J., Mayer, J.-C., Panov, A. V., Heimann, M., Birmili, W., Heintzenberg, J., Cheng, Y., and Andreae, M. O.: Long-term measurements of aerosol and carbon monoxide at the ZOTTO tall tower to characterize polluted and pristine air in the Siberian taiga, Atmos. Chem. Phys., 13, 12271-12298, doi:10.5194/acp-13-12271-2013, 2013.

Chimonas, G. and Nappo, C. J.: Wave drag in the planetary boundary layer over complex terrain, Bound.-Lay. Meteorol., 47, $217-$ 232, doi:10.1007/bf00122330, 1989.

Chou, W. W., Wofsy, S. C., Harriss, R. C., Lin, J. C., Gerbig, C., and Sachse, G. W.: Net fluxes of $\mathrm{CO}_{2}$ in Amazonia derived from aircraft observations, J. Geophys. Res., 107, 4614, doi:10.1029/2001JD001295, 2002.
Ciais, P., Sabine, C., Bala, G., Bopp, L., Brovkin, V., Canadell, J., Chhabra, A., DeFries, R., Galloway, J., Heimann, M., Jones, C., Quéré, C. L., Myneni, R. B., Piao, S., and Thornton, P.: Chapter 6: Carbon and Other Biogeochemical Cycles, in: IPCC, Climate Change 2013: The Physical Science Basis. Contribution of Working Group I to the Fifth Assessment Report of the Intergovernmental Panel on Climate Change, edited by: Stocker, T. F., Qin, D., Plattner, G.-K., Tignor, M., Allen, S. K., Boschung, J., Nauels, A., Xia, Y., Bex, V., and Midgley, P. M., Cambridge University Press, Cambridge, United Kingdom and New York, NY, USA, 465-570, 2013.

Cintra, B. B. L., Schietti, J., Emillio, T., Martins, D., Moulatlet, G., Souza, P., Levis, C., Quesada, C. A., and Schöngart, J.: Soil physical restrictions and hydrology regulate stand age and wood biomass turnover rates of Purus-Madeira interfluvial wetlands in Amazonia, Biogeosciences, 10, 7759-7774, doi:10.5194/bg-107759-2013, 2013.

Cirino, G. G., Souza, R. A. F., Adams, D. K., and Artaxo, P.: The effect of atmospheric aerosol particles and clouds on net ecosystem exchange in the Amazon, Atmos. Chem. Phys., 14, 6523-6543, doi:10.5194/acp-14-6523-2014, 2014.

Claeys, M., Graham, B., Vas, G., Wang, W., Vermeylen, R., Pashynska, V., Cafmeyer, J., Guyon, P., Andreae, M. O., Artaxo, P., and Maenhaut, W., Formation of secondary organic aerosols through photooxidation of isoprene, Science, 303, 1173-1176, 2004.

Claeys, M., Kourtchev, I., Pashynska, V., Vas, G., Vermeylen, R., Wang, W., Cafmeyer, J., Chi, X., Artaxo, P., Andreae, M. O., and Maenhaut, W.: Polar organic marker compounds in atmospheric aerosols during the LBA-SMOCC 2002 biomass burning experiment in Rondônia, Brazil: sources and source processes, time series, diel variations and size distributions, Atmos. Chem. Phys., 10, 9319-9331, doi:10.5194/acp-10-9319-2010, 2010.

Clark, D. A., Brown, S., Kicklighter, D. W., Chambers, J. Q., Thomlinson, J. R., Ni, J., and Holland, E. A.: Net primary production in tropical forests: An evaluation and synthesis of existing field data, Ecol. Appl., 11, 371-384, doi:10.2307/3060895, 2001.

Cleveland, C. C., Taylor, P., Chadwick, K. D., Dahlin, K., Doughty, C. E., Malhi, Y., Smith, W. K., Sullivan, B. W., Wieder, W. R., and Townsend, A. R.: A comparison of plot-based satellite and Earth system model estimates of tropical forest net primary production, Global Biogeochem. Сy., 29, 626-644, doi:10.1002/2014GB005022, 2015.

Coe, M. T., Costa, M. H., and Soares-Filhoc, B. S.: The influence of historical and potential future deforestation on the stream flow of the Amazon River - Land surface processes and atmospheric feedbacks, J. Hydrol., 369, 165-174, doi:10.1016/j.jhydrol.2009.02.043, 2009.

Collineau, S. and Brunet, Y.: Detection of turbulent coherent motions in a forest canopy. 2. Time-scales and conditional averages, Bound.-Lay. Meteorol., 66, 49-73, doi:10.1007/bf00705459, 1993.

Costa, F. D., Acevedo, O. C., Mombach, J. C. M., and Degrazia, G. A.: A simplified model for intermittent turbulence in the nocturnal boundary layer, J. Atmos. Sci., 68, 1714-1729, doi:10.1175/2011jas3655.1, 2011.

Crutzen, P. J.: The role of the tropics in atmospheric chemistry, in: The Geophysiology of Amazonia, edited by: Dickinson, R. E., John Wiley, New York, 107-130, 1987. 
Crutzen, P. J. and Andreae, M. O.: Biomass burning in the tropics: Impact on atmospheric chemistry and biogeochemical cycles, Science, 250, 1669-1678, 1990.

D’Amelio, M. T. S., Gatti, L. V., Miller, J. B., and Tans, P.: Regional $\mathrm{N}_{2} \mathrm{O}$ fluxes in Amazonia derived from aircraft vertical profiles, Atmos. Chem. Phys., 9, 8785-8797, doi:10.5194/acp9-8785-2009, 2009.

Da Silva, J. M. C., Rylands, A. B., and Da Fonseca, G. A. B.: The fate of the Amazonian areas of endemism, Conservation Biology, 19, 689-694, doi:10.1111/j.1523-1739.2005.00705.x, 2005.

Davidson, E. A., de Araujo, A. C., Artaxo, P., Balch, J. K., Brown, I. F., Bustamante, M. M. C., Coe, M. T., DeFries, R. S., Keller, M., Longo, M., Munger, J. W., Schroeder, W., Soares, B. S., Souza, C. M., and Wofsy, S. C.: The Amazon basin in transition, Nature, 481, 321-328, doi:10.1038/nature10717, 2012.

de Araújo, A. C., Nobre, A. D., Kruijt, B., Elbers, J. A., Dallarosa, R., Stefani, P., von Randow, C., Manzi, A. O., Culf, A. D., Gash, J. H. C., Valentini, R., and Kabat, P.: Comparative measurements of carbon dioxide fluxes from two nearby towers in a central Amazonian rainforest: The Manaus LBA site, J. Geophys. Res., 107, 8090, doi:10.1029/2001JD000676, 2002.

de Araujo, A. C., Kruijt, B., Nobre, A. D., Dolman, A. J., Waterloo, M. J., Moors, E. J., and de Souza, J. S.: Nocturnal accumulation of $\mathrm{CO}(2)$ underneath a tropical forest canopy along a topographical gradient, Ecol. Appl., 18, 1406-1419, 2008.

de Araujo, A. C., Dolman, A. J., Waterloo, M. J., Gash, J. H. C., Kruijt, B., Zanchi, F. B., de Lange, J. M. E., Stoevelaar, R., Manzi, A. O., Nobre, A. D., Lootens, R. N., and Backer, J.: The spatial variability of $\mathrm{CO}_{2}$ storage and the interpretation of eddy covariance fluxes in central Amazonia, Agr. Forest Meteorol., 150, 226-237, doi:10.1016/j.agrformet.2009.11.005, 2010.

Dias, N. L., Hong, J., Leclerc, M. Y., Black, T. A., Nesic, Z., and Krishnan, P.: A simple method of estimating scalar fluxes over forests, Bound.-Lay. Meteorol., 132, 401-414, doi:10.1007/s10546-009-9408-0, 2009.

Dias Júnior, C. Q., Sa, L. D. A., Pacheco, V. B., and de Souza, C. M.: Coherent structures detected in the unstable atmospheric surface layer above the Amazon forest, J. Wind Eng. Industr. Aerodynam., 115, 1-8, doi:10.1016/j.jweia.2012.12.019, 2013.

Dlugokencky, E. J., Lang, P. M., Masarie, K. A., Crotwell, A. M., and Crotwell, M. J.: Atmospheric Carbon Dioxide Dry Air Mole Fractions from the NOAA ESRL Carbon Cycle Cooperative Global Air Sampling Network, 1968-2013, Version: 2014-0627, available at: ftp://aftp.cmdl.noaa.gov/data/trace_gases/co2/ flask/surface/ (last access: 1 July 2015), 2014.

Doughty, C. E. and Goulden, M. L.: Seasonal patterns of tropical forest leaf area index and $\mathrm{CO}_{2}$ exchange, J. Geophys. Res.Biogeosci., 113, G00B06, doi:10.1029/2007jg000590, 2008.

Doughty, C. E., Metcalfe, D. B., Girardin, C. A. J., Amezquita, F. F., Cabrera, D. G., Huasco, W. H., Silva-Espejo, J. E., Araujo-Murakami, A., da Costa, M. C., Rocha, W., Feldpausch, T. R., Mendoza, A. L. M., da Costa, A. C. L., Meir, P., Phillips, O. L., and Malhi, Y.: Drought impact on forest carbon dynamics and fluxes in Amazonia, Nature, 519, 78-82, doi:10.1038/nature14213, 2015.

Draxler, R. R. and Rolph, G. D.: HYSPLIT (HYbrid Single-Particle Lagrangian Integrated Trajectory) Model access via NOAA ARL READY Website, available at: http://www.arl.noaa.gov/ready/ hysplit4.html (last access: 1 July 2015), NOAA Air Resources Laboratory, Silver Spring, MD., 2015.

Drüe, C. and Heinemann, G.: Characteristics of intermittent turbulence in the upper stable boundary layer over Greenland, Bound.Lay. Meteorol., 124, 361-381, doi:10.1007/s10546-007-9175-8, 2007.

Dupont, S. and Brunet, Y.: Coherent structures in canopy edge flow: a large-eddy simulation study, J. Fluid Mech., 630, 93-128, doi:10.1017/s0022112009006739, 2009.

Durden, D. J., Nappo, C. J., Leclerc, M. Y., Duarte, H. F., Zhang, G., Parker, M. J., and Kurzeja, R. J.: On the impact of wavelike disturbances on turbulent fluxes and turbulence statistics in nighttime conditions: a case study, Biogeosciences, 10, 84338443, doi:10.5194/bg-10-8433-2013, 2013.

Eck, T. F., Holben, B. N., Reid, J. S., O’Neill, N. T., Schafer, J. S., Dubovik, O., Smirnov, A., Yamasoe, M. A., and Artaxo, P.: High aerosol optical depth biomass burning events: A comparison of optical properties for different source regions, Geophys. Res. Lett., 30, 2035, doi:10.1029/2003GL017861, 2003.

Elbert, W., Weber, B., Burrows, S., Steinkamp, J., Büdel, B., Andreae, M. O., and Pöschl, U., Contribution of cryptogamic covers to the global cycles of carbon and nitrogen, Nat. Geosci., 5, 459-462, 2012.

Emilio, T., Quesada, C. A., Costa, F. R. C., Magnusson, W. E., Schietti, J., Feldpausch, T. R., Brienen, R. J. W., Baker, T. R., Chave, J., Alvarez, E., Araujo, A., Banki, O., Castilho, C. V., Honorio C., E. N., Killeen, T. J., Malhi, Y., Mendoza, E. M. O., Monteagudo, A., Neill, D., Alexander Parada, G., Pena-Cruz, A., Ramirez-Angulo, H., Schwarz, M., Silveira, M., ter Steege, H., Terborgh, J. W., Thomas, R., Torres-Lezama, A., Vilanova, E., and Phillips, O. L.: Soil physical conditions limit palm and tree basal area in Amazonian forests, Plant Ecol. Diversity, 7, 215229, doi:10.1080/17550874.2013.772257, 2014.

Farge, M.: Wavelet transforms and their applications to turbulence, Ann. Rev. Fluid Mech., 24, 395-457, doi:10.1146/annurev.fluid.24.1.395, 1992.

Feldpausch, T. R., Lloyd, J., Lewis, S. L., Brienen, R. J. W., Gloor, M., Monteagudo Mendoza, A., Lopez-Gonzalez, G., Banin, L., Abu Salim, K., Affum-Baffoe, K., Alexiades, M., Almeida, S., Amaral, I., Andrade, A., Aragão, L. E. O. C., Araujo Murakami, A., Arets, E. J. M. M., Arroyo, L., Aymard C., G. A., Baker, T. R., Bánki, O. S., Berry, N. J., Cardozo, N., Chave, J., Comiskey, J. A., Alvarez, E., de Oliveira, A., Di Fiore, A., Djagbletey, G., Domingues, T. F., Erwin, T. L., Fearnside, P. M., França, M. B., Freitas, M. A., Higuchi, N., E. Honorio C., Iida, Y., Jiménez, E., Kassim, A. R., Killeen, T. J., Laurance, W. F., Lovett, J. C., Malhi, Y., Marimon, B. S., Marimon-Junior, B. H., Lenza, E., Marshall, A. R., Mendoza, C., Metcalfe, D. J., Mitchard, E. T. A., Neill, D. A., Nelson, B. W., Nilus, R., Nogueira, E. M., Parada, A., Peh, K. S.-H., Pena Cruz, A., Peñuela, M. C., Pitman, N. C. A., Prieto, A., Quesada, C. A., Ramírez, F., Ramírez-Angulo, H., Reitsma, J. M., Rudas, A., Saiz, G., Salomão, R. P., Schwarz, M., Silva, N., Silva-Espejo, J. E., Silveira, M., Sonké, B., Stropp, J., Taedoumg, H. E., Tan, S., ter Steege, H., Terborgh, J., TorelloRaventos, M., van der Heijden, G. M. F., Vásquez, R., Vilanova, E., Vos, V. A., White, L., Willcock, S., Woell, H., and Phillips, O. L.: Tree height integrated into pantropical forest biomass estimates, Biogeosciences, 9, 3381-3403, doi:10.5194/bg-9-33812012, 2012. 
Fernandes, M. J. S.: Índice de erosividade da chuva média anual para Manaus/AM de 1981 a 2010, Revista Geonorte, 10, 46-49, 2014.

Figueroa, S. N. and Nobre, C. A.: Precipitions distribution over Central and Western Tropical South America, Climanálise, 5, 36-44, 1990.

Fisch, G., Tota, J., Machado, L. A. T., Dias, M., Lyra, R. F. D., Nobre, C. A., Dolman, A. J., and Gash, J. H. C.: The convective boundary layer over pasture and forest in Amazonia, Theor. Appl. Climatol., 78, 47-59, 2004.

Fitzjarrald, D. R. and Moore, K. E.: Mechanisms of nocturnal exchange between the rain-forest and the atmosphere, J. Geophys. Res., 95, 16839-16850, doi:10.1029/JD095iD10p16839, 1990.

Foken, T., Meixner, F. X., Falge, E., Zetzsch, C., Serafimovich, A., Bargsten, A., Behrendt, T., Biermann, T., Breuninger, C., Dix, S., Gerken, T., Hunner, M., Lehmann-Pape, L., Hens, K., Jocher, G., Kesselmeier, J., Lüers, J., Mayer, J.-C., Moravek, A., Plake, D., Riederer, M., Rütz, F., Scheibe, M., Siebicke, L., Sörgel, M., Staudt, K., Trebs, I., Tsokankunku, A., Welling, M., Wolff, V., and Zhu, Z.: Coupling processes and exchange of energy and reactive and non-reactive trace gases at a forest site - results of the EGER experiment, Atmos. Chem. Phys., 12, 1923-1950, doi:10.5194/acp-12-1923-2012, 2012.

Follath, R., Schmidt, J. S., Weigand, M., and Fauth, K.: The Xray microscopy beamline UE46-PGM2 at BESSY: AIP Conf. Proc., 1234, 323-326, doi:10.1063/1.3463201, 2010.

Formenti, P., Andreae, M. O., Lange, L., Roberts, G., Cafmeyer, J., Rajta, I., Maenhaut, W., Holben, B. N., Artaxo, P., and Lelieveld, J.: Saharan dust in Brazil and Suriname during the LargeScale Biosphere-Atmosphere Experiment in Amazonia (LBA)Cooperative LBA Regional Experiment (CLAIRE) in March 1998, J. Geophys. Res., 106, 14919-14934, 2001.

Fraser, B.: Carving up the Amazon, Nature, 509, 418-419, 2014.

Freud, E., Rosenfeld, D., Andreae, M. O., Costa, A. A., and Artaxo, P.: Robust relations between $\mathrm{CCN}$ and the vertical evolution of cloud drop size distribution in deep convective clouds, Atmos. Chem. Phys., 8, 1661-1675, doi:10.5194/acp-8-1661-2008, 2008.

Fry, J. L., Kiendler-Scharr, A., Rollins, A. W., Wooldridge, P. J., Brown, S. S., Fuchs, H., Dubé, W., Mensah, A., dal Maso, M., Tillmann, R., Dorn, H.-P., Brauers, T., and Cohen, R. C.: Organic nitrate and secondary organic aerosol yield from $\mathrm{NO}_{3}$ oxidation of $\beta$-pinene evaluated using a gas-phase kinetics/aerosol partitioning model, Atmos. Chem. Phys., 9, 14311449, doi:10.5194/acp-9-1431-2009, 2009.

Galvão, L. S., dos Santos, J. R., Roberts, D. A., Breunig, F. M., Toomey, M., and de Moura, Y. M.: On intra-annual EVI variability in the dry season of tropical forest: A case study with MODIS and hyperspectral data, Remote Sens. Environ., 115, 2350-2359, doi:10.1016/j.rse.2011.04.035, 2011.

Gao, W. and Li, B. L.: Wavelet analysis of coherent structures at the atmosphere forest interface, J. Appl. Meteor., 32, 1717-1725, 1993.

Gatti, L. V., Miller, J. B., D’Amelio, M. T. S., Martinewski, A., Basso, L. S., Gloor, M. E., Wofsy, S., and Tans, P.: Vertical profiles of $\mathrm{CO}_{2}$ above eastern Amazonia suggest a net carbon flux to the atmosphere and balanced biosphere between 2000 and 2009, Tellus Ser. B, 62, 581-594, doi:10.1111/j.16000889.2010.00484.x, 2010.
Gatti, L. V., Gloor, M., Miller, J. B., Doughty, C. E., Malhi, Y., Domingues, L. G., Basso, L. S., Martinewski, A., Correia, C. S. C., Borges, V. F., Freitas, S., Braz, R., Anderson, L. O., Rocha, H., Grace, J., Phillips, O. L., and Lloyd, J.: Drought sensitivity of Amazonian carbon balance revealed by atmospheric measurements, Nature, 506, 76-80, doi:10.1038/nature12957, 2014.

Gee, G. W. and Bauder, J. W.: Particle size analysis, in: Methods in Soil Analysis, Part 1. Physical and Mineralogical Methods, edited by: Klute, A., American Society of Agronomy and Soil Science Society of America, Madison, Wisconsin, USA, 383409, 1986.

Gilardoni, S., Vignati, E., Marmer, E., Cavalli, F., Belis, C., Gianelle, V., Loureiro, A., and Artaxo, P.: Sources of carbonaceous aerosol in the Amazon basin, Atmos. Chem. Phys., 11, 27472764, doi:10.5194/acp-11-2747-2011, 2011.

Gimeno, L., Stohl, A., Trigo, R. M., Dominguez, F., Yoshimura, K., Yu, L. S., Drumond, A., Duran-Quesada, A. M., and Nieto, R.: Oceanic and terrestrial sources of continental precipitation, Rev. Geophys., 50, RG4003, doi:10.1029/2012rg000389, 2012.

Gloor, M., Fan, S. M., Pacala, S., and Sarmiento, J., Optimal sampling of the atmosphere for purpose of inverse modeling: A model study, Global Biogeochem. Cy., 14, 407-428, 2000.

Gloor, M., Bakwin, P., Hurst, D., Lock, L., Draxler, R., and Tans, P.: What is the concentration footprint of a tall tower?, J. Geophys. Res., 106, 17831-17840, 2001.

Gloor, M., Gatti, L., Brienen, R., Feldpausch, T. R., Phillips, O. L., Miller, J., Ometto, J. P., Rocha, H., Baker, T., de Jong, B., Houghton, R. A., Malhi, Y., Aragão, L. E. O. C., Guyot, J.-L., Zhao, K., Jackson, R., Peylin, P., Sitch, S., Poulter, B., Lomas, M., Zaehle, S., Huntingford, C., Levy, P., and Lloyd, J.: The carbon balance of South America: a review of the status, decadal trends and main determinants, Biogeosciences, 9, 5407-5430, doi:10.5194/bg-9-5407-2012, 2012.

Gloor, M., Brienen, R. J. W., Galbraith, D., Feldpausch, T. R., Schöngart, J., Guyot, J. L., Espinoza, J. C., Lloyd, J., and Phillips, O. L.: Intensification of the Amazon hydrological cycle over the last two decades, Geophys. Res. Lett., 40, 1729-1733, doi:10.1002/grl.50377, 2013.

Goulding, M., Barthem, R. B., and Duenas, R.: The Smithsonian Atlas of the Amazon. Washington, D.C., Smithsonian Books, 253 pp., 2003.

Grace, J., Lloyd, J., McIntyre, J., Miranda, A. C., Meir, P., Miranda, H. S., Nobre, C., Moncrieff, J., Massheder, J., Malhi, Y., Wright, I., and Gash, J.: Carbon dioxide uptake by an undisturbed tropical rain forest in southwest Amazonia, 1992 to 1993, Science, 270, 778-780, 1995.

Greco, S., Swap, R., Garstang, M., Ulanski, S., Shipman, M., Harriss, R. C., Talbot, R., Andreae, M. O., and Artaxo, P.: Rainfall and surface kinematic conditions over Central Amazonia during ABLE 2B, J. Geophys. Res., 95, 17001-17014, 1990.

Gunthe, S. S., King, S. M., Rose, D., Chen, Q., Roldin, P., Farmer, D. K., Jimenez, J. L., Artaxo, P., Andreae, M. O., Martin, S. T., and Pöschl, U.: Cloud condensation nuclei in pristine tropical rainforest air of Amazonia: size-resolved measurements and modeling of atmospheric aerosol composition and CCN activity, Atmos. Chem. Phys., 9, 7551-7575, doi:10.5194/acp-9-75512009, 2009. 
Hari, P., Andreae, M. O., Kabat, P., and Kulmala, M.: A comprehensive network of measuring stations to monitor climate change, Boreal Environ. Res., 14, 442-446, 2009.

Healy, D. A., Huffman, J. A., O’Connor, D. J., Pöhlker, C., Pöschl, U., and Sodeau, J. R.: Ambient measurements of biological aerosol particles near Killarney, Ireland: a comparison between real-time fluorescence and microscopy techniques, Atmos. Chem. Phys., 14, 8055-8069, doi:10.5194/acp-14-80552014, 2014.

Heiblum, R. H., Koren, I., and Feingold, G.: On the link between Amazonian forest properties and shallow cumulus cloud fields, Atmos. Chem. Phys., 14, 6063-6074, doi:10.5194/acp-14-60632014, 2014.

Heimann, M., Schulze, E.-D., Winderlich, J., Andreae, M. O., Chi, X., Gerbig, C., Kolle, O., Kübler, K., Lavric, J., Mikhailov, E., Panov, A., Park, S., Rödenbeck, C., and Skorochod, A.: The Zotino Tall Tower Observatory (ZOTTO): Quantifying large scale biogeochemical changes in Central Siberia, Nova Acta Leopoldina, 117, 51-64, 2014.

Hoch, S. W., Calanca, P., Philipona, R., and Ohmura, A.: Year-round observation of longwave radiative flux divergence in Greenland, J. Appl. Meteorol. Climatol., 46, 1469-1479, doi:10.1175/jam2542.1, 2007.

Hoorn, C., Wesselingh, F. P., ter Steege, H., Bermudez, M. A., Mora, A., Sevink, J., Sanmartin, I., Sanchez-Meseguer, A., Anderson, C. L., Figueiredo, J. P., Jaramillo, C., Riff, D., Negri, F. R., Hooghiemstra, H., Lundberg, J., Stadler, T., Sarkinen, T., and Antonelli, A.: Amazonia through time: Andean uplift, climate change, landscape evolution, and biodiversity, Science, 330, 927-931, doi:10.1126/science.1194585, 2010.

Huete, A. R., Didan, K., Shimabukuro, Y. E., Ratana, P., Saleska, S. R., Hutyra, L. R., Yang, W. Z., Nemani, R. R., and Myneni, R.: Amazon rainforests green-up with sunlight in dry season, Geophys. Res. Lett., 33, L06405, doi:10.1029/2005GL025583, 2006.

Huffman, J. A., Sinha, B., Garland, R. M., Snee-Pollmann, A., Gunthe, S. S., Artaxo, P., Martin, S. T., Andreae, M. O., and Pöschl, U.: Size distributions and temporal variations of biological aerosol particles in the Amazon rainforest characterized by microscopy and real-time UV-APS fluorescence techniques during AMAZE-08, Atmos. Chem. Phys., 12, 11997-12019, doi:10.5194/acp-12-11997-2012, 2012.

Hussain, A. K. M. F.: Coherent structures and turbulence, J. Fluid Mech., 173, 303-356, doi:10.1017/s0022112086001192, 1986.

IDESAM: Plano de Gestão da Reserva de Desenvolvimento Sustentável do Uatumã, Versão para consulta pública. Instituto de Conservação e Desenvolvimento Sustentável do Amazonas, Manaus, 2009.

IUSS (International Union of Soil Science): Working Group WRB, World reference base for soil resources 2006: A framework for international classification, correlation and communication, World Soil Resources Report 103, FAO, Rome, 145 pp., 2006.

Jacob, D. J. and Wofsy, S. C.: Budgets of reactive nitrogen, hydrocarbons, and ozone over the Amazon forest during the wet season, J. Geophys. Res., 95, 16737-16754, 1990.

Kaiser, J. W., Heil, A., Andreae, M. O., Benedetti, A., Chubarova, N., Jones, L., Morcrette, J.-J., Razinger, M., Schultz, M. G., Suttie, M., and van der Werf, G. R.: Biomass burning emissions estimated with a global fire assimilation system based on observed fire radiative power, Biogeosciences, 9, 527-554, doi:10.5194/bg-9-527-2012, 2012.

Kaye, P. H., Stanley, W. R., Hirst, E., Foot, E. V., Baxter, K. L., and Barrington, S. J.: Single particle multichannel bioaerosol fluorescence sensor, Optics Express, 13, 3583-3593, doi:10.1364/opex.13.003583, 2005.

Keller, M., Bustamante, M., Gash, J., and Dias, P.: Amazonia and Global Change, Washington, DC, American Geophysical Union, 565 pp., 2009.

Kesselmeier, J., Kuhn, U., Rottenberger, S., Biesenthal, T., Wolf, A., Schebeske, G., Andreae, M. O., Ciccioli, P., Brancaleoni, E., Frattoni, M., Oliva, S. T., Botelho, M. L., Silva, C. M. A., and Tavares, T. M.: Concentrations and species composition of atmospheric volatile organic compounds (VOCs) as observed during the wet and dry season in Rondonia (Amazonia), J. Geophys. Res., 107, 8053, doi:10.1029/2000JD000267, 2002.

Kilcoyne, A. L. D., Tyliszczak, T., Steele, W. F., Fakra, S., Hitchcock, P., Franck, K., Anderson, E., Harteneck, B., Rightor, E. G., Mitchell, G. E., Hitchcock, A. P., Yang, L., Warwick, T., and Ade, H.: Interferometer-controlled scanning transmission X-ray microscopes at the Advanced Light Source, J. Synchrotron Radiat., 10, 125-136, doi:10.1107/s0909049502017739, 2003.

Kirchhoff, V. W. J. H., Setzer, A. W., and Pereira, M. C.: Biomass burning in Amazonia: Seasonal effects on atmospheric $\mathrm{O}_{3}$ and CO, Geophys. Res. Lett., 16, 469-472, 1989.

Kirchhoff, V. W. J. H., daSilva, I. M. O., and Browell, E. V.: Ozone measurements in Amazonia: Dry season versus wet season, J. Geophys. Res., 95, 16913-16926, 1990.

Krusche, N. and Oliveira, A. P.: Characterization of coherent structures in the atmospheric surface layer, Bound.-Lay. Meteorol., 110, 191-211, doi:10.1023/a:1026096805679, 2004.

Kuhn, U., Ganzeveld, L., Thielmann, A., Dindorf, T., Schebeske, G., Welling, M., Sciare, J., Roberts, G., Meixner, F. X., Kesselmeier, J., Lelieveld, J., Kolle, O., Ciccioli, P., Lloyd, J., Trentmann, J., Artaxo, P., and Andreae, M. O.: Impact of Manaus City on the Amazon Green Ocean atmosphere: ozone production, precursor sensitivity and aerosol load, Atmos. Chem. Phys., 10, 9251-9282, doi:10.5194/acp-10-9251-2010, 2010.

Kulmala, M., Petäjä, T., Ehn, M., Thornton, J., Sipilä, M., Worsnop, D. R., and Kerminen, V. M.: Chemistry of atmospheric nucleation: On the recent advances on precursor characterization and atmospheric cluster composition in connection with atmospheric new particle formation, Annu. Rev. Phys. Chem., 65, 21-37, doi:10.1146/annurev-physchem-040412-110014, 2014.

Lapola, D. M., Martinelli, L. A., Peres, C. A., Ometto, J. P. H. B., Ferreira, M. E., Nobre, C. A., Aguiar, A. P. D., Bustamante, M. M. C., Cardoso, M. F., Costa, M. H., Joly, C. A., Leite, C. C., Moutinho, P., Sampaio, G., Strassburg, B. B. N., and Vieira, I. C. G.: Pervasive transition of the Brazilian land-use system, Nature Clim. Change, 4, 27-35, doi:10.1038/nclimate2056, 2014.

Lawrence, D. and Vandecar, K.: Effects of tropical deforestation on climate and agriculture, Nature Clim. Change, 5, 27-36, doi:10.1038/nclimate2430, 2015.

Le Quéré, C., Moriarty, R., Andrew, R. M., Peters, G. P., Ciais, P., Friedlingstein, P., Jones, S. D., Sitch, S., Tans, P., Arneth, A., Boden, T. A., Bopp, L., Bozec, Y., Canadell, J. G., Chini, L. P., Chevallier, F., Cosca, C. E., Harris, I., Hoppema, M., Houghton, R. A., House, J. I., Jain, A. K., Johannessen, T., Kato, E., Keeling, R. F., Kitidis, V., Klein Goldewijk, K., Koven, C., Landa, 
C. S., Landschützer, P., Lenton, A., Lima, I. D., Marland, G., Mathis, J. T., Metzl, N., Nojiri, Y., Olsen, A., Ono, T., Peng, S., Peters, W., Pfeil, B., Poulter, B., Raupach, M. R., Regnier, P., Rödenbeck, C., Saito, S., Salisbury, J. E., Schuster, U., Schwinger, J., Séférian, R., Segschneider, J., Steinhoff, T., Stocker, B. D., Sutton, A. J., Takahashi, T., Tilbrook, B., van der Werf, G. R., Viovy, N., Wang, Y.-P., Wanninkhof, R., Wiltshire, A., and Zeng, N.: Global carbon budget 2014, Earth Syst. Sci. Data, 7, 47-85, doi:10.5194/essd-7-47-2015, 2015.

Lelieveld, J., Butler, T. M., Crowley, J. N., Dillon, T. J., Fischer, H., Ganzeveld, L., Harder, H., Lawrence, M. G., Martinez, M., Taraborrelli, D., and Williams, J.: Atmospheric oxidation capacity sustained by a tropical forest, Nature, 452, 737-740, doi:10.1038/nature06870, 2008.

Levin, E. J. T., Prenni, A. J., Palm, B. B., Day, D. A., CampuzanoJost, P., Winkler, P. M., Kreidenweis, S. M., DeMott, P. J., Jimenez, J. L., and Smith, J. N.: Size-resolved aerosol composition and its link to hygroscopicity at a forested site in Colorado, Atmos. Chem. Phys., 14, 2657-2667, doi:10.5194/acp-14-26572014, 2014.

Li, D. and Bou-Zeid, E.: Coherent Structures and the Dissimilarity of Turbulent Transport of Momentum and Scalars in the Unstable Atmospheric Surface Layer, Bound.-Lay. Meteorol., 140, 243 262, doi:10.1007/s10546-011-9613-5, 2011.

Lin, J. C., Matsui, T., Pielke, R. A., Sr., and Kummerow, C.: Effects of biomass burning-derived aerosols on precipitation and clouds in the Amazon basin: a satellite-based empirical study, J. Geophys. Res., 111, D19204, doi:10.1029/2005JD006884, 2006.

Lindinger, W., Hansel, A., and Jordan, A.: Proton-transfer-reaction mass spectrometry (PTR-MS): on-line monitoring of volatile organic compounds at pptv levels, Chem. Soc. Rev., 27, 347-354, 1998.

Liptzin, D. and Silver, W. L.: Effects of carbon additions on iron reduction and phosphorus availability in a humid tropical forest soil, Soil Biol. Biochem., 41, 1696-1702, 2009.

Lloyd, J., Kolle, O., Fritsch, H., de Freitas, S. R., Silva Dias, M. A. F., Artaxo, P., Nobre, A. D., de Araújo, A. C., Kruijt, B., Sogacheva, L., Fisch, G., Thielmann, A., Kuhn, U., and Andreae, M. O.: An airborne regional carbon balance for Central Amazonia, Biogeosciences, 4, 759-768, doi:10.5194/bg-4-759-2007, 2007.

Lohou, F., Druilhet, A., Campistron, B., Redelspergers, J. L., and Said, F.: Numerical study of the impact of coherent structures on vertical transfers in the atmospheric boundary layer, Bound.-Lay. Meteorol., 97, 361-383, doi:10.1023/a:1002641728075, 2000.

Lu, C. H. and Fitzjarrald, D. R.: Seasonal and diurnal variations of coherent structures over a deciduous forest, Bound.-Lay. Meteorol., 69, 43-69, doi:10.1007/bf00713294, 1994.

Mahrt, L.: Stratified atmospheric boundary layers, Bound.-Lay. Meteorol., 90, 375-396, doi:10.1023/a:1001765727956, 1999.

Mahrt, L.: Characteristics of submeso winds in the stable boundary layer, Bound.-Lay. Meteorol., 130, 1-14, doi:10.1007/s10546008-9336-4, 2009.

Malhi, Y. and Wright, J.: Spatial patterns and recent trends in the climate of tropical rainforest regions, Philos. Trans. Roy. Soc. London Ser. B, 359, 311-329, doi:10.1098/rstb.2003.1433, 2004.

Malhi, Y., Wood, D., Baker, T. R., Wright, J., Phillips, O. L., Cochrane, T., Meir, P., Chave, J., Almeida, S., Arroyo, L., Higuchi, N., Killeen, T. J., Laurance, S. G., Laurance, W. F.,
Lewis, S. L., Monteagudo, A., Neill, D. A., Vargas, P. N., Pitman, N. C. A., Quesada, C. A., Salomao, R., Silva, J. N. M., Lezama, A. T., Terborgh, J., Martinez, R. V., and Vinceti, B., The regional variation of aboveground live biomass in oldgrowth Amazonian forests: Global Change Biology, 12, 11071138, doi:10.1111/j.1365-2486.2006.01120.x, 2006.

Martin, S. T., Andreae, M. O., Althausen, D., Artaxo, P., Baars, H., Borrmann, S., Chen, Q., Farmer, D. K., Guenther, A., Gunthe, S. S., Jimenez, J. L., Karl, T., Longo, K., Manzi, A., Müller, T., Pauliquevis, T., Petters, M. D., Prenni, A. J., Pöschl, U., Rizzo, L. V., Schneider, J., Smith, J. N., Swietlicki, E., Tota, J., Wang, J., Wiedensohler, A., and Zorn, S. R.: An overview of the Amazonian Aerosol Characterization Experiment 2008 (AMAZE08), Atmos. Chem. Phys., 10, 11415-11438, doi:10.5194/acp10-11415-2010, 2010a.

Martin, S. T., Andreae, M. O., Artaxo, P., Baumgardner, D., Chen, Q., Goldstein, A. H., Guenther, A., Heald, C. L., MayolBracero, O. L., McMurry, P. H., Pauliquevis, T., Pöschl, U., Prather, K. A., Roberts, G. C., Saleska, S. R., Dias, M. A. S., Spracklen, D., Swietlicki, E., and Trebs, I.: Sources and properties of Amazonian aerosol particles, Rev. Geophys., 48, RG2002, doi:10.1029/2008RG000280, 2010b.

Martinez, M., Harder, H., Kubistin, D., Rudolf, M., Bozem, H., Eerdekens, G., Fischer, H., Klüpfel, T., Gurk, C., Königstedt, R., Parchatka, U., Schiller, C. L., Stickler, A., Williams, J., and Lelieveld, J.: Hydroxyl radicals in the tropical troposphere over the Suriname rainforest: airborne measurements, Atmos. Chem. Phys., 10, 3759-3773, doi:10.5194/acp-10-3759-2010, 2010.

Martins, D. L., Schietti, J., Feldpausch, T. R., Luizao, F. J., Phillips, O. L., Andrade, A., Castilho, C. V., Laurance, S. G., Oliveira, A., Amaral, I. L., Toledo, J. J., Lugli, L. F., Purri Veiga Pinto, J. L., Oblitas Mendoza, E. M., and Quesada, C. A.: Soilinduced impacts on forest structure drive coarse woody debris stocks across central Amazonia, Plant Ecol. Divers., 8, 229-241, doi:10.1080/17550874.2013.879942, 2015.

Martins, J. A., Dias, M., and Goncalves, F. L. T.: Impact of biomass burning aerosols on precipitation in the Amazon: A modeling case study, J. Geophys. Res., 114, D02207, doi:10.1029/2007jd009587, 2009.

Mayol-Bracero, O. L., Gabriel, R., Andreae, M. O., Kirchstetter, T. W., Novakov, T., Ogren, J., Sheridan, P., and Streets, D. G.: Carbonaceous aerosols over the Indian Ocean during the Indian Ocean Experiment (INDOEX): Chemical characterization, optical properties and probable sources, J. Geophys. Res., 107, 8030, doi:10.1029/2000JD000039, 2002.

McMeeking, G. R., Fortner, E., Onasch, T. B., Taylor, J. W., Flynn, M., Coe, H., and Kreidenweis, S. M.: Impacts of nonrefractory material on light absorption by aerosols emitted from biomass burning, J. Geophys. Res., 119, 12272-12286, doi:10.1002/2014JD021750, 2014.

McNaughton, K. G. and Brunet, Y.: Townsend's hypothesis, coherent structures and Monin-Obukhov similarity: Bound.-Lay. Meteorol., 102, 161-175, doi:10.1023/a:1013171312407, 2002.

Miller, J. B., Gatti, L. V., d'Amelio, M. T. S., Crotwell, A. M., Dlugokencky, E. J., Bakwin, P., Artaxo, P., and Tans, P. P.: Airborne measurements indicate large methane emissions from the eastern Amazon basin, Geophys. Res. Lett., 34, L10809, doi:10.1029/2006GL029213, 2007. 
Mölder, M., Grelle, A., Lindroth, A., and Halldin, S.: Fluxprofile relationships over a boreal forest - roughness sublayer corrections, Agr. Forest Meteorol., 98/99, 645-658, doi:10.1016/s0168-1923(99)00131-8, 1999.

Molina, L., Broquet, G., Imbach, P., Chevallier, F., Poulter, B., Bonal, D., Burban, B., Ramonet, M., Gatti, L. V., Wofsy, S. C., Munger, J. W., Dlugokencky, E., and Ciais, P.: On the ability of a global atmospheric inversion to constrain variations of $\mathrm{CO} 2$ fluxes over Amazonia, Atmos. Chem. Phys., 15, 8423-8438, doi:10.5194/acp-15-8423-2015, 2015.

Moosmüller, H., Chakrabarty, R. K., Ehlers, K. M., and Arnott, W. P.: Absorption Ångström coefficient, brown carbon, and aerosols: basic concepts, bulk matter, and spherical particles, Atmos. Chem. Phys., 11, 1217-1225, doi:10.5194/acp-11-12172011, 2011.

Morton, D. C., Nagol, J., Carabajal, C. C., Rosette, J., Palace, M., Cook, B. D., Vermote, E. F., Harding, D. J., and North, P. R. J.: Amazon forests maintain consistent canopy structure and greenness during the dry season, Nature, 506, 221-224, doi:10.1038/nature13006, 2014.

Nappo, C. J.: Sporadic breakdowns of stability in the PBL over simple and complex terrain, Bound.-Lay. Meteorol., 54, 69-87, doi:10.1007/bf00119413, 1991.

Nappo, C. J.: An Introduction to Atmospheric Gravity Waves, Amsterdam, Academic Press, 276 pp., 2002.

Nelson, D. W. and Sommers, L. E.: Total carbon and total nitrogen, in: Methods of Soil Analysis: Part 3 - Chemical Methods, edited by: Sparks, D. L., American Society of Agronomy and Soil Science Society of America, Madison, Wisconsin, USA, 961-1010, 1996.

Nepstad, D., McGrath, D., Stickler, C., Alencar, A., Azevedo, A., Swette, B., Bezerra, T., DiGiano, M., Shimada, J., Seroa da Motta, R., Armijo, E., Castello, L., Brando, P., Hansen, M. C., McGrath-Horn, M., Carvalho, O., and Hess, L.: Slowing Amazon deforestation through public policy and interventions in beef and soy supply chains, Science, 344, 1118-1123, doi:10.1126/science.1248525, 2014.

Ng, N. L., Herndon, S. C., Trimborn, A., Canagaratna, M. R., Croteau, P. L., Onasch, T. B., Sueper, D., Worsnop, D. R., Zhang, Q., Sun, Y. L., and Jayne, J. T.: An Aerosol Chemical Speciation Monitor (ACSM) for Routine Monitoring of the Composition and Mass Concentrations of Ambient Aerosol, Aerosol Sci. Tech., 45, 780-794, doi:10.1080/02786826.2011.560211, 2011.

Nobre, C. A. and Borma, L. D.: "Tipping points" for the Amazon forest: Curr. Opin. Environ. Sust., 1, 28-36, doi:10.1016/j.cosust.2009.07.003, 2009.

Nobre, C. A., Obregón, G. O., Marengo, J. A., Fu, R., and Poveda, G.: Characteristics of Amazonian climate: Main Features, in: Amazonia and Global Change, edited by: Keller, M., Bustamante, M., Gash, J., and Dias, P., American Geophysical Union, Washington, DC, 149-162, 2009.

Nölscher, A. C., Williams, J., Sinha, V., Custer, T., Song, W., Johnson, A. M., Axinte, R., Bozem, H., Fischer, H., Pouvesle, N., Phillips, G., Crowley, J. N., Rantala, P., Rinne, J., Kulmala, M., Gonzales, D., Valverde-Canossa, J., Vogel, A., Hoffmann, T., Ouwersloot, H. G., Vilà-Guerau de Arellano, J., and Lelieveld, J.: Summertime total $\mathrm{OH}$ reactivity measurements from boreal forest during HUMPPA-COPEC 2010, Atmos. Chem. Phys., 12, 8257-8270, doi:10.5194/acp-12-8257-2012, 2012.
Nölscher, A. C., Butler, T., Auld, J., Veres, P., Muñoz, A., Taraborrelli, D., Vereecken, L., Lelieveld, J., and Williams, J.: Using total $\mathrm{OH}$ reactivity to assess isoprene photooxidation via measurement and model, Atmos. Environ., 89, 453-463, doi:10.1016/j.atmosenv.2014.02.024, 2014.

Novelli, P. C. and Masarie, K. A.: Atmospheric Carbon Monoxide Dry Air Mole Fractions from the NOAA ESRL Carbon Cycle Cooperative Global Air Sampling Network, 1988-2013, Version: 2014-07-02, availablat at: ftp://aftp.cmdl.noaa.gov/data/ trace_gases/co/flask/surface/ (last access: 1 July 2015), 2014.

Oliveira, P. E. S., Acevedo, O. C., Moraes, O. L. L., Zimermann, H. R., and Teichrieb, C.: Nocturnal intermittent coupling between the interior of a pine forest and the air above it, Bound.-Lay. Meteorol., 146, 45-64, doi:10.1007/s10546-012-9756-z, 2013.

Oliveira, P. H. F., Artaxo, P., Pires, C., De Lucca, S., Procopio, A., Holben, B., Schafer, J., Cardoso, L. F., Wofsy, S. C., and Rocha, H. R.: The effects of biomass burning aerosols and clouds on the $\mathrm{CO}_{2}$ flux in Amazonia, Tellus, 59B, 338-349, doi:10.1111/j.1600-0889.2007.00270.x, 2007.

Pacifico, F., Folberth, G. A., Sitch, S., Haywood, J. M., Rizzo, L. V., Malavelle, F. F., and Artaxo, P.: Biomass burning related ozone damage on vegetation over the Amazon forest: a model sensitivity study, Atmos. Chem. Phys., 15, 2791-2804, doi:10.5194/acp15-2791-2015, 2015.

Pan, Y. D., Birdsey, R. A., Fang, J. Y., Houghton, R., Kauppi, P. E., Kurz, W. A., Phillips, O. L., Shvidenko, A., Lewis, S. L., Canadell, J. G., Ciais, P., Jackson, R. B., Pacala, S. W., McGuire, A. D., Piao, S. L., Rautiainen, A., Sitch, S., and Hayes, D.: A large and persistent carbon sink in the World's forests, Science, 333, 988-993, doi:10.1126/science.1201609, 2011.

Patton, E. G.: Large-Eddy Simulation of Turbulent Flow Above and Within a Plant Canopy, University of California at Davis, 132 pp., 1997.

Paw U, K. T., Brunet, Y., Collineau, S., Shaw, R. H., Maitani, T., Qiu, J., and Hipps, L.: On coherent structures in turbulence above and within agricultural plant canopies, Agr. Forest Meteorol., 61, 55-68, 1992.

Pella, E.: Elemental organic analysis. 2. State of the art, American Laboratory, 22, 28-32, 1990.

Phillips, O. L., Aragao, L., Lewis, S. L., Fisher, J. B., Lloyd, J., Lopez-Gonzalez, G., Malhi, Y., Monteagudo, A., Peacock, J., Quesada, C. A., van der Heijden, G., Almeida, S., Amaral, I., Arroyo, L., Aymard, G., Baker, T. R., Banki, O., Blanc, L., Bonal, D., Brando, P., Chave, J., de Oliveira, A. C. A., Cardozo, N. D., Czimczik, C. I., Feldpausch, T. R., Freitas, M. A., Gloor, E., Higuchi, N., Jimenez, E., Lloyd, G., Meir, P., Mendoza, C., Morel, A., Neill, D. A., Nepstad, D., Patino, S., Penuela, M. C., Prieto, A., Ramirez, F., Schwarz, M., Silva, J., Silveira, M., Thomas, A. S., ter Steege, H., Stropp, J., Vasquez, R., Zelazowski, P., Davila, E. A., Andelman, S., Andrade, A., Chao, K. J., Erwin, T., Di Fiore, A., Honorio, E., Keeling, H., Killeen, T. J., Laurance, W. F., Cruz, A. P., Pitman, N. C. A., Vargas, P. N., Ramirez-Angulo, H., Rudas, A., Salamao, R., Silva, N., Terborgh, J., and Torres-Lezama, A.: Drought sensitivity of the Amazon rainforest, Science, 323, 1344-1347, doi:10.1126/science.1164033, 2009.

Pleysier, J. L. and Juo, A. S. R.: A single-extraction method using silver-thiourea for measuring exchangeable cations and effective 
CEC in soils with variable charges, Soil Science, 129, 205-211, 1980.

Pöhlker, C., Wiedemann, K., Sinha, B., Shiraiwa, M., Gunthe, S., Smith, M., Su, H., Artaxo, P., Chen, Q., Cheng, Y., Elbert, W., Gilles, M. K., Kilcoyne, A. L. D., Moffet, R. C., Weigand, M., Martin, S. T., Pöschl, U., and Andreae, M. O.: Biogenic potassium salt particles as seeds for secondary organic aerosol in the Amazon, Science, 337, 1075-1078, 2012.

Pöhlker, C., Saturno, J., Krüger, M. L., Förster, J.-D., Weigand, M., Wiedemann, K. T., Bechtel, M., Artaxo, P., and Andreae, M. O.: Efflorescence upon humidification? X-ray microspectroscopic in-situ observation of changes in aerosol microstructure and phase state upon hydration, Geophys. Res. Lett., 41, 36813689, doi:10.1002/2014GL059409, 2014.

Pöschl, U., Martin, S. T., Sinha, B., Chen, Q., Gunthe, S. S., Huffman, J. A., Borrmann, S., Farmer, D. K., Garland, R. M., Helas, G., Jimenez, J. L., King, S. M., Manzi, A., Mikhailov, E., Pauliquevis, T., Petters, M. D., Prenni, A. J., Roldin, P., Rose, D., Schneider, J., Su, H., Zorn, S. R., Artaxo, P., and Andreae, M. O.: Rainforest aerosols as biogenic nuclei of clouds and precipitation in the Amazon, Science, 329, 1513-1516, 2010.

Poulter, B., Aragao, L., Heyder, U., Gumpenberger, M., Heinke, J., Langerwisch, F., Rammig, A., Thonicke, K., and Cramer, W.: Net biome production of the Amazon Basin in the 21st century, Global Change Biol., 16, 2062-2075, doi:10.1111/j.13652486.2009.02064.x, 2010.

Prospero, J. M., Glaccum, R. A., and Nees, R. T.: Atmospheric transport of soil dust from Africa to South America, Nature, 289, 570-572, 1981 .

Quesada, C. A., Lloyd, J., Schwarz, M., Patiño, S., Baker, T. R., Czimczik, C., Fyllas, N. M., Martinelli, L., Nardoto, G. B., Schmerler, J., Santos, A. J. B., Hodnett, M. G., Herrera, R., Luizão, F. J., Arneth, A., Lloyd, G., Dezzeo, N., Hilke, I., Kuhlmann, I., Raessler, M., Brand, W. A., Geilmann, H., Moraes Filho, J. O., Carvalho, F. P., Araujo Filho, R. N., Chaves, J. E., Cruz Junior, O. F., Pimentel, T. P., and Paiva, R.: Variations in chemical and physical properties of Amazon forest soils in relation to their genesis, Biogeosciences, 7, 1515-1541, doi:10.5194/bg-7-15152010, 2010.

Quesada, C. A., Phillips, O. L., Schwarz, M., Czimczik, C. I., Baker, T. R., Patiño, S., Fyllas, N. M., Hodnett, M. G., Herrera, R., Almeida, S., Alvarez Dávila, E., Arneth, A., Arroyo, L., Chao, K. J., Dezzeo, N., Erwin, T., di Fiore, A., Higuchi, N., Honorio Coronado, E., Jimenez, E. M., Killeen, T., Lezama, A. T., Lloyd, G., López-González, G., Luizão, F. J., Malhi, Y., Monteagudo, A., Neill, D. A., Núñez Vargas, P., Paiva, R., Peacock, J., Peñuela, M. C., Peña Cruz, A., Pitman, N., Priante Filho, N., Prieto, A., Ramírez, H., Rudas, A., Salomão, R., Santos, A. J. B., Schmerler, J., Silva, N., Silveira, M., Vásquez, R., Vieira, I., Terborgh, J., and Lloyd, J.: Basin-wide variations in Amazon forest structure and function are mediated by both soils and climate, Biogeosciences, 9, 2203-2246, doi:10.5194/bg-9-2203-2012, 2012.

Rammig, A., Jupp, T., Thonicke, K., Tietjen, B., Heinke, J., Ostberg, S., Lucht, W., Cramer, W., and Cox, P.: Estimating the risk of Amazonian forest dieback, New Phytol., 187, 694-706, doi:10.1111/j.1469-8137.2010.03318.x, 2010.

Ramos, F. M., Bolzan, M. J. A., Sa, L. D. A., and Rosa, R. R.: Atmospheric turbulence within and above an Ama- zon forest, Physica D - Nonlinear Phenomena, 193, 278-291, doi:10.1016/j.physd.2004.01.026, 2004.

Rap, A., Spracklen, D. V., Mercado, L., Reddington, C. L., Haywood, J. M., Ellis, R. J., Phillips, O. L., Artaxo, P., Bonal, D., Coupe, N. R., and Butt, N.: Fires increase Amazon forest productivity through increases in diffuse radiation, Geophys. Res. Lett., 42, 4654-4662, doi:10.1002/2015GL063719, 2015.

Raupach, M. R., Finnigan, J. J., and Brunet, Y.: Coherent eddies and turbulence in vegetation canopies: The mixing-layer analogy, Bound.-Lay. Meteorol., 78, 351-382, doi:10.1007/bf00120941, 1996.

Restrepo-Coupe, N., da Rocha, H. R., Hutyra, L. R., da Araujo, A. C., Borma, L. S., Christoffersen, B., Cabral, O. M. R., de Camargo, P. B., Cardoso, F. L., Lola da Costa, A. C., Fitzjarrald, D. R., Goulden, M. L., Kruijt, B., Maia, J. M. F., Malhi, Y. S., Manzi, A. O., Miller, S. D., Nobre, A. D., von Randow, C., Abreu Sa, L. D., Sakai, R. K., Tota, J., Wofsy, S. C., Zanchi, F. B., and Saleska, S. R.: What drives the seasonality of photosynthesis across the Amazon basin? A cross-site analysis of eddy flux tower measurements from the Brasil flux network, Agr. Forest Meteorol., 182, 128-144, doi:10.1016/j.agrformet.2013.04.031, 2013.

Richardson, A. D., Jenkins, J. P., Braswell, B. H., Hollinger, D. Y., Ollinger, S. V., and Smith, M.-L.: Use of digital webcam images to track spring green-up in a deciduous broadleaf forest, Oecologia, 152, 323-334, doi:10.1007/s00442-006-0657-z, 2007.

Richey, J. E., Melack, J. M., Aufdenkampe, A. K., Ballester, V. M., and Hess, L. L.: Outgassing from Amazonian rivers and wetlands as a large tropical source of atmospheric $\mathrm{CO}_{2}$, Nature, 416, 617620, 2002.

Rissler, J., Swietlicki, E., Zhou, J., Roberts, G., Andreae, M. O., Gatti, L. V., and Artaxo, P.: Physical properties of the submicrometer aerosol over the Amazon rain forest during the wetto-dry season transition - comparison of modeled and measured CCN concentrations, Atmos. Chem. Phys., 4, 2119-2143, doi:10.5194/acp-4-2119-2004, 2004.

Rizzo, L. V., Correia, A. L., Artaxo, P., Procópio, A. S., and Andreae, M. O.: Spectral dependence of aerosol light absorption over the Amazon Basin, Atmos. Chem. Phys., 11, 8899-8912, doi:10.5194/acp-11-8899-2011, 2011.

Rizzo, L. V., Artaxo, P., Müller, T., Wiedensohler, A., Paixão, M., Cirino, G. G., Arana, A., Swietlicki, E., Roldin, P., Fors, E. O., Wiedemann, K. T., Leal, L. S. M., and Kulmala, M.: Long term measurements of aerosol optical properties at a primary forest site in Amazonia, Atmos. Chem. Phys., 13, 2391-2413, doi:10.5194/acp-13-2391-2013, 2013.

Ro, C.-U., Osan, J., Szaloki, I., De Hoog, J., Worobiec, A., and Van Grieken, R. A.: Monte Carlo program for quantitative electroninduced X-ray analysis of individual particles, Anal. Chem., 75, 851-859, 2003.

Roberts, G. C., Andreae, M. O., Zhou, J., and Artaxo, P.: Cloud condensation nuclei in the Amazon Basin: "Marine" conditions over a continent?, Geophys. Res. Lett., 28, 2807-2810, 2001.

Rocha, R. P., Morales, C. A., Cuadra, S. V., and Ambrizzi, T.: Precipitation diurnal cycle and summer climatology assessment over South America: An evaluation of Regional Climate Model version 3 simulations, J. Geophys. Res., 114, D10108, doi:10.1029/2008JD010212, 2009. 
Rose, D., Gunthe, S. S., Mikhailov, E., Frank, G. P., Dusek, U., Andreae, M. O., and Pöschl, U.: Calibration and measurement uncertainties of a continuous-flow cloud condensation nuclei counter (DMT-CCNC): CCN activation of ammonium sulfate and sodium chloride aerosol particles in theory and experiment, Atmos. Chem. Phys., 8, 1153-1179, doi:10.5194/acp-8-11532008, 2008.

Rose, D., Gunthe, S. S., Su, H., Garland, R. M., Yang, H., Berghof, M., Cheng, Y. F., Wehner, B., Achtert, P., Nowak, A., Wiedensohler, A., Takegawa, N., Kondo, Y., Hu, M., Zhang, Y., Andreae, M. O., and Pöschl, U.: Cloud condensation nuclei in polluted air and biomass burning smoke near the mega-city Guangzhou, China - Part 2: Size-resolved aerosol chemical composition, diurnal cycles, and externally mixed weakly $\mathrm{CCN}$-active soot particles, Atmos. Chem. Phys., 11, 2817-2836, doi:10.5194/acp-112817-2011, 2011.

Rummel, U., Ammann, C., Kirkman, G. A., Moura, M. A. L., Foken, T., Andreae, M. O., and Meixner, F. X.: Seasonal variation of ozone deposition to a tropical rain forest in southwest Amazonia, Atmos. Chem. Phys., 7, 5415-5435, doi:10.5194/acp-75415-2007, 2007.

Saatchi, S., Asefi-Najafabady, S., Malhi, Y., Aragão, L. E. O. C., Anderson, L. O., Myneni, R. B., and Nemani, R.: Persistent effects of a severe drought on Amazonian forest canopy, Proc. Natl. Acad. Sci., 110, 565-570, doi:10.1073/pnas.1204651110, 2013.

Salati, E. and Vose, P. B.: Amazon Basin - A system in equilibrium, Science, 225, 129-138, doi:10.1126/science.225.4658.129, 1984.

Santos, I. A. and Buchmann, J.: A qualitative review emphasizing climatic aspects of the Amazon and Northeast Brazil, Anu. Inst. Geocienc., 33, 9-23, 2010.

Schafer, J. S., Holben, B. N., Eck, T. F., Yamasoe, M. A., and Artaxo, P.: Atmospheric effects on insolation in the Brazilian Amazon: Observed modification of solar radiation by clouds and smoke and derived single scattering albedo of fire aerosols, J. Geophys. Res., 107, 8074, doi:10.1029/2001JD000428, 2002.

Schimel, D., Stephens, B. B., and Fisher, J. B.: Effect of increasing $\mathrm{CO}_{2}$ on the terrestrial carbon cycle, Proc. Natl. Acad. Sci., 112, 436-441, doi:10.1073/pnas.1407302112, 2015.

Schkolnik, G., Falkovich, A. H., Rudich, Y., Maenhaut, W., and Artaxo, P.: New analytical method for the determination of levoglucosan, polyhydroxy compounds, and 2-methylerythritol and its application to smoke and rainwater samples, Environ. Sci. Technol., 39, 2744-2752, 2005.

Schöngart, J., Wittmann, F., and Worbes, M.: Biomass and net primary production of Central Amazonian floodplains forests, in: Amazonian floodplain forests: ecophysiology, biodiversity and sustainable management, edited by: Junk, W., Piedade, M. T. F., Wittmann, F., Schöngart, J., and Parolin, P., Springer New York, 347-388, 2010.

Sena, E. T., Artaxo, P., and Correia, A. L.: Spatial variability of the direct radiative forcing of biomass burning aerosols and the effects of land use change in Amazonia, Atmos. Chem. Phys., 13, 1261-1275, doi:10.5194/acp-13-1261-2013, 2013.

Serafimovich, A., Thomas, C., and Foken, T.: Vertical and horizontal transport of energy and matter by coherent motions in a tall spruce canopy, Bound.-Lay. Meteorol., 140, 429-451, doi:10.1007/s10546-011-9619-z, 2011.
Silva Dias, M. A., Rutledge, S., Kabat, P., Silva Dias, P. L., Nobre, C., Fisch, G., Dolman, A. J., Zipser, E., Garstang, M., Manzi, A. O., Fuentes, J. D., Rocha, H. R., Marengo, J., Plana-Fattori, A., Sá, L. D. A., Alvalá, R. C. S., Andreae, M. O., Artaxo, P., Gielow, R., and Gatti, L.: Clouds and rain processes in a biosphereatmosphere interaction context in the Amazon Region, J. Geophys. Res., 107, 8072, doi:10.1029/2001JD000335, 2002.

Sinha, V., Williams, J., Crowley, J. N., and Lelieveld, J.: The Comparative Reactivity Method - a new tool to measure total $\mathrm{OH}$ Reactivity in ambient air, Atmos. Chem. Phys., 8, 2213-2227, doi:10.5194/acp-8-2213-2008, 2008.

Soares-Filho, B. S., Nepstad, D. C., Curran, L. M., Cerqueira, G. C., Garcia, R. A., Ramos, C. A., Voll, E., McDonald, A., Lefebvre, P., and Schlesinger, P.: Modelling conservation in the Amazon basin, Nature, 440, 520-523, 2006.

Sorbjan, Z. and Czerwinska, A.: Statistics of turbulence in the stable boundary layer affected by gravity waves, Bound.-Lay. Meteorol., 148, 73-91, doi:10.1007/s10546-013-9809-y, 2013.

Soudani, K. and Francois, C.: Remote sensing: A green illusion, Nature, 506, 165-166, doi:10.1038/nature13052, 2014.

Spracklen, D. V., Arnold, S. R., and Taylor, C. M.: Observations of increased tropical rainfall preceded by air passage over forests, Nature, 489, 282-285, doi:10.1038/nature11390, 2012.

Steeneveld, G. J., Holtslag, A. A. M., Nappo, C. J., de Wiel, B., and Mahrt, L.: Exploring the possible role of small-scale terrain drag on stable boundary layers over land, J. Appl. Meteorol. Climatol., 47, 2518-2530, doi:10.1175/2008jamc1816.1, 2008.

Steeneveld, G. J., Nappo, C. J., and Holtslag, A. A. M.: Estimation of orographically induced wave drag in the stable boundary layer during the CASES-99 experimental campaign, Acta Geophys., 57, 857-881, doi:10.2478/s11600-009-0028-3, 2009.

Steiner, A. L., Pressley, S. N., Botros, A., Jones, E., Chung, S. H., and Edburg, S. L.: Analysis of coherent structures and atmosphere-canopy coupling strength during the CABINEX field campaign, Atmos. Chem. Phys., 11, 11921-11936, doi:10.5194/acp-11-11921-2011, 2011.

Steinkamp, K. and Gruber, N.: A joint atmosphere-ocean inversion for the estimation of seasonal carbon sources and sinks, Global Biogeochem. Cy., 27, 732-745, doi:10.1002/gbc.20064, 2013.

Stephens, B. B., Gurney, K. R., Tans, P. P., Sweeney, C., Peters, W., Bruhwiler, L., Ciais, P., Ramonet, M., Bousquet, P., Nakazawa, T., Aoki, S., Machida, T., Inoue, G., Vinnichenko, N., Lloyd, J., Jordan, A., Heimann, M., Shibistova, O., Langenfelds, R. L., Steele, L. P., Francey, R. J., and Denning, A. S.: Weak northern and strong tropical land carbon uptake from vertical profiles of atmospheric $\mathrm{CO}_{2}$, Science, 316, 1732-1735, doi:10.1126/science.1137004, 2007.

Stickler, C. M., Coe, M. T., Costa, M. H., Nepstad, D. C., McGrath, D. G., Dias, L. C. P., Rodrigues, H. O., and Soares-Filho, B. S.: Dependence of hydropower energy generation on forests in the Amazon Basin at local and regional scales, Proc. Natl. Acad. Sci. USA, 110, 9601-9606, doi:10.1073/pnas.1215331110, 2013.

Sun, J. L., Burns, S. P., Lenschow, D. H., Banta, R., Newsom, R., Coulter, R., Frasier, S., Ince, T., Nappo, C., Cuxart, J., Blumen, W., Lee, X., and Hu, X. Z.: Intermittent turbulence associated with a density current passage in the stable boundary layer, Bound.-Lay. Meteorol., 105, 199-219, doi:10.1023/a:1019969131774, 2002. 
Sun, J. L., Lenschow, D. H., Burns, S. P., Banta, R. M., Newsom, R. K., Coulter, R., Frasier, S., Ince, T., Nappo, C., Balsley, B. B., Jensen, M., Mahrt, L., Miller, D., and Skelly, B.: Atmospheric disturbances that generate intermittent turbulence in nocturnal boundary layers, Bound.-Lay. Meteorol., 110, 255-279, doi:10.1023/a:1026097926169, 2004.

Sun, J. L., Mahrt, L., Banta, R. M., and Pichugina, Y. L.: Turbulence regimes and turbulence intermittency in the stable boundary layer during CASES-99, J. Atmos. Sci., 69, 338-351, doi:10.1175/jasd-11-082.1, 2012.

Swap, R., Garstang, M., Greco, S., Talbot, R., and Kållberg, P.: Saharan dust in the Amazon Basin, Tellus, 44B, 133-149, 1992.

Talbot, R. W., Andreae, M. O., Berresheim, H., Artaxo, P., Garstang, M., Harriss, R. C., Beecher, K. M., and Li, S. M.: Aerosol chemistry during the wet season in Central Amazonia: The influence of long-range transport, J. Geophys. Res., 95, 16955-16969, 1990.

Taraborrelli, D., Lawrence, M. G., Crowley, J. N., Dillon, T. J., Gromov, S., Gross, C. B. M., Vereecken, L., and Lelieveld, J.: Hydroxyl radical buffered by isoprene oxidation over tropical forests, Nature Geosci., 5, 190-193, doi:10.1038/ngeo1405, 2012.

Targhetta, N.: Comparação florística e estrutural entre florestas de igapó e campinarana ao longo de gradientes hidroedáficos na Reserva de Desenvolvimento Sustentável do Uatumã, Amazônia Central, MSc Thesis, INPA, Manaus, 96 pp., 2012.

ter Steege, H., Nigel, C. A., Sabatier, D., Baraloto, C., Salomao, R. P., Guevara, J. E., Phillips, O. L., Castilho, C. V., Magnusson, W. E., Molino, J. F., Monteagudo, A., Vargas, P. N., Montero, J. C., Feldpausch, T. R., Coronado, E. N. H., Killeen, T. J., Mostacedo, B., Vasquez, R., Assis, R. L., Terborgh, J., Wittmann, F., Andrade, A., Laurance, W. F., Laurance, S. G. W., Marimon, B. S., Marimon, B. H., Vieira, I. C. G., Amaral, I. L., Brienen, R., Castellanos, H., Lopez, D. C., Duivenvoorden, J. F., Mogollon, H. F., Matos, F. D. D., Davila, N., Garcia-Villacorta, R., Diaz, P. R. S., Costa, F., Emilio, T., Levis, C., Schietti, J., Souza, P., Alonso, A., Dallmeier, F., Montoya, A. J. D., Piedade, M. T. F., Araujo-Murakami, A., Arroyo, L., Gribel, R., Fine, P. V. A., Peres, C. A., Toledo, M., Gerardo, A. A. C., Baker, T. R., Ceron, C., Engel, J., Henkel, T. W., Maas, P., Petronelli, P., Stropp, J., Zartman, C. E., Daly, D., Neill, D., Silveira, M., Paredes, M. R., Chave, J., Lima, D. D., Jorgensen, P. M., Fuentes, A., Schongart, J., Valverde, F. C., Di Fiore, A., Jimenez, E. M., Mora, M. C. P., Phillips, J. F., Rivas, G., van Andel, T. R., von Hildebrand, P., Hoffman, B., Zent, E. L., Malhi, Y., Prieto, A., Rudas, A., Ruschell, A. R., Silva, N., Vos, V., Zent, S., Oliveira, A. A., Schutz, A. C., Gonzales, T., Nascimento, M. T., RamirezAngulo, H., Sierra, R., Tirado, M., Medina, M. N. U., van der Heijden, G., Vela, C. I. A., Torre, E. V., Vriesendorp, C., Wang, O., Young, K. R., Baider, C., Balslev, H., Ferreira, C., Mesones, I., Torres-Lezama, A., Giraldo, L. E. U., Zagt, R., Alexiades, M. N., Hernandez, L., Huamantupa-Chuquimaco, I., Milliken, W., Cuenca, W. P., Pauletto, D., Sandoval, E. V., Gamarra, L. V., Dexter, K. G., Feeley, K., Lopez-Gonzalez, G., and Silman, M. R.: Hyperdominance in the Amazonian tree flora, Science, 342, 325, doi:10.1126/science.1243092, 2013.

Thomas, C. and Foken, T.: Detection of long-term coherent exchange over spruce forest using wavelet analysis, Theor. Appl. Climatol., 80, 91-104, doi:10.1007/s00704-004-0093-0, 2005.
Thomas, C. and Foken, T.: Flux contribution of coherent structures and its implications for the exchange of energy and matter in a tall spruce canopy, Bound.-Lay. Meteorol., 123, 317-337, doi:10.1007/s10546-006-9144-7, 2007.

Tollefson, J.: Battle for the Amazon, Nature, 520, 20-23, 2015.

Tota, J., Fitzjarrald, D. R., and da Silva Dias, M. A. F.: Amazon rainforest exchange of carbon and subcanopy air flow: Manaus LBA Site - A complex terrain condition, Scientific World J., 2012, 165067, doi:10.1100/2012/165067, 2012.

Trebs, I., Mayol-Bracero, O. L., Pauliquevis, T., Kuhn, U., Sander, R., Ganzeveld, L., Meixner, F. X., Kesselmeier, J., Artaxo, P., and Andreae, M. O.: Impact of the Manaus urban plume on trace gas mixing ratios near the surface in the Amazon Basin: Implications for the $\mathrm{NO}-\mathrm{NO}_{2}-\mathrm{O}_{3}$ photo-stationary state and peroxy radical levels, J. Geophys. Res., 117, D05307, doi:10.1029/2011JD016386, 2012.

Tuch, T. M., Haudek, A., Müller, T., Nowak, A., Wex, H., and Wiedensohler, A.: Design and performance of an automatic regenerating adsorption aerosol dryer for continuous operation at monitoring sites, Atmos. Meas. Tech., 2, 417-422, doi:10.5194/amt-2-417-2009, 2009.

Tuomisto, H., Ruokolainen, K., Aguilar, M., and Sarmiento, A.: Floristic patterns along a $43-\mathrm{km}$ long transect in an Amazonian rain forest, J. Ecol., 91, 743-756, doi:10.1046/j.13652745.2003.00802.x, 2003.

Valeriano, M. M.: Topodata: Guia para utilização de dados geomorfológicos locais do projeto de produtividade em pesquisa modelagem de dados topográficos SRTM, INPE Sao Jose dos Campos, Brazil, 2008.

Van de Wiel, B. J. H., Ronda, R. J., Moene, A. F., De Bruin, H. A. R., and Holtslag, A. A. M.: Intermittent turbulence and oscillations in the stable boundary layer over land. Part I: A bulk model, J. Atmos. Sci., 59, 942-958, 2002.

van der Laan-Luijkx, I. T., van der Velde, I. R., Krol, M. C., Gatti, L. V., Domingues, L. G., Correia, C. S. C., Miller, J. B., Gloor, M., van Leeuwen, T. T., Kaiser, J. W., Wiedinmyer, C., Basu, S., Clerbaux, C., and Peters, W.: Response of the Amazon carbon balance to the 2010 drought derived with CarbonTracker South America, Global Biogeochem. Cy., 29, 1092 1108, doi:10.1002/2014GB005082, 2015.

van Eijck, A.: Atmospheric degradation of reactive biogenic VOCs and their role in aerosol formation: Modeling activities, laboratory experiments and field studies in different vegetation zones, PhD Diss., University of Mainz, Germany, 113 pp., 2013.

van Gorsel, E., Harman, I. N., Finnigan, J. J., and Leuning, R.: Decoupling of air flow above and in plant canopies and gravity waves affect micrometeorological estimates of net scalar exchange, Agr. Forest Meteorol., 151, 927-933, doi:10.1016/j.agrformet.2011.02.012, 2011.

Vendrasco, E. P., Dias, P. L. S., and Freitas, E. D.: A case study of the direct radiative effect of biomass burning aerosols on precipitation in the Eastern Amazon, Atmos. Res., 94, 409-421, doi:10.1016/j.atmosres.2009.06.016, 2009.

Vestenius, M., Hellén, H., Levula, J., Kuronen, P., Helminen, K. J., Nieminen, T., Kulmala, M., and Hakola, H.: Acidic reaction products of monoterpenes and sesquiterpenes in atmospheric fine particles in a boreal forest, Atmos. Chem. Phys., 14, 7883-7893, doi:10.5194/acp-14-7883-2014, 2014. 
Vieira, I. C. G., Toledo, P. M., Silva, J. M. C., and Higuchi, H.: Deforestation and threats to the biodiversity of Amazonia, Brazilian J. Biology, 68, 949-956, 2008.

Wan, F. and Porte-Agel, F.: A large-eddy simulation study of turbulent flow over multiscale topography, Bound.-Lay. Meteorol., 141, 201-217, doi:10.1007/s10546-011-9648-7, 2011.

Wang, X., Piao, S., Ciais, P., Friedlingstein, P., Myneni, R. B., Cox, P., Heimann, M., Miller, J., Peng, S., Wang, T., Yang, H., and Chen, A.: A two-fold increase of carbon cycle sensitivity to tropical temperature variations, Nature, 506, 212-215, doi:10.1038/nature12915, 2014.

Wendisch, M., Pöschl, U., Andreae, M. O., Machado, L. A. T., Albrecht, R., Schlager, H., Rosenfeld, D., Buchholz, B., Ebert, V., Fisch, G., Curtius, J., Frank, F., Kohl, R., Rose, D., Hüneke, T., Knecht, M., Pfeilsticker, K., Longo, K., Afchine, A., Costa, A., Krämer, M., Jaervinen, E., Schnaiter, M., Ehrlich, A., Jäkel, E., Krisna, T. C., Kanter, S., Rosenow, D., Werner, F., Mertes, S., Kästner, U., Dorf, M., Klimach, T., Krüger, M., Nillius, B., Pöhlker, C., Schneider, J., Schulz, C., Borrmann, S., Mahnke, C., Molleker, S., Weigel, R., Ewald, F., Kölling, T., Mayer, B., Zinner, T., Fix, A., Fütterer, D., Jurkat, T., Kenntner, M., Sauer, D., Paul Stock, Voigt, C., Weinzierl, B., Ziereis, H., Barbosa, H., Artaxo, P., Souza, R. A. F. d., and Yamasoe, M. A.: The ACRIDICON-CHUVA observational study of tropical convective clouds and precipitation using the new German research aircraft HALO, Bull. Am. Meteorol. Soc., in review, 2015.

Williams, C. A., Scanlon, T. M., and Albertson, J. D.: Influence of surface heterogeneity on scalar dissimilarity in the roughness sublayer: Bound.-Lay. Meteorol., 122, 149-165, doi:10.1007/s10546-006-9097-x, 2007.

Williams, E., Rosenfeld, D., Madden, N., Gerlach, J., Gears, N., Atkinson, L., Dunnemann, N., Frostrom, G., Antonio, M., Biazon, B., Camargo, R., Franca, H., Gomes, A., Lima, M., Machado, R., Manhaes, S., Nachtigall, L., Piva, H., Quintiliano, W., Machado, L., Artaxo, P., Roberts, G., Renno, N., Blakeslee, R., Bailey, J., Boccippio, D., Betts, A., Wolff, D., Roy, D., Halverson, J., Rickenbach, T., Fuentes, J., and Avelino, E.: Contrasting convective regimes over the Amazon: Implications for cloud electrification, J. Geophys. Res., 107, 8082, doi:10.1029/2001JD000380, 2002.

Wilson, K. L. and Birks, J. W.: Mechanism and elimination of a water vapor interference in the measurement of ozone by UV absorbance, Environ. Sci. Technol., 40, 6361-6367, 2006.

Winderlich, J., Chen, H., Gerbig, C., Seifert, T., Kolle, O., Lavric, J. V., Kaiser, C., Höfer, A., and Heimann, M.: Continuous lowmaintenance $\mathrm{CO}_{2} / \mathrm{CH}_{4} / \mathrm{H}_{2} \mathrm{O}$ measurements at the Zotino Tall Tower Observatory (ZOTTO) in Central Siberia, Atmos. Meas. Tech., 3, 1113-1128, doi:10.5194/amt-3-1113-2010, 2010.
Winderlich, J., Gerbig, C., Kolle, O., and Heimann, M.: Inferences from $\mathrm{CO}_{2}$ and $\mathrm{CH}_{4}$ concentration profiles at the Zotino Tall Tower Observatory (ZOTTO) on regional summertime ecosystem fluxes, Biogeosciences, 11, 2055-2068, doi:10.5194/bg-112055-2014, 2014.

Wittmann, F., Householder, E., Piedade, M. T. F., de Assis, R. L., Schöngart, J., Parolin, P., and Junk, W. J.: Habitat specifity, endemism and the Neotropical distribution of Amazonian whitewater floodplain trees, Ecography, 36, 690-707, 2013.

$\mathrm{Xu}, \mathrm{X} ., \mathrm{Yi}, \mathrm{C}$, and Kutter, E.: Stably stratified canopy flow in complex terrain, Atmos. Chem. Phys., 15, 7457-7470, doi:10.5194/acp-15-7457-2015, 2015.

Yáñez-Serrano, A. M., Nölscher, A. C., Williams, J., Wolff, S., Alves, E., Martins, G. A., Bourtsoukidis, E., Brito, J., Jardine, K., Artaxo, P., and Kesselmeier, J.: Diel and seasonal changes of biogenic volatile organic compounds within and above an Amazonian rainforest, Atmos. Chem. Phys., 15, 3359-3378, doi:10.5194/acp-15-3359-2015, 2015.

Zemp, D. C., Schleussner, C.-F., Barbosa, H. M. J., van der Ent, R. J., Donges, J. F., Heinke, J., Sampaio, G., and Rammig, A.: On the importance of cascading moisture recycling in South America, Atmos. Chem. Phys., 14, 13337-13359, doi:10.5194/acp-1413337-2014, 2014.

Zeri, M. and Sa, L. D. A.: Horizontal and vertical turbulent fluxes forced by a gravity wave event in the nocturnal atmospheric surface layer over the Amazon forest, Bound.-Lay. Meteorol., 138, 413-431, doi:10.1007/s10546-010-9563-3, 2011.

Zeri, M., Sa, L. D. A., Manzi, A. O., Araujo, A. C., Aguiar, R. G., von Randow, C., Sampaio, G., Cardoso, F. L., and Nobre, C. A.: Variability of carbon and water fluxes following climate extremes over a tropical forest in southwestern Amazonia, Plos One, 9, e88130, doi:10.1371/journal.pone.0088130, 2014.

Zhang, K., Castanho, A. D. d. A., Galbraith, D. R., Moghim, S., Levine, N., Bras, R. L., Coe, M., Costa, M. H., Malhi, Y., Longo, M., Knox, R. G., McKnight, S., Wang, J., and Moorcroft, P. R.: The fate of Amazonian ecosystems over the coming century arising from changes in climate, atmospheric $\mathrm{CO}_{2}$ and land-use, Global Change Biol., 21, 2569-2587, doi:10.1111/gcb.12903, 2015.

Zhou, J., Swietlicki, E., Hansson, H.-C., and Artaxo, P.: Submicrometer aerosol particle size distribution and hygroscopic growth measured in the Amazon rain forest during the wet season, J. Geophys. Res., 107, 8055, doi:10.129/2000JD000203, 2002.

Zilitinkevich, S. S., Elperin, T., Kleeorin, N., Rogachevskii, I., and Esau, I.: A hierarchy of energy- and flux-budget (EFB) turbulence closure models for stably-stratified geophysical flows, Bound.-Lay. Meteorol., 146, 341-373, doi:10.1007/s10546-0129768-8, 2013. 